

\title{
Public \\ JOURNAL OF \\ Transportation
}

\author{
Gary L. Brosch, Editor
}

Patricia Henderson, Managing Editor

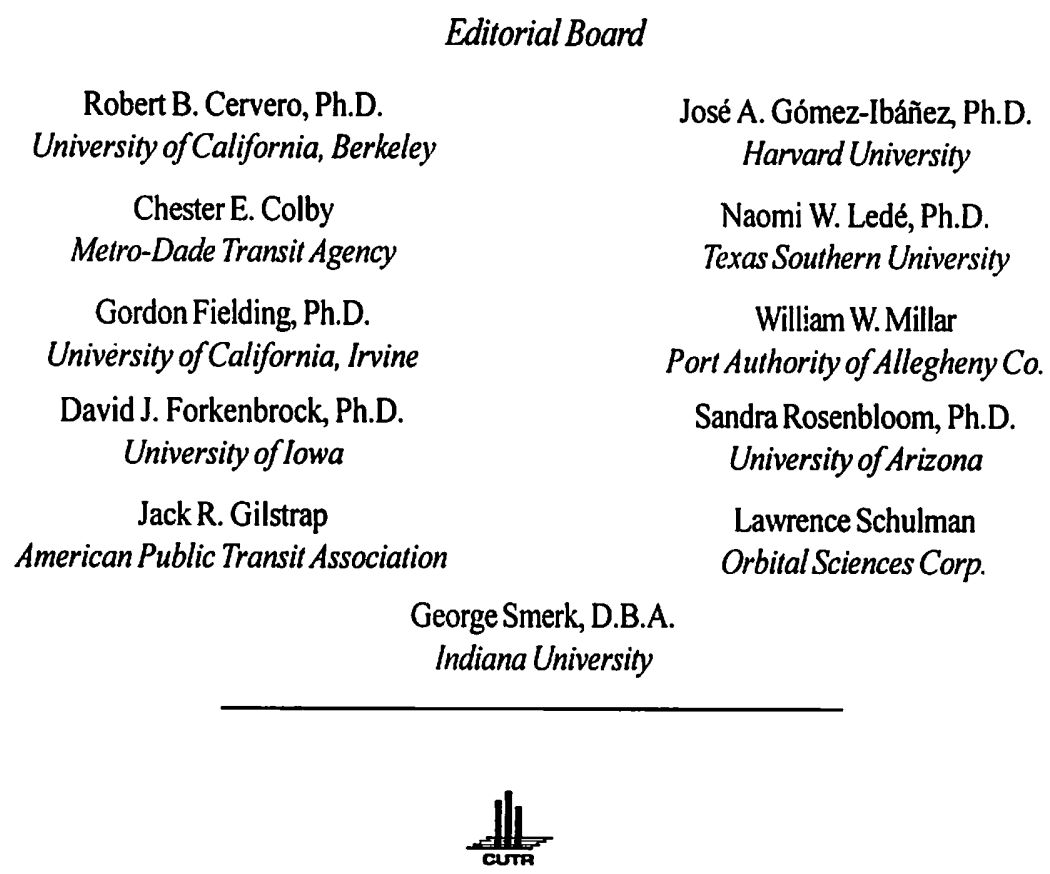

The Journal of Public Transportation (ISSN 1077-291X) is published quarterly by the Center for Urban Transportation Research (CUTR) in the College of Engineering at the University of South Florida. The contents of this document reflect the views of the authors, who are responsible for the facts and the accuracy of the information presented herein. This document is disseminated under the sponsorship of the U.S. Department of Transportation, University Research Institute Program, in the interest of information exchange. The U.S. Government assumes no liability for the contents or use thereof. Subscriptions are complimentary and may be obtained by contacting the Center for Urban Transportation Research, University of South Florida, 4202 E. Fowler Avenue, ENB 118, Tampa, FL 336205350,(813)974-3120,E-mail: phenders@cutreng.usf.edu. 


\section{Public Joursal or Transportation}

Volume 1, No. 1, Fall 1996

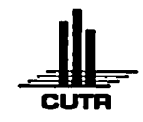

(C) 1996 Center for Urban Transportation Research

National Urban Transit Institute

Center for Urban Transportation Research

College of Engineering - University of South Florida

4202 E. Fowler Avenue, ENB 118, Tampa, FL 33620-5350

(813)974-3120 - Fax(813)974-5168

E-mail:phenders@cutreng.usf.edu

Web Site: http://www.cutreng.usf.edw/CUTR/cutrhome.html 



\section{Public soursal or Transportation}

Volume 1, No. 1, Fall 1996

\section{Contents}

Editorial

The Changing Federal Role in Support of Public Transportation

Jack R. Gilstrap

Transit Service, Parking Charges, and Mode Choice for the Journey to Work: An Analysis of the 1990 NPTS

James G. Strathman \& Kenneth J. Dueker

A Taxonomy for Advanced Public Transportation Systems

Asad J. Khattak, Hisham Noeimi \& Haitham M. Al-Deek

Public Transit in the Social Marketing Framework

Devajyoti Deka

The Puzzle of Income, Race, and Density: Preliminary Evidence on Transit Use from the 1991 American Housing Survey

Sandra Rosenbloom with Kelly Cliffon

California's Transit Village Movement

Robert Cervero

"Our troubled planet can no longer afford the haxury of pursuits confined to an ivory tower. Scholarship has to prove its worth. not on its own terms, but by service to the nation and the world."

- Oscar Handlin 



\section{Editorial}

The best reason to begin a new journal is to satisfy the need for information in a particular field of research. The Journal of Public Transportation will strive to increase communication between academics and practitioners in public transportation, aiming towards the common goal of solving problems related to the mobility of our citizens.

There are many questions about the future of public transportation. Will it eventually go the way of the horse and buggy in all but the largest urban areas, or will it prove to be our economic and social salvation when the oil crisis finally arrives? Will intelligent transportation systems and alternatively-fueled vehicles help or hurt public transportation? How do we decide which new technologies should be implemented? What are the roles of the federal, state, and local governments in support of public transportation? How important is public transportation in helping people move from welfare to work? What can be done to increase the cost effectiveness and efficiency of public transportation? Can the transit village concept work? By what standards, policies, and values should we measure the success of public transportation?

This journal will assist in encouraging academics to continue to study and develop innovative solutions to public transportation problems and in encouraging practitioners to consider and implement such solutions. A continuing dialogue between both is essential to the full understanding of the problems. We must take seriously the challenge stated by historian Oscar Handlin: "Our troubled planet can no longer afford the luxury of pursuits confined to an ivory tower. Scholarship has to prove its worth, not on its own terms, but by service to the nation and the world." The Journal of Public Transportation strives to help meet that challenge.

This first issue of the journal has been designed to provide perspective and practical tools from both researchers and practitioners. Six papers are included, covering a variety of topics and providing examples of the types of articles we are seeking to publish. Information on submitting papers is included on the back cover.

In completing the first issue of the Journal of Public Transportation, I would like to acknowledge the Editorial Board, the authors, and the referees, many of whom made special efforts to make this journal a reality. Papers from three members of our Editorial Board, comprised of both researchers and practitioners with lifelong dedication to enhancing mobility, are included in this first issue. I look forward to working with the many new individuals who will become a part of the journal in future issues.

Gary L. Brosch, Editor

October 1996 



\title{
The Changing Federal Role in Support of Public Transportation
}

\author{
Jack R. Gilstrap \\ Executive Vice President, American Public Transit Association
}

Public transportation is working for America every day, carrying people to jobs, the elderly to health services, and students to school. It is an essential element of America's transportation infrastructure, and part of the economic engine that keeps our nation running. From crowded cities to rural America, people depend on public transportation nine billion times each year to keep their lives in motion, at an affordable price.

As a 30-year partner with the federal government-across eight Republican and Democratic administrations-public transportation is good value for the money. It fuels our nation's economy by promoting jobs and leading to personal economic independence. It serves people with disabilities. As an essential element of interstate commerce, it frees up commuter highways so goods and services can get to market efficiently. And it stimulates private development while enhancing our quality of life.

A strong federal transit program has an important role in any vision of America's future. In an era of limited resources, federal policy must encourage efficient use of all transportation resources. Only transit simultaneously reduces congestion, limits pollution, provides accessible transportation for all Americans, and saves energy. 
Over the past 30 years, the U.S. transit industry and its riders have prevented:

- the emission of 1.6 million tons of hydrocarbons, 10 million tons of carbon monoxide, and 275,000 tons of nitrogen oxides into our air;

- the importation of 20 billion gallons of gasoline; and

- the construction and maintenance of 20,000 lane-miles of freeways and arterial roads and 5 million parking spaces to meet rush-hour demands, saving at least $\$ 220$ billion (as much as all federal highway spending for the last 15 years).

We provide these benefits by serving people who would otherwise have driven their own vehicles, adding to congestion, pollution, and increasing the demand for public spending on roads. Federal policy should increase, not reduce, the incentive for people to choose transit so these benefits can be maintained. The federal role takes on renewed importance, given the findings in numerous recent studies that subsidies for automobiles and trucks are somewhere between $\$ 378$ billion and $\$ 935$ billion per year.

We also have served people who depend on transit as a primary source of mobility. Some are too poor to own and operate personal vehicles. Some are unable to drive because of age, youth, or other reasons. Transit provides essential mobility to some 80 million Americans without ready access to personal vehicles.

Following are five reasons why the federal transit program should be preserved.

- Access to Economic Opportunity. For millions of American workers, transit means access to job opportunities and economic independence. Public transit serves low-income workers and minorities in disproportionate numbers. Approximately one out of four transit riders is from a family with below-poverty-line income. This is almost double the 14.2 percent of Americans below the Census Bureau's poverty level of $\$ 13,924$ for a family of four.

Transit fares rose 22 percent above inflation from 1980 to 1993. Cuts in federal operating aid will mean fare increases and service reductions, making it 
harder for transit-dependent workers to commute. Now is not the time to limit access to personal economic independence through work.

Affordable transit has important implications for the success of welfare reform. All welfare reform proposals seek to move people from the welfare rolls into jobs. The existing Job Opportunities and Basic Skills (JOBS) training program recognizes that people need transportation to move from welfare to work. JOBS-related transportation benefits include the provision of tokens or tickets (32 states), reimbursement for public transportation (21 states), and rideshare/ vanpool/carpool benefits (21 states). For example, Arizona allows $\$ 6$ per day for reimbursement of transit costs, and Georgia allows $\$ 35$ per month for tokens or tickets. Since 1989, JOB-RIDE (a Wisconsin Department of Transportation reverse commute program) has provided access to more than 3,500 suburban jobs, reducing the Aid to Families with Dependent Children/general assistance/ unemployment rolls.

Current state welfare reform efforts also recognize the importance of transportation. The recently-passed Virginians' Initiative for Employment not Welfare (VIEW) is one example. Local social service agencies are authorized to give VIEW families "assistance with transportation, if such transportation enables the individual to work."

- An Alternative to Congestion. In 1992, congestion cost individual drivers more than $\$ 45$ billion in wasted time and fuel in 50 U.S. metropolitan areas. Interstate commerce is threatened as businesses pay billions of dollars in reduced productivity and higher shipping costs. Every year, the economic losses from congestion are growing in suburbs and central cities. America's metropolitan areas are investing in transit to protect themselves from future traffic gridlock and economic stagnation. Congress should encourage local efforts to safeguard our economic future by maintaining transit funding and protecting ISTEA's flexible funding programs and provisions to guarantee equitable consideration of transit investments.

- More Transportation Choices. Over the past several years, transit ridership has increased. Especially noteworthy are the significant commuter rail rid- 
ership increases because they demonstrate that there is a demand for transit options in suburban communities. Whether or not they ride transit, all Americans benefit when affordable transit gives people more transportation choices. Cuts in federal transit funding will mean higher fares and service reductions. Some riders will return to their personal vehicles, making it harder to reduce congestion, clean up the air, and conserve energy. Transit-dependent people will have no choice but to limit their travel.

It is no accident that Governor Christine Todd Whitman of New Jersey has proposed to freeze her state's transit fares. Governor Whitman understands that improving the quality of life for her constituents depends on infrastructure investments, preservation of a wide range of transportation choices, and support for transit's ability to reduce congestion, clean up the air, and improve mobility for everyone in the community.

- The Cost of Federal Mandates. The issue of federal mandates is very important to the transit industry. APTA recommends that no additional unfunded federal mandates be imposed on providers of public transportation services. We welcomed the enactment of the Unfunded Mandates Reform Act of 1995 because it brought a healthy perspective to future discussions of mandates. The new law did not, however, limit the federal mandates that add more than $\$ 790$ million in operating and $\$ 340$ million in capital expenses each year to state and local transit agency budgets.

We support the goals of the Americans with Disabilities Act (ADA), the Clean Air Act, federal drug and alcohol testing laws, the Clean Water Act, and other laws that impose mandates on transit systems. But these goals cannot be achieved without sufficient funding. Without federal aid to compensate for these costs, transit agencies are forced to raise fares or reduce services. Higher fares and service cuts hurt those who depend on transit and make it harder to attract customers away from their personal vehicles, jeopardizing progress in reducing congestion, cleaning up polluted air, conserving energy, and making the most efficient and productive use of our transportation resources.

While APTA has developed a capital incentive policy in response to outlay constraints, it is still true that mandates cost our transit systems much more than 
the current $\$ 400$ million in operating aid. The estimated annual operating costs of three federal mandates are: ADA, $\$ 693$ million; federal drug and alcohol testing requirements, $\$ 44$ million; and Clean Air Act fuel costs, $\$ 57$ million.

The Americans with Disabilities Act establishes a civil right to transit service for people with disabilities. The transit industry wants to comply with ADA and meet the needs of other riders-a major challenge, without full funding of ADA capital and operating costs that exceed $\$ 950$ million per year. ADA is a promise that should be kept so people with disabilities can participate fully in our society. Our entire society must share in the costs of keeping this promise; transit operators cannot do it alone.

- The Public-Private Transit Partnership. The transit industry historically has been a working partnership between public agencies and private businesses. Transit's greatest economic contribution is to move people efficiently, providing access to jobs and reducing the economic costs imposed by congestion. The federal transit program provides critical support for local efforts to improve private sector productivity by providing more transportation choices. In northern Virginia, for example, development around Metrorail stations has generated 65,000 permanent jobs since 1973 and provided a net gain of $\$ 1.2$ billion in tax revenues. Modernization of existing transit systems also promises significant economic benefits. A 1991 study found that full investment in Philadelphia's transit agency would return $\$ 9$ to the economy for each $\$ 1$ invested. As firms located near the new St. Louis Metrolink rail system and many other transit lines have found, proximity to transit is good for business.

Transit operators are applying business principles to improve productivity. Between 1988 and 1993, the real cost of transit service went down by 6.5 percent per vehicle mile despite greater federal regulations and mandates. Average transit wages are lower than wages for workers in motor vehicle manufacturing, water transportation, highway construction, and other transportation and public utility jobs. In fact, many transit agencies purchase service from privately-owned firms. Commuter rail, fixed-route bus, and demand-responsive paratransit services are some of the services that private firms supply. 
APTA wants to continue to work with Congress to encourage innovative public-private investments without limiting local flexibility. We will continue to develop new policy initiatives, including proposals to encourage more private investment in transit capital projects and encouragement of the public-private transit partnership.

\section{Maintaining the Federal Investment in Transit}

APTA wishes to strengthen partnerships among all levels of government and the private sector, recognizing that state and local governments are best able to set priorities that respond to local needs and conditions. APTA encourages and wants to accelerate the ongoing efforts of Congress, the Federal Transit Administration, and other governmental agencies to eliminate unnecessary federal regulations and improve the efficiency of federal programs. This includes modifying ISTEA's planning requirements so that limited transportation funds can be spent in the most cost-effective ways.

The federal transit program is critical to the nation's well-being. Federal investment in transit infrastructure produces valuable assets in every community and long-term benefits for the nation. For example, there is a definite connection between effective transit service and operating efficiency of our National Highway System. The more people use transit, the less crowded urban roadways are. Fewer cars on the road means that commercial vehicles will move more efficiently, without the need for additional highway construction that has become prohibitively expensive in many regions.

Furthermore, transit also provides mobility and economic independence to millions of people each day. About 55 percent of the nine billion annual transit trips are taken to and from the work place, and each $\$ 10$ million invested in transit creates or maintains 550 full time jobs in a community.

Transit is also vital to the success of welfare reform. Many current welfare recipients do not own cars and must rely on public transportation to get to work. Increasingly, new jobs are being created in the suburbs, and transit operators are providing central-city dwellers with access to the job markets with special bus, rail, and van services. 
Transit is also critical to economic development. It returns three times its cost in business revenue to the communities it serves, according to an APTA study. When cities add a bus route or build a rail station, they stimulate private investment around the new transit service in the form of housing, retail, and other privately-financed development.

Our industry is working vigorously to deal with the new reality of federal funding. Last year's cut of nearly 12 percent in overall transit funding and almost 50 percent in operating assistance has forced transit systems to raise fares and cut service. We are working at the state and local levels to enhance public and private financing and revenue. These state and local efforts can work best if the federal program provides a stable source of funding in FY 1997 and beyond.

\section{Capital Funding Needs}

The transit industry's capital funding requirements are $\$ 13.9$ billion per year from 1995 through 2004. Over this ten-year period, capital needs include:

- $\$ 35$ billion for new vehicles, including 67,800 buses and 51,400 vans;

- $\$ 23$ billion for new bus facilities including parking facilities for bus passengers;

- $\$ 22$ billion to modernize and rehabilitate existing fixed guideway rail and bus routes, stations, and maintenance facilities;

- $\$ 43$ billion for additional fixed guideway services that respond to new customer demands; and

- $\$ 4$ billion to rehabilitate more than 14,900 buses, rail cars, and other vehicles to extend their useful lives.

The typical transit agency depends on federal funds for 63 percent of its budget to buy new vehicles and upgrade old facilities. A decrease in federal support for capital investments will cause immediate hardships for transit customers. In the long run, communities of all sizes will pay a price, both in decreased mobility for individuals and in reduced productivity as congestion forces up the costs of moving goods in interstate and local commerce. 


\section{APTA Reauthorization Proposals}

The Intermodal Surface Transportation Efficiency Act (ISTEA) reformed Federal policy to meet the mobility challenge of the post-Interstate era by integrating surface transportation planning, programs, and services. ISTEA recognizes that our economic health and the quality of life in our communities depend on more efficient use of infrastructure and careful planning in regions and states.

ISTEA also addresses the complications posed by the environmental and social impacts of massive urban freeway construction, which has helped to build up public resistance to needed transportation improvements. We need more effective strategies to blend transportation infrastructure into the social and neighborhood fabric of our cities and suburbs, addressing human needs and impacts as well as physical engineering questions.

The Federal government looks to public transit to provide transportation for people with disabilities, the elderly, and other transit-dependent riders; to protect the environment and conserve energy; and to ease the burden on crowded roads.

By standing firm on ISTEA's reforms and allowing the federal-state-local transportation partnership to flourish, the Federal government can ensure that transit will function even more effectively as a thriving part of a balanced national transportation system. Continued federal support for balanced transportation will enable every community to improve its transit service and increase the range of affordable, convenient transportation options, revitalize our central cities, maintain the health of our suburbs, and weave our smaller towns and rural America more closely into the fabric of our national life.

The mission of public transportation is to foster personal mobility, economic opportunity, and an improved quality of life through partnerships, communication, and technology. Investments in transit are needed to enhance the economic health and the quality of life in central cities, suburbs, small towns, and rural areas. These transit investments will improve the quality of all citizens' lives.

Accordingly, APTA makes the following recommendations for the reauthorization of ISTEA:

1. ISTEA's innovative flexible funding and level playing field provisions have been successful and should be retained. Among these are the Surface Trans- 
portation Program; the Congestion Mitigation and Air Quality (CMAQ) program, with metropolitan suballocations; the equal 80 percent federal shares for highway and transit projects; and the use of local "soft match" for transit projects. Additional flexible funding should be authorized by expanding the Surface Transportation Program using revenue from the Highway Trust Fund's Highway Account and Mass Transit Account.

2. The existing transit program structure should be retained because it works well. Fiscal Year 1998 funding for the transit program should be authorized at the Fiscal Year 1996 authorized level of $\$ 5.125$ billion and should be adjusted for inflation in later years.

3. Expand the definition of allowable capital expenditures to include maintenance and mandate relief.

Despite ISTEA's overall record of success, annual appropriations measures have significantly reduced urbanized area transit operating assistance, causing serious problems for transit agencies. To ameliorate the problems caused by this operating assistance shortfall, APTA proposes to expand the transit program's definition of allowable capital expenditures. For small UZAs, APTA proposes to eliminate the distinction between capital and operating assistance as is now the case for non-urban areas, so that transit operators in these areas could use all of their funds for capital or operating purposes as currently defined. If Congress retains operating assistance for large UZAs, APTA further proposes that transit operators in these UZAs be able to trade in $\$ 1$ of operating assistance for $\$ 2$ of capital assistance.

4. Support transit in small urbanized areas and rural areas by keeping the existing ISTEA formulas for smaller UZA and non-urban funding. Also, a provision should allow these funds to be used for operating assistance. Minimum regulatory requirements should be imposed for these areas.

5. To create more stability and predictability in annual transit funding levels, APTA proposes that transit funds be appropriated in a block amount as is done for the Federal-Aid Highway Program. This would result in a uniform firstyear outlay rate for the total transit program in the same way that a uniform firstyear outlay rate is calculated for the Federal-Aid Highway Program. Enactment 
of this proposal would establish equality in first-year outlay rates for transit and highways and establish a level playing field for the highway and transit programs in the way they are treated in the budget and appropriations processes.

6. Increase the Federal Transit Program's efficiency by building on Congressional and U.S. Department of Transportation initiatives in the area of administrative and regulatory changes in a number of areas. These changes should include, among others:

- increasing capital flexibility by eliminating the associated capital maintenance item threshold and expanding capital maintenance eligibility to be consistent with FHWA programs;

- applying Federal procurement requirements only to capital funds;

- permitting transit operators to coordinate or combine Federal and state reviews to avoid duplication of efforts;

- modifying the employee benefit for parking to narrow the difference between the $\$ 65$ per month tax-free transit benefit and the $\$ 165$ per month tax-free parking benefit; creating a federal income tax deduction for transit commuter expenses;

- ensuring that compliance with the Americans with Disabilities Act establishes a method that accommodates financial burden on transit systems, provides discretion to local officials, defines compliance that is certified by the FTA, and strengthens the coordination process at the federal level to ensure transit access to all Federal funding for transportation services; and

- reforming section 13 (c) legislatively with respect to its applicability, to ensure that it complies with the Administrative Procedure Act (APA) and is subject to a time limit.

7. Modify the Congestion Mitigation and Air Quality program. Steady annual increases in flexible funding transfers to transit demonstrate that ISTEA's flexible funding provisions respond to the needs of states and metropolitan regions. APTA favors adjustments to the CMAQ program so it will continue to provide resources for areas that come into attainment, but that continue to face 
serious congestion problems and potential deterioration of air quality in the long term. The Federal government should not penalize states and regions for achieving air quality goals.

8. ISTEA's planning provisions are fundamentally sound, including current authority for Metropolitan Planning Organizations, public participation requirements, transportation and land use linkages, and multimodal corridor analysis through the Major Investment Study (MIS) criteria. APTA recommends changes to ensure that the planning process fully accounts for often-ignored benefits of transit investments and to provide sufficient resources so that planning does not become another "unfunded federal mandate."

9. Apply the highway solvency test instead of the more stringent mass transit solvency test to the Mass Transit Account. Spending from the Mass Transit Account of the Highway Trust Fund should be required to comply with the Byrd Test instead of the more restrictive Rostenkowski Test. This change will create a more level playing field between highways and transit since the Byrd Test applies to the Highway Account.

10. Return the 4.3 cents per gallon gasoline tax now used for general government spending to the Highway Trust Fund. In keeping with the precedent set by President Reagan, a minimum of 20 percent of this amount should be deposited into the Mass Transit Account.

11. Continue to support the Transit Cooperative Research Program (TCRP), University Transportation Centers, and university institutes created by ISTEA. Create a new Technology Development and Demonstration Program. TCRP makes a significant contribution to the national interest, and it deserves continued support. Likewise, the university transportation centers (UTCs) and the university institutes established by ISTEA also conduct important research, education, and training programs. The next authorization should retain these programs and provide them with no less than their current percentage of transit program funding. APTA also recommends the creation of a Technology Development and Demonstration Program as a partnership of the Federal government, transit agencies, and the private sector to support the implementation of new transit technologies and practices. 
12. Allow states to use the state shares of flexible funding programs for intercity passenger rail and commuter rail investments, provided there is an increase in the total amount of flexible funding available (as proposed in recommendation \#1).

\section{Conclusion}

In 1991, ISTEA gave states and metropolitan areas more control over transportation decisions, reduced federal biases against local transit investments, and called for more efficient ways to increase personal mobility. The next Congress should support ISTEA's pioneering efforts to strengthen the economy and return power to states and local communities.

Federal transit investments give people more transportation choices, improve economic productivity, and protect the quality of life in our communities. As rising congestion points toward economic stagnation and decreasing mobility for all Americans, the national interest depends on a strong federal transit program.

\section{About the Author}

JACK R. GiLSTRAP is Executive Vice President of the American Public Transit Association. He is retiring in early October after leading the association for 16 years. 


\title{
Transit Service, Parking Charges, and Mode Choice for the Journey to Work: An Analysis of the 1990 NPTS
}

\author{
James G. Strathman \\ Kenneth J. Dueker \\ Portland State University
}

\begin{abstract}
In this paper, the effects of transit service and parking charges on the choice of commuters to drive alone, carpool, or use transit are estimated. The analysis is based on dat a for 20 Consolidated Metropolitan Statistical Areas from the 1990 Nationwide Personal Transportation Survey, FTA's Section 15, and the Texas Transportation Institute's estimates of traffic congestion. Both the level of transit service and the likelihood of being charged for parking are found to have significant positive effects on the likelihood of choosing transit for the commute. The results also indicate that improving transit access leads to a very small increase in transit's mode share, while improving the level of service produces a much greater mode share increase.
\end{abstract}

\section{Introduction}

Public transit's importance as a commuting option has steadily declined in recent years. The 1990 Census found that transit serves only 5.1 percent of all 
commuters, down nearly 60 percent from 1960 (Rossetti and Eversole 1993). Carpooling has also not fared well, with the share of commuters choosing this mode falling 32 percent between 1980 and 1990 alone (Rossetti and Eversole 1993). One consequence of these changes is a disproportionate increase over time in the number of vehicle trips required to transport the nation's work force to their work places, with corresponding negative implications for congestion and air quality management (Pisarski 1992). Thus, reducing single occupant vehicle (SOV) commuting has become an increasingly prominent urban transportation policy objective in the 1990s. The regulation and pricing of parking have the potential to make a large contribution to this objective (Kain 1994; Shoup 1994).

This paper analyzes the effects of transit service and the pricing of parking on commuters' mode choices. The data employed in the analysis cover commuters from 20 large metropolitan areas who were interviewed for the 1990 Nationwide Personal Transportation Survey (NPTS). These data are enriched by transit level of service information from the Federal Transit Administration's $1990 \mathrm{Sec}$ tion 15 Report (U.S. Department of Transportation 1991), and congestion estimates from the Texas Transportation Institute (TTI) (Schrank et al. 1993).

\section{Effects of Parking Costs on Commuting}

While many factors affect mode choice for the journey to work, the value of employer-paid parking is so substantial that it "invites commuters to drive to work alone" (Shoup 1982: 352). For commuters to downtown Los Angeles, for example, the estimated value of free parking by itself exceeds all other variable costs of driving by more than 35 percent (Willson and Shoup 1990).

If employer-paid parking is a major cause of SOV commuting, market pricing of parking ought to be considered in attempts to address congestion and air quality problems. But as Segelhorst and Kirkus (1973) noted, rather than impose taxes to compel commuters to take these externalities into account, we instead extend a subsidy to drive alone and make congestion problems even worse. Thus, Kain (1994) suggests that the elimination of employer-paid parking should precede consideration of congestion pricing, and that scrapping parking subsidies 
might in many instances mitigate the need for congestion pricing. Downs (1992) favors market-priced parking over congestion pricing because it can be more easily administered and it does not pose as much a threat to privacy.

Research on the effect that parking prices have on mode choice for the journey to work has been expanding rapidly. This research can be divided into two general categories. The first consists of experimental design-type case studies, whose purposes include 1) documenting changes in mode or utilization following a price increase at selected parking facilities (Kunze et al. 1980; May 1973); 2) estimating changes in mode and parking utilization following a change in parking prices at specific work sites (Miller and Everett 1982; Surber et al. 1984); and 3) assessing differences in commute mode for similarly situated work sites, where one employer provides free or subsidized parking and the other does not (Mehranian et al. 1987; Pickrell and Shoup 1980). The second general category consists of studies that use disaggregate mode choice models, in which the cost of parking is specified as one of the choice attributes (Ben-Akiva and Atherton 1977; Brown 1972; Ganek and Saulino 1976; Gillen 1977; Miller 1993; Ricklin et al. 1994; Willson 1992).

Since excellent reviews of this research already exist, we will not discuss the studies here.' Several issues do deserve comment, however. First, although the case studies attempt to control for or assess spillover parking (i.e., following a price increase, the diversion of previous users of a facility to on-street parking or other facilities), it is not clear that they have been entirely successful. This is evidenced by the greater responses commonly observed in these studies compared to disaggregate choice studies. Second, the case studies commonly find that individuals who shift away from SOV commuting are more likely to become carpoolers than transit riders, while the disaggregate mode choice studies typically estimate the reverse. This may be due to direct promotion of carpooling as a substitute for SOV commuting in many of the reported case studies. It could also reflect a tendency of case studies to focus on locations outside downtowns where carpooling is more attractive, and a tendency of the data in disaggregate choice models to reflect commuting to downtowns, where transit service is bet- 
ter. More generally, the case studies are very anemic in terms of their representation of non-parking factors that affect mode choice.

A shortcoming shared by both the disaggregate choice models and the case studies is their limited treatment of transit and carpool service quality attributes. This is more understandable in the case studies because it would be extremely difficult to set up the analysis so that attributes of transit and carpooling could be systematically varied.?

While the disaggregate mode choice studies are more firmly linked to travel behavior theory, they are not without problems. In contrast to the case study approach, mode choice models may underestimate the parking price elasticity of demand for SOV commuting for several reasons. First, parking costs are frequently expressed as a component of vehicle operating costs, which implies that commuters evaluate the unit costs of parking and other operating outlays equivalently. But Gillen (1977) found that commuters' mode choices were significantly more responsive to unit parking costs, indicating that these costs should be specified separately. Second, efforts to represent parking costs in mode choice models face serious measurement problems. When auto commuters are asked in surveys whether and how much they pay for parking, for example, their responses do not reflect variations in the parking services they consume. Thus, a worker who pays $\$ 100$ per month for a secure on-site space is not necessarily worse off than a coworker who pays less (or nothing) to park blocks away. More troublesome, in virtually all travel surveys parking cost information is not recovered from people who commute by modes other than auto. To estimate mode choices of this group, analysts must first determine how much they would pay for parking if they were to drive. Non-auto commuters could be asked how much they would have to pay for parking in travel surveys, although the reliability of their responses would be unknown. An alternative would be to survey parking facilities in the few Traffic Analysis Zones where pricing exists. Prevailing parking costs could then be applied to all commutes to that zone. Moreover, if both the surveyed work places and the surveyed parking charges are geocoded, the two could be directly linked and measurement error from within zone variation of parking costs greatly reduced. 
Lastly, however precisely parking prices are measured at work destinations, they will not accurately reflect on mode choice decisions when employers pay them. The Tax Reform Act of 1986 added a special rule for parking to the Internal Revenue Code, defining employer-paid parking as a "working condition fringe benefit." Ironically, because commuters cannot deduct parking costs as a workrelated expense (a qualification that applies to other working condition fringes) employer-paid parking is worth considerably more than its face value to them. Employers thus have a strong incentive to substitute free or subsidized parking for higher wages. The employer's incentive is greater for workers in higher marginal tax brackets who, in turn, are also more likely to work where parking charges exist. Peat Marwick (1990) estimated that the value of employer parking subsidies exceeds $\$ 50$ billion per year, indicating that the gap between posted parking prices and the amounts many auto commuters actually pay is substantial.

Willson's (1992) study of commuters to downtown Los Angeles probably represents the most thorough attempt to deal with the problems noted above. Willson assembled parking data from three sources. First, from a household travel survey he recovered the parking costs auto commuters reported paying. For nonauto commuters he determined from their employers whether free parking was provided for everyone. In the cases where employers did not provide free parking, he used information from a survey on the posted parking prices in the sub areas of downtown Los Angeles where these people worked.

\section{Data Description}

The NPTS provides the primary source of data for this study. This periodic survey is the only source of information on travel for all purposes in the U.S. The 1990 survey included nearly 50,000 individuals comprising 22,000 households. In addition to travel activity the survey recovered information on household socioeconomic characteristics and on residential location. Among the locational data is the Consolidated Metropolitan Statistical Area (CMSA) identity of the place of residence. CMSA identification allows NPTS trip and household records to be linked to FTA Section 15 transit service data and TTI congestion estimates. 
Given the focus on commuting, households from the 20 CMSAs who reported making work trips during the survey period were first selected. Commutes, represented by trip chains, were then formed by linking the sequence of trips connecting each worker's residence and work place. ${ }^{3}$ These trip chains can be characterized as either simple, in which the commute is composed of single work trips connecting the residence and place of work, or complex, in which the journey-to-work, time-at-work, or journey-to-home segments contains both work and non-work trips. An example of a complex commute chain would be a worker who first drops a child off at a day care center (the journey to which is classified as a non-work trip), then proceeds to work (a work trip), meets a friend for lunch (a non-work trip) and, at the end of the work day stops again at the day care center (a non-work trip), and finally returns home (a work trip).

Section 15 transit service data for the $20 \mathrm{CMSAs}$, specifically revenue hours of service per capita, were then added. Finally, TTI estimates of the per capita costs of congestion were included. ${ }^{4}$ Congestion cost estimates were available for each of the CMSAs except Buffalo and Providence. For commuters from these two CMSAs, which account for one percent of the observations in the data base, TTI's respective regional estimates of per capita congestion costs were used.

The data base consists of 3,645 observations, or round-trip commutes. Some of the salient characteristics of these commutes, the transit service environment, and congestion conditions are shown in Table $1 .{ }^{5}$ The first data column in the table reports the number of observations for each CMSA. More than half of the CMSAs have fewer than 100 observations, indicating that the NPTS metropoli$\tan$ level statistics in the table may not be very precise. ${ }^{6}$ Over all CMSAs, however, the NPTS variables in the table do provide a fairly representative picture of U.S. metropolitan commuting activity.

Regarding the NPTS variables in Table 1, more than one-third of the commutes include trip-making beyond direct travel between home and work. The SOV mode accounts for 75 percent of commutes, while carpools and transit account for 13 and 8 percent, respectively, and other modes (mainly walking) make up the remainder. Auto commuters were asked if they paid for parking at work, 
and only 5 percent indicated that they did, a substantial decline from the near 15 percent who reported doing so in a roughly comparable 1965 survey (Lansing and Hendricks 1967).

Table 1

Selected Commuting Characteristics in the 1990 NPTS-Section 15-TTI Sample

\begin{tabular}{|c|c|c|c|c|c|c|c|c|c|c|}
\hline \multirow[b]{2}{*}{$C M S A$} & \multirow[b]{2}{*}{$N$} & \multirow[b]{2}{*}{$\begin{array}{c}\text { Complex } \\
\text { Com- } \\
\text { mutes }\end{array}$} & \multicolumn{4}{|c|}{ Travel Mode } & \multicolumn{3}{|c|}{ Transit Service } & \multirow{2}{*}{$\begin{array}{l}\text { Per } \\
\text { Cap. } \\
\text { Con- } \\
\text { gest. }\end{array}$} \\
\hline & & & sov & $\begin{array}{l}\text { Car- } \\
\text { Pool }\end{array}$ & $\begin{array}{c}\text { Mass } \\
\text { Tran- } \\
\text { sit }\end{array}$ & Other & $\begin{array}{c}\text { Pay } \\
\text { to } \\
\text { Park }\end{array}$ & $\begin{array}{c}\text { Access } \\
(I / 4 \\
\text { mi.) }\end{array}$ & $\begin{array}{l}\text { Per } \\
\text { Cap. } \\
\text { Hrs. }\end{array}$ & \\
\hline Boston & 97 & $42.3 \%$ & $72.2 \%$ & $11.3 \%$ & $6.2 \%$ & $10.3 \%$ & $6.6 \%$ & $46.4 \%$ & 1.45 & $\$ 490$ \\
\hline Buffalo & 24 & 41.7 & 75.0 & 25.0 & 0.0 & 0.0 & 4.5 & 58.3 & .99 & 380 \\
\hline Chicago & 255 & 38.4 & 74.9 & 13.7 & 8.2 & 3.1 & 4.1 & 47.1 & 1.81 & 300 \\
\hline Cincinnati & 81 & 29.6 & 86.4 & 11.1 & 0.0 & 2.5 & 5.2 & 32.1 & .82 & 160 \\
\hline Cleveland & 91 & 30.8 & 81.3 & 12.1 & 3.3 & 3.3 & 7.2 & 30.8 & 1.10 & 120 \\
\hline Dallas & 138 & 47.8 & 84.8 & 14.5 & 0.7 & 0.0 & 6.1 & 30.4 & .73 & 570 \\
\hline Denver & 78 & 33.3 & 85.9 & 7.7 & 5.1 & 1.3 & 5.8 & 53.8 & 1.07 & 370 \\
\hline Detroit & 151 & 37.1 & 89.4 & 9.3 & 0.7 & 0.7 & 4.9 & 21.2 & .67 & 380 \\
\hline Hartford & 269 & 37.2 & 84.0 & 9.7 & 2.2 & 4.1 & 2.5 & 28.3 & 1.19 & 220 \\
\hline Houston & 132 & 38.6 & 89.4 & 7.6 & 1.5 & 1.5 & 6.6 & 25.8 & .84 & 570 \\
\hline Los Angeles & 447 & 39.6 & 77.9 & 16.3 & 2.7 & 3.1 & 3.4 & 49.9 & .92 & 670 \\
\hline Miami & 74 & 36.5 & 71.6 & 25.7 & 2.7 & 0.0 & 1.4 & 43.2 & 1.31 & 520 \\
\hline Milwaukee & 61 & 27.9 & 77.0 & 13.1 & 3.3 & 6.6 & 13.7 & 26.2 & 1.51 & 160 \\
\hline New York & 1152 & 34.6 & 64.2 & 12.1 & 15.9 & 7.8 & 5.5 & 46.0 & 2.74 & 390 \\
\hline Philadelphia & 194 & 36.6 & 72.7 & 13.4 & 7.7 & 6.2 & 4.4 & 39.7 & 1.40 & 270 \\
\hline Pittsburgh & 79 & 35.4 & 67.1 & 22.8 & 5.1 & 5.1 & 7.6 & 36.7 & 1.96 & 270 \\
\hline Portland & 44 & 31.8 & 81.8 & 15.9 & 2.3 & 0.0 & 7.7 & 50.0 & 1.35 & 330 \\
\hline Providence & 27 & 37.0 & 74.1 & II.I & 7.4 & 7.4 & 4.8 & 37.0 & .56 & 380 \\
\hline San Fran. & 153 & 41.8 & 80.4 & 9.2 & 5.9 & 4.6 & 4.6 & 60.1 & 2.13 & 760 \\
\hline Seattle & 98 & 39.8 & 78.6 & 15.3 & 2.0 & 4.1 & 5.7 & 53.1 & 1.31 & 660 \\
\hline Overall & 3645 & 36.9 & 74.7 & 12.9 & 7.6 & 4.8 & 5.0 & 42.3 & 1.71 & 420 \\
\hline
\end{tabular}


Over 40 percent of the sample resides within $1 / 4$ mile of transit service, a distance that transit planners generally consider "accessible." Transit service averages 1.7 revenue hours per urban area resident. Not surprisingly, the older, more densely developed eastern metropolitan areas generally provide higher levels of transit service, while service levels in the southern and western metropolitan areas are lower. This pattern is not universal; San Francisco and Portland offer fairly high levels of service, while Detroit and Providence provide comparatively less than their regional counterparts. Ignoring the polar cases of New York and Providence, the range of transit service provided in these CMSAs is noteworthy. San Francisco's transit service ( 2.13 hours per capita) is more than three times the level supplied in Detroit.

The TTI estimates indicate that the annual costs of congestion average $\$ 420$ per resident. The most noteworthy pattern among the 20 CMSAs is an inverse association of congestion costs and transit service. Metropolitan areas with higher congestion costs per capita-Seattle, Los Angeles, Houston, and Dallas, for example-tend to provide relatively lower levels of transit service. Alternatively, metropolitan areas with relatively high levels of transit service, such as Chicago, Milwaukee, New York, and Pittsburgh, tend to have lower congestion costs. In contrast, however, are San Francisco and Boston, where relatively high congestion costs occur with high levels of transit service, and Buffalo, Cincinnati, Detroit, and Providence, where both congestion costs and transit service levels are relatively low. These two "deviant" groups may reflect the pressures of accelerated growth on the transportation infrastructure of the former, and the consequences of economic maturity or decline for the latters' transportation systems.

\section{Model Specification}

As discussed earlier, the first step in estimating a mode choice model containing parking costs is to reconcile the "missing data" problem for non-auto commuters. Thus, we begin by estimating the probability that auto commuters will pay for parking at work as a function of various characteristics, and then use the parameters of this model to predict the probability of parking charges for everyone else. The purpose here is to recover an instrumental estimate of the 
likelihood that each commuter would have to pay for parking that is independent of his or her reported mode. Consistent with an approach employed by Cambridge Systematics (1990), a binary logit model is estimated in which the probability of being charged for parking at work is related to auto commuters' age and income, work trip distance, and several urban and locational characteristics. The model is specified as follows:

where

$$
\log \left(\mathrm{P}_{\mathrm{p}} / 1-\mathrm{P}_{\mathrm{p}}\right)=\mathrm{f}(\mathrm{POP}, \mathrm{WTD}, \mathrm{DEN}, \mathrm{Y}, \mathrm{A})
$$

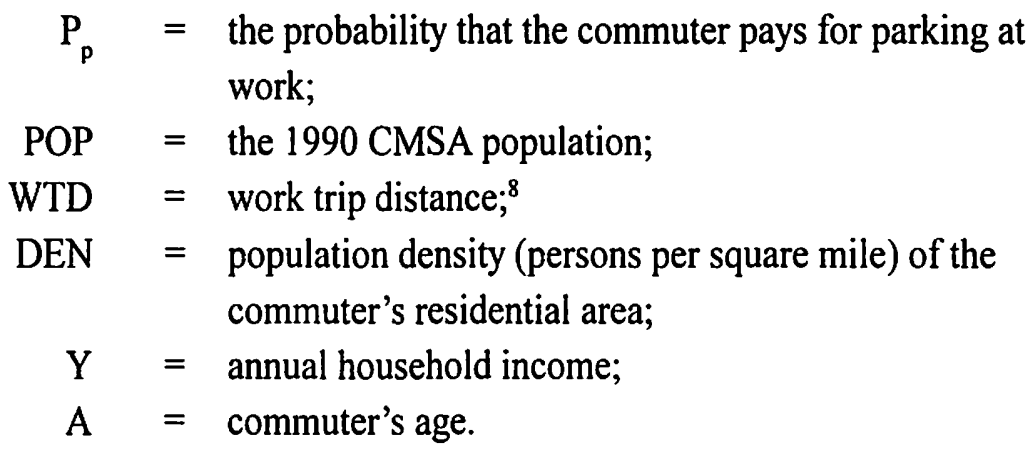

As the parking studies cited earlier have found, persons who must pay for parking at work are more likely to commute by transit or carpools than those who park free. The likelihood that a given worker will pay for parking, in turn, can be characterized as a function of his or her work place location. Work place location is important because parking charges are commonly observed only where the opportunity cost of the land devoted to parking is high, in other words, in the Central Business District (CBD).

Unfortunately, the NPTS does not identify work place location. As a result, several other locational proxies are included in the parking price probability model. The first proxy is the CMSA population. It is hypothesized that the pay-to-park probability will be inversely related to this variable, reflecting the fact that the CBD's share of total employment is smaller in larger metropolitan areas. Second, we have included the density of the worker's residential area, and hypothesize that it is directly related to the likelihood of work place parking charges. This 
hypothesis is based on the evidence that workers live in high density areas to be more accessible to their work places (Rossetti and Eversole 1993), and that work places in higher density areas are more likely to charge for parking. We have also included the distance of the work trip because longer commutes are more likely to be destined for the CBD (Giuliano and Small 1992). Income is included to reflect the urban wage gradient's maximum in the CBD. Finally, the worker's age is included as a crude surrogate for job tenure, which is hypothesized to be greater for CBD workers.

Given the instrumental estimate of the probability of paying for parking for all commuters in the sample, a multinomial logit model is then specified to estimate the relative probabilities of driving alone, carpooling and transit as a function of various personal, household, locational and metropolitan factors. The general specification of the model is as follows:

$$
\log \left(\mathrm{P}_{i} \mathrm{P}_{\mathrm{j}}\right)=\mathrm{f}\left(\mathrm{CC}, \mathrm{D}, \mathrm{TA}, \mathrm{Y}, \mathrm{F}, \mathrm{A}, \mathrm{TRH}, \mathrm{CPC}, \mathrm{S}, \mathrm{E}, \mathrm{S}_{1}, \mathrm{~S}_{2}, \mathrm{MAH}, \mathrm{SAC}, \mathrm{MAC}, \mathrm{E}(\mathrm{PP})\right)
$$

where

$\log \left(\mathrm{P}_{\mathrm{i}} / \mathrm{P}_{\mathrm{j}}\right) \quad=$ the $\log$ of the relative probabilities of selecting modes $\mathrm{i}$ and $\mathrm{j}$;

$\mathrm{CC}=$ complex commute: a dummy variable equaling one if the journey to work consists of a combination of work and non-work trips, zero otherwise;

$\mathrm{D}=$ total home-to-work commute distance (in miles);

$\mathrm{TA}=$ transit access: a dummy variable equaling one if the person resides within $1 / 4$ mile of transit service, zero otherwise;

$\mathrm{Y}=$ annual household income (in thousands);

$\mathrm{F}=$ gender: a dummy variable equaling one if the commuter is female, zero otherwise;

$\mathrm{A}=$ commuter's age;

$\mathrm{TRH}=$ transit revenue hours of service per CMSA resident; 


\section{$\mathrm{CPC}=\mathrm{CMSA}$ congestion costs per capita; \\ $\mathrm{S}=$ residential location: a dummy variable equaling one if the commuter is a suburban resident, zero otherwise; \\ $\mathrm{E}=$ residential location: a dummy variable equaling one if the commuter is an exurban resident, zero otherwise; \\ $\mathrm{S}_{1} \quad=$ city size: a dummy variable equaling one if the 1990 CMSA population is greater than 2.5 million and less than 5.0 million, zero otherwise; \\ $\mathrm{S}_{2} \quad=$ city size: a dummy variable equaling one if the 1990 CMSA population is less than 2.5 million, zero other- wise;}

$\mathrm{MAH}=$ life cycle: a dummy variable equaling one if the commuter's household consists of multiple adults with no dependents, zero otherwise;

$\mathrm{SAC}=$ life cycle: a dummy variable equaling one if the commuter's household consists of a single adult with dependent children, zero otherwise;

MAC = life cycle: a dummy variable equaling one if the commuter's household consists of multiple adults with dependent children, zero otherwise;

$\mathrm{E}(\mathrm{PP})=$ the estimated probability that the commuter would pay for parking at work if he or she commuted by auto.

It is hypothesized that individuals with complex commutes will favor the SOV mode. Activities linked to the commute can be more flexibly scheduled and conveniently accessed by the SOV mode, while the transit and carpool options imply either substantial time or activity choice penalties (Kondo and Kitamura 1987). For example, if the commute includes stops at a pre-school, commuting by transit might limit a person's choice to a program that is directly accessible to his or her place of work, whereas an SOV commute would expand the options. 
Longer commutes tend to enhance the relative attractiveness of transit and carpooling. The waiting or assembly times for these modes are essentially fixed, and thus their share of total travel time declines with increases in commuting distance.

Both access and level of service are posited to have positive effects on the relative attractiveness of transit to commuters. First, residing within walking distance of transit service signals that this service can be conveniently accessed, which enhances the likelihood that it will be chosen (Talvitie 1972). Second, higher service levels tend to shorten headways, which reduces passenger waiting time and lessens transit's relative travel time disadvantage. Lave (1970), for example, estimated that a 10-minute reduction in transit's relative travel time would divert about 7 percent of the Chicago region's commuters to transit.

The opportunity cost of time is known to be a positive function of income. Therefore, higher-income commuters implicitly value travel time at higher levels and have a higher willingness-to-pay for more time-saving modes. All other things being equal, higher-income workers are thus more likely to be SOV commuters.

Historically, women have had a greater tendency to commute by transit and carpools. However, women workers are now just as likely to be licensed to drive as men (Rosenbloom 1994). Also, women accounted for about two-thirds of the 42 million new workers added between 1969 and 1990 (Hu and Young 1993). In turn, the jobs these workers have filled have been concentrated in suburban and exurban locations, where transit has not been a very effective competitor.

The effect of age on the mode choice of commuters has not been very thoroughly researched. The 1990 NPTS shows a commonly observed profile, with workers younger than 20 and older than 60 being relatively less likely to commute by private vehicle (Hu and Young 1993). Since the potentially confounding effects of income and life cycle status are controlled for in the present specification, basic age-related phenomena, such as habit formation or preferences for comfort and convenience, may exert a more discernible effect. 
Congestion affects mode choice by undermining the automobile's travel time advantage over transit (Downs 1962). Clearly, transit (bus in particular) is also negatively affected by congestion, but because transit's in-vehicle times are a smaller component of total travel time, it is penalized relatively less than the auto. While this effect is straightforward in principle, it is important to remember that congestion affects travel in a localized way. The congestion data employed here reflect general traffic conditions in each of the urban areas. The experiences of commuters in each of these areas vary widely, however, and it is the congestion experienced by each commuter that affects his or her mode choice. The TTI index is thus a fairly crude proxy in the context of disaggregate analysis.

One consequence of the decentralization of employment in U.S. metropolitan areas is that the commutes of suburban and exurban residents are now about twice as likely to be destined for suburban and exurban work places as they are for work places in the central city (Gordon et al. 1989). These commutes occur in an environment where both origins and destinations are dispersed and relatively less well-suited to transit. Thus, even in metropolitan areas with frequent transit service and good access to transit on average, suburban residents tend to find that transit service in their areas and to their work places is less attractive.

Gordon et al.'s (1989) analysis of commuting in the 1977 and 1983 NPTS suggests that the most substantial locational realignment of work places and residences occurred in metropolitan areas with more than three million residents, leading them to conclude that "the spatially extensive very large metropolitan areas offer the most opportunities for relocational adjustments to avoid congestion" (pp. 52-53). We have thus included two dummy variables to capture categorical effects of CMSA size.

Household composition and life cycle status have been shown to have important effects on travel activity and mode choice (Strathman et al. 1994). With licensing and automobile availability nearing saturation levels among the adult population, household size and structure also have become key determinants of vehicle occupancy (and thus carpool formation). ${ }^{9}$ Workers in multi-person households are expected to be less likely to commute by transit due to a greater poten- 
tial for either carpooling (in the case of multiple working adults) or increased demands for meeting the needs of non-driving dependents.

The effect of parking on mode choice is defined to be the probability of discrete event rather than a monetary function as in other studies. The NPTS does contain the amount that respondents reported paying for parking, but success in estimating a parking price model with this value as the dependent variable was limited. ${ }^{10}$ Thus, a simpler but better-performing alternative was adopted.

The mode choice specification is fairly rich in its representation of the commuter's personal and household characteristics, but it is also noticeably weak in its characterization of transportation system elements and other important factors (such as relative travel times and costs, and work place location). While it would be desirable to have these system variables in the model, their absence does not necessarily undermine the analysis. Talvitie (1972), for example, tested a variety of alternative mode choice specifications and found that a model containing commuter characteristics and only one system variable (walk access to transit) performed as well as a model in which system attributes were fully represented.

\section{Results}

The pay-to-park probability model was estimated for the subset of nearly 3,200 automobile commuters, and the results are presented in Table 2. The model estimates that the likelihood of parking charges is positively related to household income and residential density, and negatively related to metropolitan size. The coefficients for commute distance and age have the expected signs, but are not statistically significant.

Aside from the likelihood ratio statistic, one way of assessing the parking probability model is to determine whether its probability estimates differ in a meaningful way for auto and transit commuters. If parking costs are the single most important reason why downtown commuters choose transit, as Willson (1991) reported, one would expect that the parking charge probabilities calculated for "out-of-sample" transit riders would be higher than the estimated probabilities for "in-sample" auto commuters. This difference is evident and statisti- 
cally significant: transit users are estimated to be nearly 60 percent more likely than auto commuters to face parking charges at work (i.e., .073 versus .046). By comparison, a national travel survey in 1965 determined that transit riders were more than 30 percent more likely to face parking charges at work than auto commuters (Lansing and Hendricks 1967),

Parameter estimates for the mode choice model are presented in Table 3. The coefficients for both of the transit variables and the parking probability variable are consistent with their hypothesized effects and are statistically significant." "The likelihood of choosing either transit or carpooling over SOV is significantly greater for workers who reside within one-quarter of a mile of transit service

\section{Table 2}

Logit Model Parameter Estimates of the Probability That

Auto Commuters Will Pay for Parking

(Asymptotic $t$ values in parentheses)

Variable

Intercept

Parameter Estimate

CMSA Population $-.03826$

Work Trip Distance .00401

Residence Area Pop. Density .00004

Household Income .00002

Commuter's Age .00497

Log Likelihood Function (0) $-593.0$

Log Likelihood Function (b)

Likelihood Ratio Statistic

$\mathrm{N}$

3193

* Significant at the .05 level.

than those who do not. Greater transit access does not significantly alter the relative likelihood of choosing transit over carpooling. Independent of transit access, increasing the level of transit service significantly enhances the likelihood that transit will be chosen over both SOV and carpooling. Workers with a higher. probability of having to pay for parking are significantly less likely to drive alone, and transit is estimated to gain relative to carpooling from the consequent diversion of SOV commuters. 


\section{Table 3}

Multinomial Logit Estimates of Commute Mode Choice Model Coefficients (Asymptotic t values in parentheses)

\begin{tabular}{|c|c|c|c|}
\hline \multirow[t]{2}{*}{ Variable } & \multicolumn{3}{|c|}{ Dependent Variables* } \\
\hline & $\log \left(P_{c} / P_{d}\right)$ & $\log \left(P_{t} / P_{d}\right)$ & $\log \left(P_{t} / P_{c}\right)$ \\
\hline \multirow{2}{*}{ Intercept } & -2.002 & -2.962 & -.960 \\
\hline & $(-4.38)^{* *}$ & $(-4.45)^{* *}$ & $(-1.28)$ \\
\hline \multirow[t]{2}{*}{ Complex Commute $(1,0)$} & -.045 & -.319 & -.273 \\
\hline & $(-.40)$ & $(-1.60)$ & $(-1.26)$ \\
\hline \multirow[t]{2}{*}{ Commute Distance } & .007 & .020 & .012 \\
\hline & $(1.73)$ & $(3.37)^{* *}$ & $(2.21)^{* *}$ \\
\hline \multirow[t]{2}{*}{ Transit Access within $1 / 4$ Mile $(1,0)$} & .323 & .574 & .250 \\
\hline & $(2.71)^{* *}$ & $(2.79)^{* *}$ & $(1.10)$ \\
\hline \multirow[t]{2}{*}{ Household Income } & -.017 & -.038 & -.021 \\
\hline & $(-5.42)^{* *}$ & $(-7.80)^{* *}$ & $(-4.01)^{* *}$ \\
\hline \multirow[t]{2}{*}{ Female Commuter $(1,0)$} & .372 & .262 & -.109 \\
\hline & $(3.33)^{* *}$ & $(1.60)$ & $(-.59)$ \\
\hline \multirow[t]{2}{*}{ Age } & -.012 & -.028 & -.015 \\
\hline & $(-3.19)^{* *}$ & $(-4.33)^{* *}$ & $(-2.27)^{* *}$ \\
\hline \multirow[t]{2}{*}{ CMSA Transit Revenue Hours per Capita } & .105 & .989 & .883 \\
\hline & $(1.15)$ & $(6.31)^{* *}$ & $(5.18)^{* *}$ \\
\hline \multirow[t]{2}{*}{ CMSA Congestion Costs per Capita } & .0003 & -.001 & -.001 \\
\hline & $(.56)$ & $(-1.56)$ & $(-1.72)$ \\
\hline \multirow[t]{2}{*}{ Suburban Resident $(1,0)$} & -.497 & -.925 & -.428 \\
\hline & $(-4.04)^{* *}$ & $(-4.55)^{* *}$ & $(-1.88)$ \\
\hline \multirow[t]{2}{*}{ Exurban Resident $(1,0)$} & -.140 & -1.907 & -1.767 \\
\hline & $(-.78)$ & $(-2.70)^{* *}$ & $(-2.42)^{* *}$ \\
\hline \multirow[t]{2}{*}{ CMSA Pop. Equals $2.5-5.0$ Mil. $(1,0)$} & -.405 & -.366 & .039 \\
\hline & $(-2.49)^{* *}$ & $(-1.38)$ & $(.13)$ \\
\hline \multirow[t]{2}{*}{ CMSA Pop. Less Than 2.5 Mil. $(1,0)$} & -.133 & -.608 & -.475 \\
\hline & $(-.79)$ & $(-1.71)$ & $(-1.27)$ \\
\hline \multirow[t]{2}{*}{ Multiple Adult Household $(1,0)$} & .910 & .445 & -.466 \\
\hline & $(3.37)^{* *}$ & $(1.65)$ & $(-1.33)$ \\
\hline \multirow[t]{2}{*}{ Single Adult with Child(ren) $(1,0)$} & 1.109 & .011 & -1.098 \\
\hline & $(3.08)^{* *}$ & $(.02)$ & $(-2.27)^{* *}$ \\
\hline \multirow[t]{2}{*}{ Multiple Adults with Child(ren) $(1,0)$} & 1.117 & .385 & -.733 \\
\hline & $(4.08)^{* *}$ & $(1.35)$ & $(-2.01)^{* *}$ \\
\hline \multirow[t]{2}{*}{ Pay-to-Park Probability } & 5.699 & 30.253 & 24.554 \\
\hline & $(1.98)^{* *}$ & $(10.89)^{* *}$ & $(8.05)^{* *}$ \\
\hline \multirow{2}{*}{\multicolumn{2}{|c|}{$\begin{array}{ll}\text { Log Likelihood Function (0): } & -2293.1 \\
\text { Log Likelihood Function (B): } & -1925.1\end{array}$}} & & \\
\hline & $\mathrm{n}:$ & 3469 & \\
\hline \multicolumn{4}{|c|}{ * $P_{t} P_{d}$ and $P_{t}$ are the probabilities of carpool, drive alone and transit choice. } \\
\hline
\end{tabular}


Commuters with complex trip chains are estimated to be more likely to drive alone, although the effect is not statistically significant. This may reflect the efforts taken to ensure that walk trips were fully represented in the NPTS. Because walk trips are usually under-reported in travel surveys, there is a greater tendency for transit commuters to report simple chains. It has been reported (Lawton 1995) that when walk trips are fully represented transit commuters are as likely to have complex trip chains as auto commuters. Alternatively, it may be that trip-chaining considerations are secondary to transit service level/quality considerations in mode choice decisions.

Commute distance has a positive effect on the relative probabilities of choosing transit over SOV and carpooling, and no effect on the relative probabilities of SOV and carpool choice. Increases in household income reduce the likelihood of choosing transit over both SOV and carpools, and diminish the likelihood of carpooling relative to SOV commuting. The only significant effect associated with gender is the relatively greater likelihood that women will choose to carpool over driving alone. Older commuters are relatively less likely to choose carpooling or transit over SOV commuting, and they also find transit less attractive than carpooling.

Generally, higher levels of congestion are estimated to be unrelated to individual mode choice decisions. As discussed earlier, this may simply indicate the gross nature of the proxy in this context. Compared with central city residents, suburbanites and exurbanites are progressively less likely to choose transit over carpooling and SOV commuting. Suburban residents are also relatively less likely than their central city counterparts to favor carpooling over SOV. This latter distinction does not extend to exurbanites, however. The only significant finding with respect to metropolitan size is that commuters in urban areas with 2.5 to 5.0 million residents are less likely to choose carpooling over SOV than commuters in areas with more than 5.0 million residents.

Household structure is estimated to have significant effects on mode choice. Compared to single workers, households composed of multiple adults, single adults with children, and multiple adults with children are progressively more likely to choose carpooling over SOV commuting. In addition, households com- 
posed of multiple adults with children and single adults with children are progressively less likely to choose transit over carpooling than are single worker households.

Table 4 presents predicted mode shares for prescribed levels of the three attributes this paper is mainly concerned with, namely transit access, transit revenue hours per capita, and the probability of paying for parking. The attribute levels chosen are well within the range of observed values in the data. For each of these attribute levels, the mode choice probabilities were predicted for each commuter. A weighted average probability was then calculated, using the NPTS

\begin{tabular}{|c|c|c|c|}
\hline \multicolumn{4}{|c|}{$\begin{array}{c}\text { Table } 4 \\
\text { Predicted Mode Shares for } \\
\text { Alternative Levels of Transit Access, } \\
\text { Transit Service, and } \\
\text { “Pay-to-Park” Probability } \\
\text { Modal Shares }\end{array}$} \\
\hline $\begin{array}{c}\text { Attributed } \\
\text { Level }\end{array}$ & sov & Carpool & Transit \\
\hline \multicolumn{4}{|c|}{ 1/4 mi Transit Access (\%) } \\
\hline 30 & .785 & .129 & .086 \\
\hline 40 & .781 & .130 & .089 \\
\hline 50 & .778 & .131 & .091 \\
\hline 60 & .775 & .132 & .093 \\
\hline \multicolumn{4}{|c|}{ Revenue Hrs Per Capita } \\
\hline .75 & .806 & .141 & .053 \\
\hline 1.00 & .800 & .138 & .062 \\
\hline 1.25 & .792 & .135 & .073 \\
\hline 1.50 & .782 & .132 & .086 \\
\hline 1.75 & .772 & .128 & .100 \\
\hline 2.00 & .760 & .125 & .115 \\
\hline \multicolumn{4}{|c|}{ Pay-to-Park Probability } \\
\hline .01 & .816 & .138 & .046 \\
\hline .05 & .771 & .131 & .098 \\
\hline .10 & .674 & .121 & .205 \\
\hline .15 & .544 & .119 & .337 \\
\hline
\end{tabular}
person weights. Thus, the predictions in Table 4 are representative of U.S. metropolitan commuters.

While most of the estimated parameters associated with the three transit and parking attributes are statistically significant, it is clear from Table 4 that there are marked differences in their predicted mode share effects. For instance, changes in transit access have a very small effect on the shares, while increases in the level of transit service and the pay-to-park probability have fairly substantial effects. An increase in transit revenue hours per capita from 1.0 to 2.0 , for example, is predicted to increase transit's share from 6 to more than 11 percent, and a doubling of the pay-to-park probability from .05 to .10 is predicted to boost transit's share by 110 percent. Transit's 6 percentage point share gain from the revenue hour 
increase is predicted to come at the expense of reductions of 2 and 4 percentage points in the shares of carpooling and SOV. Alternatively, its gain from increasing the pay-to-park probability comes almost entirely from an SOV share reduction.

While the parking-related changes in shares for transit and SOV are consistent with outcomes of other studies, the slight decline in carpooling associated with increasing the likelihood of charging for parking is not. Willson (1992), for example, estimated that an increase in parking costs from $\$ 3$ to $\$ 6$ per day would result in a 3 percentage point increase in carpooling's share.

It is important to recognize issues that condition interpretation of these findings. It should be emphasized that the relationship between the level of transit service and the likelihood of choosing transit is not unilateral. Clearly, while one can expect that improving transit service will lead to more riders, it is also known that transit planners consider ridership in making service changes. Thus, increases in transit use can lead to more service. This simultaneity has been analyzed by Peng et al. (1995). Also, as discussed earlier, an ideal parking probability instrument would be estimated from factors that influence the likelihood of being charged for parking but are yet unrelated to mode choice decisions. In reality, however, we know that there is considerable confounding of factors linked to parking conditions and transit use.

\section{Conclusions}

Our analysis indicates that there is an opportunity for increasing transit utilization and reducing SOV commuting. This opportunity can be realized by increasing the level of transit service and ensuring that a larger share of commuters face parking charges if they decide to drive. Along with this opportunity, however, is a challenge facing transit represented by several less favorable tendencies and conditions.

As the mode share predictions show, making transit more accessible to metropolitan commuters will lead to a much smaller gain in utilization than would increasing the frequency of service provided within existing systems. This is not 
surprising, given that one would expect transit service to be initially concentrated in high density corridors containing commuters who live there in part because they prefer transit. Given limited resources, transit decisionmakers must make trade-offs between coverage and frequency of service. Our analysis suggests that decisionmakers seeking to maximize ridership should make frequency improvements. However, the evidence is that transit decisionmakers have tended to extend service at the expense of increasing frequency (Sale and Green 1979).

Commuter parking charges are only feasible in settings where parking supply is constrained, namely in CBDs. Elsewhere, minimum parking requirements in local zoning ordinances have produced a ubiquitous supply of spaces whose market price is effectively zero (Shoup 1995). Fortunately, the highest quality service provided by most transit systems is to the CBD, and our analysis indicates that market pricing of parking there would effectively reduce SOV commuting. But market pricing alone is not likely to be feasible. Given that the incidence of such pricing would be so narrowly focused on downtowns, this would have the effect of promoting urban fringe development and paradoxically leading to greater rather than less SOV commuting (see Hamerslag et al. 1995). Thus, the most effective long-run strategy would be a transition to market pricing of parking in areas of intense development (e.g., the CBD and special generators like edge cities, hospitals, universities, and airports) combined with immediate reductions in minimum parking requirements elsewhere.

\section{Acknowledgments}

The authors gratefully acknowledge the assistance of Zhen Liu and Zhongren Peng, and the comments of Martha Bianco, Gerard Mildner, Randall Pozdena, Anthony Rufolo, Donald Shoup, and two referees. Research support was provided by the Transit Cooperative Research Program, which is sponsored by the Federal Transit Administration and administered by the Transportation Research Board, National Research Council.

\section{Notes}

1 See Feeney (1989) for a review of the research using disaggregate choice models, and Willson and Shoup (1990), Shoup and Willson (1992), Shoup (1992), Willson (1995), and Shoup (1995) for a review of the case studies and a more general appraisal of the 
causes and consequences of employer-paid parking and parking requirements contained in zoning ordinances.

2 For this reason, a stated preference approach may provide a more fruitful alternative to the before $v$. after and employer-provided $v$. priced studies, because in a stated preference model the levels of key level-of-service attributes can be systematically varied.

3 A more detailed description of the construction of the trip chains is given by Strathman and Dueker (1994).

4 As described by Schrank et al. (1993), these cost estimates cover operating and time losses from recurring and incidental delays.

5 The NPTS file contains both person and household weights so that national level inferences can be made. The values reported in the table for the NPTS variables are in unweighted form, however. It should be noted that because the weights relate to the national level, their application may not yield representative estimates of conditions prevailing in any particular CMSA. New York and Hartford were oversampled, as they participated in a local option program to enrich their data.

- Obviously, some workers in Buffalo walk, bicycle, or use transit, but they weren't among the 24 individuals whose commutes are portrayed in the table. The same applies to Dallas, Miami, and Portland in regard to modes other than auto and transit.

7 For example, see Vincent et al. (1994). New York CMSA observations do have a disproportionate effect on the overall averages, which is most noticeably reflected in the relatively higher share of transit commutes and smaller percentage of commutes involving complex trip chains.

8 This distance measures only the length of the work trip portion of the commute. For commutes that do not involve non-work stops, the work trip distance and the commuting distance specified in the mode choice equation are equivalent. In the case of more complex commutes involving non-work stops, the work trip distance is less than the total commuting distance. Since we expect that complex commuting routines will affect mode choice and that longer commutes are more likely to be complex, it is important to minimize mode-specific confounding effects in specifying the parking charge model.

9 Ferguson's (1994) analysis of carpooling in the 1990 NPTS, for example, shows that the majority of journey-to-work carpools contain members of the same household.

10 NPTS respondents reported the amount paid in various scales (per hour, day, week and month). These values were converted to a monthly equivalent, and we then per- 
formed a Tobit regression of monthly parking costs on the same independent variables defined above in an attempt to estimate an "expected parking price." The poor results obtained may have been due to varying explicit and implicit subsidies that commuters receive from their employers, so that the amount reported represented the respondent's out-of-pocket cost.

"We also explored the possibility of joint effects among the transit and parking probability variables by including interaction terms in initial specifications of the model. Interactive effects of parking price increases and transit service enhancement are considered to be key elements of successful parking demand management programs (e.g., see Williams and Petrait 1993). None of the interaction terms involving transit access, transit revenue hours, and pay-to-park probability were statistically significant, however.

\section{References}

Ben-Akiva, M., and T. J. Atherton. 1977. Choice-Model Predictions of Car-Pool Demand: Methods and Results. Transportation Research Record 637: 13-17.

Brown, G. R. 1972. Analysis of User Preferences for System Characteristics to Cause a Modal Shift. Highway Research Record 417: 25-36.

Cambridge Systematics, Inc. 1994. Interim Report: Home-Based Work Parking Cost Model. Unpublished report. Cambridge, MA: Cambridge Systematics, Inc., 1994.

Downs, A. 1992. Stuck in Traffic: Coping With Peak-Hour Traffic Congestion. Washington, D. C., The Brookings Institution.

Downs, A. 1962. The Law of Peak-Hour Expressway Congestion. Traffic Quarterly: 393409.

Feeney, B. P. 1989. A Review of the Impact of Parking Policy Measures on Travel Demand. Transportation Planning and Technology 13 (1989): 229-244.

Ferguson, E. 1994. Recent Declines in Carpooling. NPTS Special Subject Reports: 1990 Nationwide Personal Transportation Survey. U. S. Department of Transportation, Federal Highway Administration, Office of Highway Information Management, Washington, D. C.

Ganek, J., and R. Saulino. 1976. A Disaggregate Modal-Split Model for Work Trips Involving Three Mode Choices. Transportation Research Record 610: 25-29.

Gillen, D. W. 1977. Estimation and Specification of the Effects of Parking Costs on Urban Transport Mode Choice." Journal of Urban Economics 4: 186-199. 
Gordon, P., A. Kumar, and H. W. Richardson. 1989. Congestion, Changing Metropolitan Structure, and City Size in the United States. International Regional Science Review 12: 45-56.

Giuliano, G., and K. A. Small. 1992. Is the Journey to Work Explained by Urban Structure? Working Paper No. 107, The University of California Transportation Center, University of California at Berkeley.

Hamerslag, R., J. D. Fricker, and P. Van Beek. 1995. Parking Restrictions in Employment Centers: Implications for Public Transport and Land Use. Paper presented at the 74th Annual Meeting of the Transportation Research Board, Washington, D.C.

Hu, P. S., and J. Young. 1992. Summary of Travel Trends: 1990 Nationwide Personal Transportation Survey. U. S. Department of Transportation, Federal Highway Administration, Office of Highway Information Management, Washington, D. C.

Hu, P. S., and J. Young. 1993. 1990 NPTS Databook: Nationwide Personal Transportation Survey, Volume II. U. S. Department of Transportation, Federal Highway Administration, Office of Highway Information Management, Washington, D. C.

Kain, J. 1994. Impacts of Congestion Pricing on Transit and Carpool Demand and Supply. In Transportation Research Board, Curbing Gridlock, Vol. 2. National Research Council, Washington, D. C.: National Academy Press.

Kondo, K., and R. Kitamura. 1987. Time-Space Constraints and the Formation of Trip Chains. Regional Science and Urban Economics 17: 49-65.

Kunze, B., C. Heramb, and T. Martin. 1980. Impacts of Municipal Parking Fee Increases in Downtown Chicago. Transportation Research Record 786: 21-30.

Lansing, J. B., and G. Hendricks. 1967. Automobile Ownership and Residential Density. Report prepared for the Bureau of Public Roads, Federal Highway Administration, U.S. Department of Transportation. Ann Arbor, MI: Survey Research Center, Institute for Social Research, University of Michigan.

Lave, C. A. 1970. The Demand for Urban Mass Transportation. The Review of Economics and Statistics, 52: 320-323.

Lawton, K. 1995. Surveys for Improved Models, A Response to ISTEA and the CAAA requirements. Presentation at the Fifth National Conference on Transportation Planning Methods Applications, Seattle, WA: Transportation Research Board.

May, A. D. 1973. Traffic Management and Restraint by Parking Control in Greater London. Highway Research Record 474: 19-30. 
Mehranian, M., M. Wachs, D. Shoup, and R. Platkin. 1987. Parking Costs and Mode Choices among Downtown Workers: A Case Study. Transportation Research Record 1130: $1-5$.

Miller, E. J. 1993. Central Area Mode Choice and Parking Demand. Transportation Research Record 1413: 60-69.

Miller, G. K., and C. T. Everett. 1982. Raising Commuter Parking Prices-An Empirical Study. Transportation 11: 105-129.

Peat Marwick, Inc. 1990. The Dimensions of Parking. Unpublished study prepared for the U.S. Department of Transportation, Washington, D.C.

Peng, Z., K. J. Dueker, J. Strathman, and J. Hopper. "A Simultaneous Route-Level Transit Patronage Model." Transportation (forthcoming).

Pickrell, D. H., and D. C. Shoup. 1980. Employer-Subsidized Parking and Work-Trip Mode Choice. Transportation Research Record 786: 30-37.

Pisarski, A. E. 1992. Travel Behavior Issues in the 90's. U. S. DOT, Federal Highway Administration, Office of Highway Information Management, Washington, D. C.

Riklin, E. S., D. Vozzolo, P. A. Ehrhardt, and J. Colman. 1994. The Projected Effect of Parking Policies on Transit Ridership in the Hartford, Connecticut, Region. Paper presented at the 73rd Annual Meeting of the Transportation Research Board, Washington, D. C.

Rosenbloom, S. 1994. Travel by Women. In NPTS Special Subject Reports: 1990 Nationwide Personal Transportation Survey. U. S. Department of Transportation, Federal Highway Administration, Office of Highway Information Management, Washington, D. C.

Rossetti, M. A., and B. S. Eversole. 1993. Journey to Work Trends in the United States and Its Major Metropolitan Areas, 1960-1990. U. S. Department of Transportation, Research and Special Programs Administration, John A. Volpe National Transportation Systems Center, Cambridge, MA.

Sale, J. E., and B. Green. 1979. Operating Costs and Performance of American Public Transit Systems. Journal of the American Planning Association 45: 22-27.

Schrank, D. L., S. M. Turner, and T. J. Lomax. 1993. Estimates of Urban Roadway Congestion-1990. Research Report 1131-5, Texas Transportation Institute, Texas A\&M University System, College Station, TX.

Segelhorst, E. W., and L. D. Kirkus. 1973. Parking Bias in Transit Choice. Journal of Transport Economics and Policy 7: 58-70. 
Shoup, D. C. 1982. Cashing Out Free Parking. Transportation Quarterly 36: 351-364.

Shoup, D. C. 1992. Cashing Out Employer-Paid Parking. Report No. FTA-CA-11-003592-1, Washington, D. C.: U. S. Department of Transportation.

Shoup, D. C. 1994. Cashing Out Employer-Paid Parking: A Precedent for Congestion Pricing? In Transportation Research Board, Curbing Gridlock, Vol. 2. National Research Council, Washington, D. C.: National Academy Press.

Shoup, D. C. 1995. An Opportunity to Reduce Minimum Parking Requirements. Journal of the American Planning Association 61: 14-28.

Shoup, D. C., and R. W. Willson. 1992. Employer-Paid Parking: The Problem and Proposed Solutions. Transportation Quarterly 46: 169-192.

Strathman, J. G., K. J. Dueker, and J. S. Davis. 1994. Effects of Household Structure and Selected Travel Characteristics on Trip Chaining." Transportation 21: 23-45.

Strathman, J. G., and K. J. Dueker. 1994. Understanding Trip Chaining. In NPTS Special Subject Reports: 1990 Nationwide Personal Transportation Survey, U. S. DOT, Federal Highway Administration, Office of Highway Information Management, Washington, D. C.

Surber, M., D. Shoup, and M. Wachs. 1984. Effects of Ending Employer-Paid Parking for Solo Drivers. Transportation Research Record 957: 67-71.

Talvitie, A. 1972. Comparison of Probabilistic Modal-Choice Models: Estimation Methods and System Inputs. Highway Research Record 392: 111-120.

U. S. Department of Transportation, Urban Mass Transportation Administration. 1991. Transit Profiles: Agencies in Urbanized Areas Exceeding 200,000 Population. 1990 Section 15 Report, Washington D. C.

Vincent, M. J., M. A. Keyes, and M. Reed. 1994. NPTS Urban Travel Patterns: 1990 Nationwide Personal Transportation Survey. U. S. Department of Transportation, Federal Highway Administration, Office of Highway Information Management, Washington, D. C.

Williams, M. E., and K. L. Petrait. 1993. U-PASS: A Model Transportation Management Program That Works. Transportation Research Record 1404: 73-81.

Willson, R. W. 1991. Employer Parking Subsidies, Mode Choice, and Public Policy. Unpublished Ph.D. dissertation, University of California at Los Angeles.

Willson, R. W. 1992. Estimating the Travel and Parking Demand Effects of EmployerPaid Parking. Regional Science and Urban Economics 22: 133-145. 
Willson, R. W. 1995. Suburban Parking Requirements: A Tacit Policy for Automobile Use and Sprawl. Journal of the American Planning Association 61: 29-42.

Willson, R. W., and D. C. Shoup. 1990. Parking Subsidies and Travel Choices: Assessing the Evidence. Transportation 17: 141-157.

\section{About the Authors}

James K. Strathman is Professor of Urban Studies and Assistant Director of the Center for Urban Studies, School of Urban and Public Affairs, Portland State University, Portland, Oregon. Kenneth J. Dueker is Professor of Urban Studies and Director of the Center for Urban Studies, School of Urban and Public Affairs, Portland State University. 


\title{
A Taxonomy for Advanced Public Transportation Systems
}

\author{
Asad J. Khattak \\ University of North Carolina at Chapel Hill \\ Hisham Noeimi \\ JRH Transportation Engineering \\ Haitham M. Al-Deek \\ University of Central Florida
}

\begin{abstract}
This study explores the development and availability of APTS (Advanced Public Transportation Systems) technologies. APTS technologies can revitalize transit by directly improving service, increasing transit efficiency and reducing operating costs, as well as by producing direct benefits for travelers such as reduced travel times, increased safety and security, and reduced stress in dealing with transit unreliability. To understand APTS impacts, this study develops a taxonomy of transit technologies and uses it to explore the availability of new technologies and their impacts. The taxonomy is based on defining the features, functions, and performance characteristics of transit technologies. Further, the implementation of new technologies can be described by their spatial, temporal, and user dimensions, i.e., where, when, and for whom is the technology implemented. These dimensions, along with the implementation context, determine the impacts of APTS technologies. To explore the availability of APTS technologies, technology suppliers were surveyed. They were asked about the features, functions, and perfor-
\end{abstract}


mance of transit technologies, their testing and deployment in transit agencies, and their potential impacts on travelers and transit operators. The survey results suggest a trend toward transfer of data in real-time through electronic media and increased automation. It was found that about a dozen APTS technologies queried in the survey were commercially available for field testing. From a policy perspective, there is a need to develop a strategy that considers the individual and joint testing of two or more APTS technologies and facilitates synthesis of the resulting information. Individually, the benefits of APTS technologies may be limited, but, collectively, APTS technologies may have significant benefits. Cases of joint APTS technology implementations need to be designed, implemented and synthesized.

\section{Introduction}

While traffic congestion grows, public transportation continues to lose market share in the United States. Specifically, the share of transit trips shows a declining trend: 3.6 percent in 1969, 2.6 percent in 1983 and 2 percent in 1990 (Pisarski 1992). Moreover, the use of public transportation for work travel has declined from 12.6 percent in 1960 to 5.3 percent in 1990 (Ball 1994). Recent advances in electronic technologies may allow greater integration of transit services and increase transit use. Advanced Public Transportation System (APTS) technologies may increase transit efficiency, improve transit level of service, reduce costs, and avoid further reductions in transit use. To assess the potential of APTS technologies, there is a need to systematically explore their impacts (Khattak et al. 1993). The main objectives of this study are to:

- define and classify APTS technologies and identify their impacts;

- use the classification structure for exploring availability of new transit technologies; and

- provide ideas on individual and joint testing of APTS technologies.

The structure developed to classify and investigate the availability of new transit technologies is based on defining technologies in terms of their features, functions, and performance. For example, one feature of transit information technology is the communication medium (whether information is disseminated through visual or audio means); a function is provided by the content of dissemi- 
nated information (subject matter and whether the information is historical or real-time); and a key performance measure is information quality (accuracy and relevance).

To support the implementation of APTS technologies, their spatial, temporal, and user dimensions should be defined. For example, the spatial dimensions of transit information technologies are the transit vehicles that are monitored and the links served. The temporal dimensions are the free-flow travel times on transit links and the times monitoring is in effect. The user dimensions are whether certain travelers access transit information devices and actually choose to take transit.

APTS technologies can be traveler-based, operator-based, or both. The traveler-based technologies influence traveler behavior directly but can indirectly impact operators (e.g., pre-trip or in-terminal information systems). Similarly, operator-based technologies influence transit operators directly and travelers indirectly (e.g., Automatic Vehicle Monitoring systems). Mixed technologies simultaneously impact both travelers and operators. Finally, the technologies are implemented, and the impacts occur in a context characterized by the spatial, temporal, and user dimensions. For example, the transportation network structure, its state at various times, and population characteristics (density and socioeconomics) can be important determinants of APTS impacts.

The following section describes the process of transit technology implementation. Then, taxonomies for new transit technologies and their impacts are discussed. Next, the development and implementation of a transit technology supplier survey and results are presented. Finally, conclusions are drawn and the need to develop a strategy for systematically testing new transit technologies is identified.

\section{Process of Technology Implementation}

Figure 1 shows the process of technology supply, demand, and implementation. The demand for transit technologies may come from the political process, which can encourage the use of APTS technologies. For example, the ISTEA (Intermodal Surface Transportation and Efficiency Act) legislation encourages 


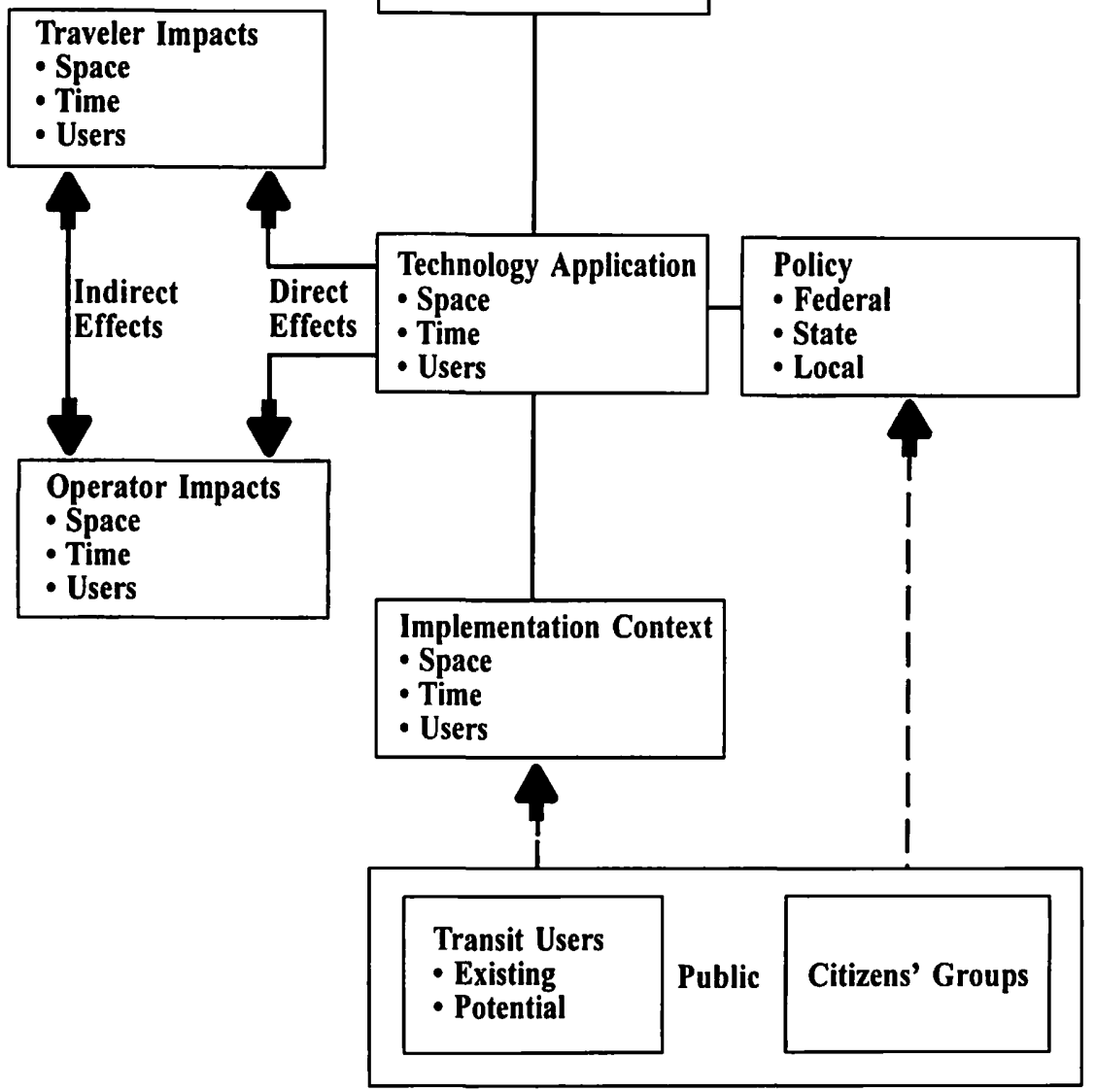

Technology

Developers/Suppliers

Technology

- Features

- Functions

- Performance

Implementation Context

- Space

- Time

- Users

- Existing

Citizens' Groups

Figure 1. The process of technology supply, demand, and implementation. 
multimodal systems because they can achieve certain goals such as reduce traffic congestion and pollution. Further, ISTEA encourages increased transit security by giving incentives. The Americans with Disabilities Act (ADA) promotes the use of certain technologies because it mandates accessibility for the disabled. Besides the federal policies, state and local policies create the demand for new transit solutions. The demand for improved technology in transit systems is also stimulated by the public, i.e., existing and potential transit users and citizens' groups (who advocate transit improvements).

Transit technology developers and suppliers respond to the market (or sometimes create a market) by designing new technologies using advances in electronics and machines. To satisfy demand, suppliers develop technologies that have certain features, functions, and performance characteristics. Table 1 gives a summary of advanced transit information technologies in terms of their features, functions and performance criteria (Khattak et al. [1993] provide similar summaries for other transit technologies). The technology features, functions and performance measures are based on a review of literature and our judgment (see Khattak et al. [1993] for a comprehensive review of relevant literature). Table 1 suggests that pre-trip information systems can disseminate information by several means, including telephone, computer, and television. Therefore, the medium of information dissemination is important in technology definition. Transit information systems provide historical and real-time information on transit operations (routes, schedules, and fares) to travelers and some systems do advance ticketing and reservation. Therefore, the content of information and other functions are important. Moreover, the accuracy and relevance of information provided is likely to vary. The quality of information is important in traveler decisionmaking. Thus, a set of design factors for pre-trip information technologies that partly determine impacts are the medium, content, and quality of information.

The spatial, temporal, and user dimensions of the technologies and the implementation context influence impacts. The technology application takes place in an implementation context defined by the transit agency characteristics such as service to certain populations (e.g., commuters, lower income, disabled) in a 


\section{Table 1}

\section{Characteristics of Selected Advanced Transit Information Technologies}

\begin{tabular}{|c|c|c|c|}
\hline Technology & $\begin{array}{c}\text { Features } \\
\text { (Information } \\
\text { Medium) }\end{array}$ & $\begin{array}{l}\text { Functions } \\
\text { (Information } \\
\text { (content) }\end{array}$ & $\begin{array}{c}\text { Performance } \\
\text { (Information } \\
\text { Quality) }\end{array}$ \\
\hline $\begin{array}{l}\text { Pre-Trip } \\
\text { Information } \\
\text { Systems }\end{array}$ & $\begin{array}{l}\text { - Auto dial phone } \\
\text { - Telephone to } \\
\text { computer operator } \\
\text { - Voice recognition } \\
\text { - Computer \& modem } \\
\text { - Teletext } \\
\text { - Videotext } \\
\text { - Audiotext } \\
\text { - Cable TV } \\
\text { - Interactive voice } \\
\text { response } \\
\text { - Interactive TV }\end{array}$ & $\begin{array}{l}\text { - Provides historical } \\
\text { or real time information: } \\
\text { - schedule/departure times } \\
\text { - multimodal itinerary } \\
\text { - trip chaining (itinerary } \\
\text { optimization) } \\
\text { - ride share opportunities } \\
\text { - best route based on } \\
\text { traveler criteria: } \\
\text { - shortest time } \\
\text { - lowest fare } \\
\text { - intermediate stops } \\
\text { - maximum use of } \\
\text { rapid transit } \\
\text { - least walking distance } \\
\text { - Provides advance } \\
\text { ticketing \& reservations }\end{array}$ & $\begin{array}{l}\text { - Presentation quality } \\
\text { - Accuracy of information } \\
\text { - Relevance of information }\end{array}$ \\
\hline $\begin{array}{l}\text { In-Terminal } \\
\text { Information } \\
\text { Systems }\end{array}$ & $\begin{array}{l}\text { - Dot matrix display } \\
\text { - Flipover display } \\
\text { - LCD } \\
\text { - TV monitors } \\
\text { - Synthesized } \\
\text { voice messages } \\
\text { - Audio terminals } \\
\text { - Video terminals: } \\
\text { - with keypads } \\
\text { - with touch screens }\end{array}$ & $\begin{array}{l}\text { - Provides historical or } \\
\text { real-time information: } \\
\text { - schedule/departure times } \\
\text { - multimodal itinerary } \\
\text { - trip chaining (itinerary } \\
\text { optimization) } \\
\text { - ride share opportunities } \\
\text { - best route based on } \\
\text { traveler criteria: } \\
\text { - shortest time } \\
\text { - lowest fare } \\
\text { - intermediate stops } \\
\text { - maximum use of } \\
\text { rapid transit } \\
\text { - least walking distance } \\
\text { - connection points } \\
\text { - transit vehicle location/ } \\
\text { delays information } \\
\text { - terminal related informat } \\
\text { (e.g., layout) } \\
\text { - destination } \\
\text { - Provides advance ticketing } \\
\text { \& reservations }\end{array}$ & $\begin{array}{l}\text { - Presentation quality } \\
\text { - Accuracy of information } \\
\text { - Relevance of information }\end{array}$ \\
\hline
\end{tabular}

Source: Khattak et al., 1993 
specific area, on certain routes, and at specific times (e.g., frequencies and schedules). In addition to the implementation context, the technology is also defined in terms of space, time, and user dimensions. For example, Automatic Vehicle Monitoring (AVM) systems report transit vehicle location on specific network links at certain times, and the position information of vehicles is relevant to supervisors who make operations decisions (e.g., advise drivers on maintaining headways and schedules). To refer to various aspects of APTS technologies, the term "technology space" is defined as having design dimensions (features, functions, and performance) and application dimensions (space, time, and user). Equivalently, "impacts space" is defined in terms of performance criteria or dimensions (efficiency, service quality, cost, time savings) and distribution dimensions (space, time and users). Technologies can have direct, indirect, and simultaneous impacts on operators and travelers. For example, transit operations software, AVI (Automatic Vehicle Identification) and AVL (Automatic Vehicle Location) systems are expected to have strong direct impacts on transit operators. Transit information systems are expected to directly influence travelers. The following direct transit operator impacts occur:

- reduced costs such as maintenance, fuel, labor, management and marketing costs, and

- improved efficiency through better transit planning and operations-

- the planning functions that can be improved include the selection of service area, routes, stops, and service frequencies, and

- the operations improvements can come from better ability to monitor driver and vehicle performance, improved scheduling and dispatching, reduced human errors, improved fare structure, and enhanced safety and security.

The indirect benefits of transit improvements accrue to transit travelers (and non-transit travelers through reduced congestion and pollution on highways). Impacts from APTS technologies are distributed in space and time and by various types of operator decisions. The magnitude of direct operator impacts depends on the technology design dimensions, technology application dimensions, and the implementation context. 
The following direct traveler benefits due to APTS technologies can be expected:

- travel time savings and reduced uncertainty in travel times;

- improved accessibility;

- improved content, medium and quality of transit information;

- increased flexibility in travel choices;

- improved (accident) safety and security;

- ease of transit use, improved travel comfort and convenience; and

- improved satisfaction with transit service and customer feedback.

The key indirect benefit to a transit agency is increased ridership. The impacts from individual APTS technologies can vary across the impacts space, i.e., the traveler impacts are distributed in space, time, and by different travelers. Sometimes, APTS technologies may influence travelers differently by design. For example, a technology that enhances ease of transit use may be particularly appealing to the elderly and disabled, whereas a technology that increases travel choices may be attractive for shoppers (because of opportunities to shop at more destinations). The extent of direct traveler impacts depends on the technology design and application dimensions and the implementation context.

This study explores the availability of newly developed transit technologies for field testing in transit agencies. There are several projects in the United States aiming to test different advanced technologies (see Khattak et al. 1993). For example, the Federal Transit Administration (FTA) and California Department of Transportation (Caltrans) are co-funding a four-phase California Smart Traveler Project where public and private sectors will jointly test an audiotext/videotextbased Advanced Traveler Information System in suburban California. We hope to help the development of such projects through research on the features, functions, and performance of new transit technologies and through suggestions on deployment strategies. This requires that the technologies and their implementation context and impacts be defined in terms of spatial, temporal, and user dimensions. Importantly, knowledge and models are needed to determine the impacts of APTS technologies individually and collectively. 


\section{Technology Definition and Evaluation}

\section{Traveler Information Systems}

Information content, medium, and quality can influence various traveler choices. The taxonomy with regards to information content is explained below. Information can be either static or dynamic. Static information related to travel choices does not change with time, whereas dynamic information changes with time. Information can be further divided into qualitative or quantitative. Infor-

Technology:

Manufacturer/Sponsor:

\begin{tabular}{|l|l|l|l|l|}
\hline \multirow{2}{*}{$\begin{array}{l}\text { Information } \\
\text { Traveler } \\
\text { Choices }\end{array}$} & \multicolumn{2}{|c|}{ Static } & \multicolumn{2}{c|}{ Dynamic } \\
\cline { 2 - 5 } & Qualitative & Quantitative & Qualitative & Quantitative \\
\hline Destination & & & & \\
\hline Multimodal & A & B & C & D \\
\hline Departure Time & & & & \\
\hline Route & & & & \\
\hline Park and Ride & & & & \\
\hline Trip Chaining & & & & \\
\hline
\end{tabular}

Technology Functions:

$\begin{array}{lll}\text { Multimodal Reservation } & \square \text { Yes } & \square \text { No } \\ \text { Integrated Billing System } & \square \text { Yes } & \square \text { No } \\ \text { Seating Availability } & \square \text { Yes } & \square \text { No }\end{array}$

Information Medium:
$\square$ Portable
$\square$ Non-Portable
$\square$ In-Vehicle
๑ Out-of-Vehicle
$\checkmark$ Audio
$\square$ Visual

Figure 2. Taxonomy of traveler-based transit information systems. 
mation content and travel choices form a two dimensional taxonomy matrix (Figure 2). As an illustration of this matrix, consider the following examples:

- Static Qualitative, Multimodal Information (Cell " $A$ "). Static information about the availability of trip connections may support multimodal choice. For example, based on trip connections information, a traveler may use bus instead of auto to reach the nearest train station.

- Static Quantitative, Multimodal Information (Cell " $B$ "). Static information about transit schedules can reduce wait times and support mode choice.

- Dynamic Qualitative, Multimodal Information (Cell " $C$ "). Real-time information about whether a bus is on-time can support the choice of using a bus or walking to a train station.

- Dynamic Quantitative, Multimodal Information (Cell " $D$ "). Real-time information about expected arrival times of the next bus or train and expected delays can support travelers' modal choice.

In addition to static and dynamic information, transit systems may provide predictive information such as the expected time to recovery of a breakdown. Other functions provided by information systems are integrated billing service and multimodal (park-and-ride) trip reservation.

Information medium is important in determining traveler impacts. Whether a device is portable or fixed (and if fixed, whether it is in-vehicle or out-ofvehicle) and visual or audio are important aspects of traveler information technologies. Furthermore, information quality is an important performance criterion. Clearly, individuals prefer higher quality information.

From a technology implementation perspective, the spatial, temporal and user dimensions are important. Specifically, where and when the information technology is implemented and who are the expected users is important in determining its impacts. The spatial dimensions of transit information technologies are the transit vehicles that are monitored through surveillance technologies and the relevant routes. The temporal dimensions are the free-flow travel times on transit links and the times vehicles are monitored. The user dimensions are whether travelers access transit information devices and decide to take public transit. 


\section{Rideshare Systems Technologies}

Real-time rideshare matching systems allow trip makers to call in for sharing a ride either as drivers or as passengers. Rideshare matching software allows travelers to review rideshare options, identify individuals whose needs closely match their own, and reserve the trip in advance. Real-time rideshare systems will provide information on other travelers to potential ridesharers. The taxonomy matrix can be used to understand how travel decisions may be influenced by the content of rideshare information. The following information can be provided by a rideshare information service (for high occupancy vehicles):

- Static-Qualitative Information. Examples of static-qualitative information are potential candidates for rideshare, location of candidates' homes and their preferences.

- Static-Quantitative Information. Examples of static-quantitative information are preferred times of departure and distance to homes of the candidates.

- Dynamic-Qualitative Information. The rideshare system may inform customers of delays due to personal emergencies.

- Dynamic-Quantitative Information. The service may give information on the number of persons available at certain times of the day, expected length of delays, and dynamic travel time information for HOV (High Occupancy Vehicle) and mixed-flow lanes.

\section{Automatic Vehicle Control Technologies}

Early versions of Automatic Vehicle Control System technologies provide driver warning and assistance, resulting in collision avoidance. The technologies can perform collision avoidance by obstacle detection, lane edge warning, and some level of lateral/longitudinal control. These systems are in their early stages of development. They use radar, infrared laser, or sonar and provide either warning only or warning with braking. They can improve transportation safety by reducing accidents. The information provided to drivers is dynamic. It can be qualitative, such as "You are very close to the right edge of the lane," or quantitative, such as "You are $x$ feet away from the vehicle in the right lane." The 
information will be disseminated through visual, audio, or both means. The content, medium, and quality of information will influence the driver response to the warnings.

\section{Automatic Vehicle Monitoring, Automatic Ticketing,}

\section{Automatic Passenger Counters, and On-Board Computer Systems}

To support supervision and coordination, certain technologies provide surveillance and monitoring. Automatic Vehicle Monitoring systems can simultaneously improve transit operations (dispatching, scheduling, and security) while providing real-time transit system operation information to travelers. Electronic Ticketing Systems (ETS) automate fare collection, increasing convenience and adding modest travel time savings to a trip. Automatic Passenger Counters (APC) send passenger counts to a central facility in real-time. Together, APC and ETS provide valuable data to transit operators on passenger loads and schedule adherence. These data can be used to support transit operations (dispatching and scheduling) and planning.

A taxonomy of technologies can be applied to the information that comes from various technology sources to a central transit management center. The operator decisions that can be supported include operations (dispatching, scheduling, supervision, monitoring, coordination, and fare collection) and planning (area and routes to serve, service type-regular or express, stops, frequencies, fare structure, and maintenance). The content of information and its medium and quality are likely to influence operator decisions. In addition, the analysis techniques used to process information (e.g., expert systems and breakdown duration prediction models) influence operator decisions. The information can be historical (qualitative or quantitative) or real-time (qualitative or quantitative). For example, real-time information about the location of buses and whether they are on time is available to operators through AVI and AVL systems. Such information can be used to avoid bunching, detect breakdowns, and disseminate the information to travelers. On-board computers collect vehicle data (oil, water, engine temperature, vehicle speed, etc.), which can be used by the driver and transit operators to monitor vehicle performance and detect and deal effectively with breakdowns. Transit operations software supports transit planning decisions of ve- 
hicle and crew scheduling, maintenance, and marketing. The software can also be connected to AVI/AVL systems for greater effectiveness.

More generally, the information and how transit operators choose to process it can support their decisions. The information can relate to transit system performance, traffic system performance, and traveler demand at various origins and destinations and times of day.

\section{Survey Methodology}

The objectives of this study are to define APTS technologies, track their development, and suggest a strategy to evaluate their impacts on transit operators and travelers. Ideally, the study should be designed to address these objectives simultaneously. However, when the study commenced, APTS technologies were still under development and not implemented by transit agencies. Therefore, a decision was made to survey technology suppliers during the first phase of the study. The subsequent phases focus on surveying technology implementers and travelers (and these phases are ongoing). The remainder of this section presents the methodology, and the next section reports the results of the technology supplier survey.

The methodology for the technology supplier survey is illustrated in Figure 3. After classifying Advanced Public Transportation Systems (APTS) according to their features, functions, and performance, a survey was designed to explore their (commercial) availability. The survey also inquired (from technology suppliers) about supplier attributes, the application of their technologies in transit agencies, and their perceived impacts on travelers and transit operators. The survey was structured as follows:

- available APTS technologies defined in terms of features, functions and technology performance;

- technology deployment in transit agencies, i.e., "typical customers" and customer attributes;

- perceived impacts of technologies on operators and travelers; and

- technology supplier attributes. 


\section{Objective}

- Develop a framework for classifying APTS technologies

- Explore their impacts and availability

\section{$\checkmark$}

Address Objective

- Develop structure based on technology features, functions, and performance

- Implementation of technologies based on temporal, spatial, and user dimensions

- Use survey research to investigate availability of advanced transit technologies

- APTS technology

\section{Design Survey Based On}

- Features

- Functions

- Performance

- Technology implementation in transit agencies

- Typical customers

- Customer attributes

- Technology Impacts

- Operator benefits

- User benefits

- Technology supplier/developer attributes

\section{Pre-Test and Implement Survey, Code and Analyze Data}

Figure 3. Study methodology. 
About 100 surveys were mailed to technology suppliers; 20 were used for analysis $(\mathrm{N}=20)$. The respondents included most major APTS companies in the United States. The details of the survey appear in Khattak et al. (1993). The purpose of these surveys was not so much to conduct formal statistical comparisons, but to obtain information on available transit technologies.

\section{Results}

Responses were spread evenly across technology categories. Given the comprehensive list of APTS technologies explored in the survey, this suggests that most APTS technologies are commercially available for field testing. As a result of the survey, a database of technology suppliers in the United States was created.

The responses suggest that both small and large companies are competing in the APTS technology market. Most respondents manufactured their products in the U.S., and most fabricated their products in-house. Supplier responses to each transit technology are presented below.

\section{Pre-Trip Information Systems}

Ten companies sell pre-trip information systems: Schlumberger Technologies, Tidewater Inc., Etak Inc., Qualcomm Inc., Megadyne Info Systems, Fone Link Inc., Commuter Transportation Services, Teleride Sage Ltd., Westinghouse, and Peek Traffic. For the information medium, 5 companies use automatic dial phone technology, 6 use telephone to computer operator technology, 2 use telephone and voice recognition technology, 5 use computer modem technology, 7 use teletext, 4 use videotext, 1 uses cable TV, and 4 systems use other kinds of technology. In terms of the information content provided to the traveler, 9 have systems that provide schedule/departure times ( 3 are based on historical information and 6 are real time); 7 provide multimodal itinerary information; 3 provide trip chaining (itinerary optimization) information ( 3 are historical and 4 are real time); and 6 provide information on rideshare opportunities ( 4 are historical and 2 are real time). Further, the systems can provide best route information based on traveler selected criteria, which include: (i) shortest time6 of the suppliers, (ii) lowest fare- 6 , (iii) intermediate stops- -5 , (iv) maximum 
use of rapid transit-5, and (v) least walking distance- 6 . In addition, 8 of the systems provide information on connection points, and 7 provide information about transit vehicle location. In terms of a map base, only 1 uses Etak, 5 use Tiger, and 4 use other map bases. Only 1 system provides advance ticketing and reservation capability.

\section{In-Terminal Traveler Information Systems}

Seven suppliers have in-terminal information systems. The suppliers include: Tidewater Inc., Westinghouse, Etak Inc., Megadyne Information Systems, Teleride Sage Ltd., Peek Traffic, and Midwest Electronic Industries. Of the available systems, six disseminate information by dot matrix displays (6), 4 use flipover displays, 4 use Liquid Crystal Displays (LCD), 2 use TV monitors, 5 use synthesized voice messages, 2 use interactive audio terminals, 3 use interactive video terminals with keypads, and 4 use interactive video terminals with touch sensitive screens.

In terms of information content, 4 provide schedule/departure times ( 2 are historical and 2 are real time), 5 provide multimodal itinerary information, 3 provide trip chaining information (itinerary optimization), and 3 provide rideshare opportunities information. The systems can provide best route information based on traveler selected criteria, which include: (i) shortest time- 3 (2 are historical and 1 is real time), (ii) lowest fare-3, (iii) intermediate stops-2, (iv) maximum use of rapid transit -3 , and ( $v$ ) least walking distance-3. All available systems provide information on connection points, 6 provide information on transit vehicle location, 5 provide information on delays, and all provide information on the destination. Only 1 available system uses Etak as the map base, 4 use Tiger, and 2 use other map bases. None provide advanced ticketing and reservation, and all available systems can be linked to other sources of information.

\section{In-Vehicle Traveler Information Systems}

Six out of 20 companies have in-vehicle information systems: AEG Westinghouse, Motorola, Etak Inc., Megadyne Info Systems, Peek Traffic, and Midwest Electronic Industries. Among the available systems, 5 use synthesized voice messages to disseminate information, 5 use dot matrix displays, 3 use video 
displays, 2 use flap displays, and 2 use other technologies. In terms of information content provided to travelers, 5 give schedule information ( 2 are historical and 3 are real time), 4 provide the expected arrival time at the next stop ( 1 is historical and 3 are real time), 3 provide waiting times at connecting points, 4 provide connecting services, 1 provides seating availability information, and 4 provide next stop announcements. Only 1 available system uses Etak as the map base, 7 use Tiger, and 10 use other map bases. None provide advance ticketing and reservation.

\section{Rideshare Matching Software}

Five suppliers provide real-time rideshare matching software: Tidewater Inc., Comsis, Megadyne Information Systems, Fone Link Inc., and Commuter Transportation Services. A majority (3) provide real-time matching, and 4 use Tiger as their map base. Two of the latest systems match passengers by grid, and 2 match them by zip code.

\section{Automatic Vehicle Identification}

Six suppliers have AVI technologies: Amtech Technologies, EMX Inc., AEG Westinghouse, Fone Link Inc., LazerData, and Peek Traffic. Among the available technologies, 2 are based on Infrared/Optical, 3 on Radio Frequency (RF)/ Microwave, 2 on Inductive Loop, and 1 on Surface Acoustic Wave (SAW). Four out of 6 have two-way communications capability between reader unit and vehicle mounted transponder, and 1 encodes variable data. In terms of technology performance, 1 respondent claimed that its system misses no vehicles, and the rest miss less than 1 percent of the vehicles.

\section{Automatic Vehicle Location}

Ten of the suppliers sell AVL systems: EMX Inc., AEG Westinghouse, Motorola, Etak Inc., Qualcomm Inc., Megadyne Information Systems, Rockwell RR Electronics, II Morrow Inc., Teleride Sage Ltd., and Peek Traffic. Of the systems on the market, only 1 uses dead reckoning, 2 use dead reckoning with map matching, 4 use GPS with dead reckoning, 2 use GPS with map matching, 2 use Proximity Beacon Sign Post, (all of which use "sharp" transmissions [localized signals] as opposed to "broad" transmissions [long range signals]), 4 use 
Radio Determination ( 2 of which use Loran-C), 5 use Satellite Based systems (4 of which are GPS/NAVSTAR), and 5 systems use other methods.

In terms of technology performance, 2 track the location of the transit vehicle within 30 feet, 60 percent track it between 30 and 100 feet, 1 tracks it between 100 and 500 feet, and 1 tracks it at more than 500 feet. Four of 8 systems update location information every 1 second, 1 updates information every 30 seconds, 2 update it every 60 seconds, and 1 updates the position information every 60 minutes.

\section{Collision Avoidance Systems}

Only two companies have collision avoidance systems: Westinghouse and Rockwell RR Electronics. Both provide warning and braking functions.

\section{On-Board Computers}

Seven vendors have on-board computers: Westinghouse, Etak Inc., Qualcomm Inc., Pulse Electronics, Rockwell RR Electronics, II Morrow Inc., and Peek Traffic. The computers collect data on speedometers (6), and ignition status (on/off) (5). Most systems (6) are connected to a central computer for data integration and processing. Only 1 system each uses Etak and Tiger as the map base, and the remaining 5 use other map bases.

\section{Transit Operations Software}

Three suppliers provide transit operations software. They include: Westinghouse, Megadyne Information Systems, and Teleride Sage Ltd. None of the available systems provide marketing functions; only 1 provides management and administration functions; 1 provides network and operations planning based on historical and real-time information; and 2 provide vehicle and crew scheduling. Two use Tiger as their map base. Two of the latest transit operations software systems can be connected to an Automatic Vehicle Location system, and 2 can be connected to Automatic Vehicle Identification systems.

\section{Electronic Ticketing Systems}

The companies that supply Electric Ticketing Systems include Schlumberger and AEG Westinghouse. Both systems collect origin destination data and revenue information disaggregated by route and ticket type; 1 collects passenger 
information disaggregated by class, route, and time of day. In terms of payment, 1 system can accept credit cards; both have tickets that can be reused by adding fare to them; 1 has tickets good for one ride only. Both have tickets good for a limited number of rides, whereas 1 has tickets good for unlimited rides. Moreover, 1 of the ETS has tickets that the traveler can use for multimodal transportation.

\section{Automatic Passenger Counter}

The suppliers who have Automatic Passenger Counters are Westinghouse, Red Pine Instruments, and Peek Traffic. One company provides a pressure-sensitive mat for counting, and the rest use infrared beams. All use random access memory (RAM) to store information. A majority (2) send passenger counts at bus stops to the dispatcher in real time. One company reported that their system misses less than 1 percent of passengers and provides information on the total number of passengers served along a route, the actual number of passengers on the bus, and the number of passengers boarding and alighting at certain stops.

\section{Automatic Demand-Responsive Dispatching Systems}

Six suppliers have automatic demand responsive dispatching systems. All provide scheduling functions ( 4 are based on historical data and 2 on real time data); all provide dispatching ( 4 are based on historical data and 2 on real time data); 3 provide billing functions; and 5 provide service monitoring and reporting. Four consider traveler preferences, 5 provide transit vehicle location information to the traveler in real-time, 4 provide best route information according to traveler selected criteria, 2 have reservations capabilities, 5 can respond to immediate requests, and all can respond to standing orders. Two of the systems use Tiger as their map base, and 3 use other map bases.

\section{Impacts of APTS Technologies}

Casey and Collura (1993) recognize the need to have a consistent and carefully structured approach to operational test evaluation. In this study, the factors that will influence the outcomes of APTS field tests are hypothesized, and the potential impacts are examined from the technology suppliers' perspective. The true impacts of new technologies will depend on the design and application di- 
mensions of the APTS technologies and the implementation context. Further, the traveler and operator impacts will vary across space, time, and users. Ultimately, knowledge and models are needed to relate APTS technologies and the implementation context to specific traveler and operator impacts. Such knowledge can come from designing and examining case studies. Technology implementation decisions can be made based on historical evidence from field tests; successful field tests can be replicated and unsuccessful ones avoided (Khattak and Kanafani 1995). The implementation decisions can also be made by specifying the inputs (technologies and their implementation context) and the desired outputs (operator and traveler impacts) and running models. The models can evaluate impacts for alternative technology design and application scenarios. However, APTS knowledge is scarce, and models do not exist for APTS evaluation. This study, by collecting information about available APTS technologies, is one effort in the direction of building an APTS knowledge base. In this regard, the opinions of technology suppliers with respect to traveler and operator impacts are examined.

A simplified representation of technology and impact combination is shown in Table 2. It is simplified because no consideration is given to the implementation context and the distribution dimensions of impacts. The table represents scores given by vendors to their highest revenue technologies. The subjective technology evaluations (opinions) provided by the respondents are likely to be biased because the suppliers are selling these products. Also, the small sample size limits generalization. Yet the responses provide insights into the "relative" impacts across the categories and the potential for direct impacts. As expected, operator-based technologies get higher ratings on operator performance (e.g., monitoring, headways, labor hours, operating time, and human error), while traveler-based technologies get higher ratings on operator performance (e.g., user complaints, safety, travel flexibility).

The overall trend in new technologies is toward transfer of data in real-time through electronic media. Most APTS technologies can support either traveler decisions or transit operator decisions and, in some cases, both types of decisions.

In the field of advanced transit technologies, some relatively large companies, such as Schlumberger, Westinghouse, Motorola, and Rockwell, have en- 
Table 2 Ophions of APTS Technology Suppliers Regarding Their Main Transit Product

\begin{tabular}{|c|c|c|c|c|c|c|c|c|c|c|c|c|}
\hline $\begin{array}{l}\text { Tech- } \\
\text { nology }\end{array}$ & $\begin{array}{l}\text { Improved } \\
\text { Monitor- } \\
\text { ing }\end{array}$ & $\begin{array}{l}\text { Controls } \\
\text { Transit } \\
\text { Head- } \\
\text { ways }\end{array}$ & $\begin{array}{l}\text { Reduced } \\
\text { Labor } \\
\text { Hburs }\end{array}$ & $\begin{array}{c}\text { Reduced } \\
\text { Operating } \\
\text { Time }\end{array}$ & $\begin{array}{c}\text { Reduced } \\
\text { Human } \\
\text { Error }\end{array}$ & $\begin{array}{l}\text { Improved } \\
\text { Security }\end{array}$ & $\begin{array}{l}\text { Reduced } \\
\text { User } \\
\text { Com. } \\
\text { plaints }\end{array}$ & $\begin{array}{l}\text { Improved } \\
\text { Safety }\end{array}$ & $\begin{array}{l}\text { Increased } \\
\text { Travel } \\
\text { Flex- } \\
\text { ibility }\end{array}$ & $\begin{array}{c}\text { Easier to } \\
\text { Use } \\
\text { Transit }\end{array}$ & $\begin{array}{l}\text { Improved } \\
\text { Travel } \\
\text { Comfort }\end{array}$ & $\begin{array}{l}\text { Improved } \\
\text { User } \\
\text { Satis- } \\
\text { faction }\end{array}$ \\
\hline $\mathrm{AVI}$ & 3.00 & 3.00 & 3.33 & 3.00 & 3.66 & 3.00 & 2.33 & 3.33 & 3.00 & 3.33 & 3.66 & 3.66 \\
\hline AVL & 3.66 & 3.66 & 3.00 & 2.66 & 3.00 & 3.00 & 3.00 & 2.33 & 2.66 & 2.66 & 2.66 & 3.33 \\
\hline $\mathrm{OBC}$ & 4.00 & 2.00 & 2.00 & 2.00 & 4.00 & 3.00 & 2.00 & 4.00 & 2.00 & 2.00 & 2.00 & 2.00 \\
\hline $\mathrm{APC}$ & 2.00 & 2.00 & 3.00 & 3.00 & 3.00 & 2.00 & 3.00 & 2.00 & 2.00 & 2.00 & 2.00 & 2.00 \\
\hline PTI & 2.00 & 2.50 & 3.50 & 3.50 & 3.50 & 2.00 & 3.50 & 2.00 & 3.50 & 4.00 & 2.50 & 3.50 \\
\hline IVI & 2.00 & 2.00 & - & 4.00 & 4.00 & 3.00 & 3.00 & 2.00 & 3.00 & 4.00 & 4.00 & 4.00 \\
\hline Rideshar & 4.00 & 4.00 & 4.00 & 4.00 & 4.00 & 2.00 & 4.00 & 2.00 & 4.00 & 4.00 & 2.00 & 4.00 \\
\hline Software & 4.00 & 4.00 & 4.00 & 4.00 & 4.00 & 2.00 & 4.00 & 2.00 & 2.00 & 2.00 & 2.00 & 4.00 \\
\hline ETS & - & - & 3.00 & 3.00 & 4.00 & 4.00 & 3.00 & - & - & 3.00 & 3.00 & 4.00 \\
\hline
\end{tabular}

Averages are taken from responses by suppliers of the transit technologies. The responses are coded: $0=$ strongly disagnee; $1=$ disagree; 2 = neutral; $3=$ agree; $4=$ strongly agree.

AVI = Automatic Vehicle Identification; AVL $=$ Automatic Vehicle Location; $\mathbf{O B C}=$ On Boand Computers; $\mathbf{A P C}=$ Automatic Passenger

Counter; PTI = Pre-Trip Info System; IVI = In Vehicle Info System; Rideshare = Rideshare Matching Software; Software = Transit Operations

Software; ETS = Electronic Ticketing System 
tered the market. Smaller companies are also competing. However, their longterm survival seems uncertain. Based on the data, the larger companies did not focus on specific products or technology areas. Furthermore, certain products, such as collision avoidance systems and electronic ticketing systems, are supplied by the larger companies only.

\section{Conclusions and Recommendations}

This study has developed a structure for APTS technologies that can help in:

- evaluating the operator and traveler impacts of alternative technologies in terms of performance measures;

- selecting the appropriate technologies for field testing and deployment;

- representing knowledge about existing and new transit technologies; and

- modeling or optimizing transit system performance and designing surveys to understand traveler response.

APTS technologies can be defined by their design and application dimensions. The design dimensions are technology features, functions, and performance. The application dimensions are spatial, temporal, and user measures. This structure facilitates planning for APTS technologies as explained below. Technology deployment takes place in an implementation context. The spatial, temporal, and user dimensions of the implementation context are also important determinants of technology impacts. For APTS deployment, the interrelationships between operator and traveler impacts are important. The technology and context dimensions will have direct, indirect, and simultaneous impacts on transit operators and travelers. The impacts can be classified in terms of operator and traveler performance dimensions (and these measures are distinct from technology performance measures) and distribution dimensions. The impacts have spatial, temporal, and user distributions, and they are distinct from technology application dimensions. That is, the impacts may not always occur where the technology is implemented (at the same locations and/or times). Technologies that have direct impacts on traveler decisions (e.g., mode and route) are termed traveler-based, and those with direct impacts on operator decisions (operations and planning) are termed operator-based. 
The structure developed in the study was used to explore the commercial availability of new transit technologies. Survey research showed that technology suppliers had several products that were likely to vary in their direct and indirect impacts on transit operators and travelers. The opinions provided by technology suppliers give some insights into technology impacts. For example, AVL systems were rated highly on improving monitoring and also controlling transit headways while information technologies were rated highly on traveler impacts, i.e., they can increase traveler comfort and satisfaction. Although closely connected, traveler-based technologies are more suitable for sustaining (and possibly increasing) transit riderships, whereas operator-based technologies are likely to improve transit efficiency and service, and reduce costs.

A strategy for implementation of these technologies must consider the broader mix of technology alternatives. Importantly, there is a need to identify APTS technologies that can be mixed to provide the correct balance between operator effectiveness and customer satisfaction. Individually, APTS technologies may be of limited value but, collectively, they may significantly enhance the performance of the transit system and attract travelers. Therefore, the issue of APTS integration is critical.

Before testing, a strategy should be designed to select appropriate technologies. Besides testing technologies individually, the collective testing of a balanced set of operator- and traveler-based technologies is needed. Furthermore, the tests need to be conducted in a set of carefully selected "high impact" implementation contexts. Among traveler-based technologies, it is possible that pretrip transit information systems (including real-time rideshare systems) have relatively greater potential. This is because during the pre-trip stage, travelers have greater flexibility in travel choices and also because such systems are expected to have significant impacts on traveler response to unexpected congestion (Khattak and Le Colletter 1994). Among operator-based technologies, Automatic Vehicle Monitoring systems can improve transit operations, and the information obtained on transit system performance can be used synergistically with a pre-trip information system. The point is that technology selection process should consider 
synergistically testing various operator- and traveler-based technologies. Specifically, the design and application dimensions of various technologies may be systematically varied across implementation contexts and their impacts observed. The joint implementation of two transit technologies may enhance their individual benefits (compared with implementing them separately). Moreover, technologies may be mutually customized to enhance their individual benefits. Overall, the interaction effects of technologies may be significant and need to be explored.

There are several projects aimed at testing advanced technologies throughout the United States. Following are some guidelines for systematically and consistently evaluating APTS technologies in "high impact" implementation contexts:

1. Develop selection criteria for technologies and impact dimensions, e.g., - policy relevance of impact measures and specific APTS technology solutions;

- design dimensions (features, functions and performance) and application dimensions (space, time and user) of APTS technologies;

- appropriate mix of operator- and traveler-based technologies;

- potential interaction of various technologies if jointly deployed;

- extent and nature of desired impacts on transit operators and travelers;

- compatibility of the new technology with the implementation context and existing transit system; and

- funding and financing opportunities for technology testing.

2. Select candidate technologies for field testing.

3. Design the experiment and develop methodology for evaluation:

- conduct pre-experiment analysis;

- conduct traveler behavior and operator performance surveys; and

- collect and analyze transit system performance and traveler data before and after testing.

4. Test the technology in different contexts (if possible).

5. Systematically evaluate impacts in terms of performance measures and distribution across space, time, and users. 
6. Synthesize outcomes of field experiments:

- direct, indirect, and simultaneous impacts of advanced transit technologies on transit operators and travelers; and

- improvements in design and application dimensions of specific technologies and synergies among technologies.

To synthesize knowledge from APTS field tests, Case-Based Reasoning (CBR) can be used (Khattak and Kanafani 1995). In CBR, the decision to deploy a set of APTS technologies can be made by examining similar historical cases. Rough estimates of traveler and operator impacts for proposed APTS technology "bundles" can be based on previous experiences with similar bundles. All historical cases will be structured according to (a) the design and application dimensions of APTS technologies, (b) the performance and distribution dimensions of impacts, and (c) spatial, temporal and user dimensions of the implementation context. In addition, cases will contain information about lessons learned, such as inferences regarding their success or failure, prescriptions, and case quality. Information about impacts in historical cases can be retrieved by matching the desired and historical bundle of APTS technologies. Increasing similarity of current and historical situations will require (a) matching the desired APTS technology bundle on the design and application dimensions of historical APTS technologies and (b) matching dimensions of the current implementation context with historical implementation contexts. Based on the impacts in historical cases, decisionmakers can infer the extent of impacts in their current situation.

Of course, the selection of new transit technologies and their testing/evaluation in real-life situations will be iterative and semi- or un-structured. The key point is that we need a systematic strategy to determine the value of new transit technologies and to avoid a muddled and opportunistic transit technology testing process that can result in sloppy research, inconsistent conclusions, and inappropriate APTS deployment.

\section{Acknowledgments}

Funding for this study was provided by the California Department of Transportation through the California PATH Program. Professor Randolph Hall has contributed sig- 
nificantly to the development of this study. Mr. Robert Ratcliff's support at Caltrans is appreciated. Ms. Neeloufar Hemassi's help in the analysis and editing was crucial. Finally, we have received valuable ideas from Professor Adib Kanafani.

\section{References}

Ball W. 1994. Commuting Alternatives in the United States: Recent Trends and a Look to the Future, Office of University Research and Education, Research and Special Programs Administration, DOT-T-95-11, Washington, D.C.

Casey R., and J. Collura. 1993. Advanced Public Transportation Systems: Evaluation Guidelines, Federal Transit Administration, US Department of Transportation, FTAMA-26-0007-94-2, Washington, D.C.

Pisarski, A. 1992. Travel Behavior Issues in the 90's, Prepared for Office of Highway Information and Management, HPM-40, USDOT, FHWA, Washington, D.C.

Khattak, A., H. Noeimi, H. Al-Deek, and R. Hall. 1993. Advanced Public Transportation Systems: A Taxonomy and Commercial Availability, Partners in Advanced Transit and Highways (PATH) Research Report UCB-ITS-PRR-93-9, Institute of Transportation Studies, University of California at Berkeley, California.

Khattak, A., and E. Le Colletter. 1994. Stated and Reported Diversion to Public Transportation under Incident Conditions: Implications on the Benefits of Multimodal ATIS, Partners for Advanced Transit and Highways (PATH) Research Report UCBITS-PRR-94-14, Institute of Transportation Studies, University of California at Berkeley, California, 1993, Presented at the 4th Annual Meeting of IVHS America, Atlanta, Georgia.

Khattak, A., and A. Kanafani. 1995. PLANiTS: The Case-Based Reasoner as a Planning Tool for Intelligent Transportation Systems, Partners for Advanced Transit and Highways (PATH) Research Report UCB-ITS-PRR-95-23, Institute of Transportation Studies, University of California at Berkeley, California (forthcoming in Transportation Research C).

\section{About the Authors}

ASAD J. Khattak is Professor in the Department of City and Regional Planning at the University of North Carolina at Chapel Hill. Hisham NoEIMI is a consultant with JRH Transportation Engineering. Haitham M. Al-Deek is Professor with the Department of Civil Engineering at the University of Central Florida in Orlando. 


\title{
Public Transit in the Social Marketing Framework
}

\author{
Devajyoti Deka \\ University of Southern California
}

\begin{abstract}
In view of the recent successes of social marketing in the various areas within the public, nonprofit sector, this study considers public transit as a socially marketable concept. The study contends that although service marketing is also important for the transit industry, there is a greater need for emphasizing the social marketing of transit. It is argued that social marketing of transit will have to deviate from the conventional service marketing approach in the key areas of market identification and segmentation, communication, distribution, and consideration of price.
\end{abstract}

\section{Introduction}

The purpose of this study is to show that the social marketing approach can be a useful mechanism for reviving the deteriorating public transit market. Although current transit service marketing practices utilize some aspects of the social marketing approach, public transit is now essentially marketed as a service rather than a socially desirable concept. Based or this assertion, the study considers public transit in the framework of social marketing, or concept marketing approach, and provides some recommendations for the future. It is ex- 
pected that the arguments in this article will provide the basis for further research, especially empirical investigations regarding potential benefits from the social marketing of transit.

It is argued that public transit deserves a certain amount of voluntarism from the general population due to its significant welfare and environmental missions, which can be obtained by the social marketing approach. The fact that transit is predominantly in the public sector makes a still stronger case in favor of its social marketing since this marketing approach emerged in the public, nonprofit sector.

The study claims that social marketing of transit will have to deviate from the conventional transit service marketing in the key areas of market identification and segmentation, communication, and distribution. In addition, there is a need to realize that the notion of price in social marketing has a different connotation than in transit service marketing.

The study recommends that social marketing of transit should be simultaneously carried out with transit's service marketing, for the two approaches address significantly different targets and follow different strategies. Since service marketing is already popular with transit agencies, the study addresses the social marketing of transit almost exclusively. Social marketing of transit will have to address larger and nontraditional audiences. While the transit service marketing approach has conventionally focused on the transit users, the social marketing approach will have to address the affluent or elite, the educated, and the socially concerned sections of the society. Appeals to women and children are also likely to have significant consequences on the transit market. Because of the large audience addressed, it becomes imperative that the marketing efforts identify precise market segments within these sections of the population.

In regards to communication of the marketing concept, the study emphasizes the importance of emotional and moral messages. It recommends that the concept marketing of transit should utilize the mass media, advocacy and pressure groups, and interpersonal channels of distribution in a sequential manner. Due to the important role of advocacy and pressure groups, the study envisions 
an active involvement of politicians in the social marketing of transit. Finally, it is emphasized that the high price of a modal shift from the automobile to transit, in terms of time, efforts, lifestyle, and psyche of the target adopters, may require somewhat upgraded and differentiated transit service than is currently available.

\section{The Social Marketing Approach}

Kotler and Roberto equate social marketing with social change campaigns and define such campaigns as "an organized effort conducted by one group (the change agent), which intends to persuade others (the target adopters) to accept, modify, or abandon certain ideas, attitudes, practices, and behavior."' In recent times, Andreasen has provided two similar definitions of social marketing. According to him, "Social marketing is the adaptation of commercial marketing technologies to the analysis, planning, execution and evaluation of programs designed to influence the behavior of target audiences in order to improve their physical and mental well-being and/or that of the society of which they are a part." In a more recent literature, Andreasen defines social marketing as the "adaptation of commercial marketing technologies to programs designed to influence the voluntary behavior of target audiences to improve their personal welfare and that of the society as a whole." ${ }^{\prime 3}$ Andreasen maintains that the essential quality of social marketing is that it aims at changing the behavior of the target adopters. He further cautions that educational or awareness generation programs should not be equated with social marketing since such programs do not necessarily aim at behavior change.

Social marketing evolved for marketing concepts rather than products or services. Although the cited definitions of social marketing do not specify whether a product or a service can qualify for social marketing, in social marketing literature, the term is essentially used to describe the marketing of concepts rather than products or services. This study, therefore, uses the terms "social marketing" and "concept marketing" as synonymous.

It has not been long since social marketing emerged as a discipline, and yet its popularity is increasing rather rapidly. In fact, due to the increasing importance of marketing concepts or ideas, the definition of marketing has undergone 
a significant change. In 1985, for example, the American Marketing Association changed its definition of marketing to include ideas with products and services. ${ }^{4}$

\section{Successes in Social Marketing}

The areas where social marketing seems to have made the most ground are environment and health, especially in anti-smoking, safe sex, recycling, and blood donation campaigns. Safe sex campaigns among homosexual populations and anti-smoking campaigns have been some of the most apparent successes in social marketing. ${ }^{5}$ The increasing consciousness about environmental degradation has also added to the popularity of social marketing, as is apparent from the recycling movement. The increase in the recycling of aluminum beverage cans almost quadrupled in this country between 1972 and $1989,{ }^{6}$ indicating the effectiveness of the recycling campaign. The increase in recycling of cans is found to be significant irrespective of deposit payment requirements. ${ }^{7}$ This is a clear indication that a large part of the success in recycling is due to voluntarism. While recycling of glass has shown an even greater rate of increase in the last decade, ${ }^{8}$ a significant promise is evident in the case of paper, plastic, steel cans, and motor oil.

Similar to the recycling campaign, social campaigns have also proved to be an important contributor to voluntary blood donation. ${ }^{9}$ The successes of marketing in the campaigns for anti-smoking, safe sex, recycling, and voluntary blood donation indicate that social marketing may have applicability in many other areas of social concern, including public transit.

Although the popularity of concept marketing is increasing in recent years, it does not ensure that all socially marketed concepts will be equally successful in changing behavior of the target adopters. In anti-smoking and safe sex campaigns, the benefits from the behavior change are accrued directly to the individual participant, while in recycling and voluntary blood donation, the beneficiary is the society as a whole. Concepts that directly benefit an individual are readily perceptible by the target adopters, but not the concepts having benefits for the entire society. Campaigns such as recycling and blood donation, in the 
absence of perceptible direct return to the targets, need a significant amount of voluntarism from the general population.

Since the affluent or elite and the educated populations are in a relatively favorable position to understand environmental and social problems, they are the populations that recycling and blood donation campaigns appeal. Public transit as a social concept is similar to recycling and blood donation campaigns, for its social benefits accrue to the society rather than the transit user.

\section{Transit as a Social Concept}

It is noted from Andreasen's definition in an earlier section that an essential objective of the social marketing approach is the well-being of the target audience and the society as a whole. According to this definition, the welfare and the environmental missions of public transit certainly qualify it for social marketing. Some of the principal socially desirable benefits from transit arise from reductions of roadway congestion, fuel consumption, and air pollution and creation of substantial job opportunities. ${ }^{10}$ Moreover, transit provides services to those who cannot afford more expensive modes of travel, to the physically disabled, and to the elderly. These benefits of public transit accrue not only to the transit users but to the society as a whole. An increase in the popularity of public transit is, therefore, desirable for the general population. The basic objective of social marketing for public transit will be to convey this message to the society.

\section{The Social Marketing Process}

A marketing process normally involves analysis related to product differentiation, product life-cycles, market segmentation, price, communication, and distribution. In the context of social marketing of transit, market identification, market segmentation, price, communication, and distribution have particular importance, for this marketing approach differs from the service marketing approach in regards to these components.

Market segmentation is the partitioning of consumers on the basis of some criteria so that marketing can focus on a particular group. Market segmentation is said to have four levels: mass market, segmented markets, micromarkets, and 
individual markets, where degrees of segmentation increase from the mass market to the individual markets. "I

Price in commercial marketing includes the likes of list price, discounts, allowances, payments, credits, etc. ${ }^{12}$ In social marketing, however, price could be both monetary or non-monetary. Four types of non-monetary prices have been identified as important in social marketing: time, effort, lifestyle, and psyche. ${ }^{13}$

Communication is the process by which a message is transmitted from the change agent to the target adopters. The objective of communication is to generate awareness, interest, and desire and, subsequently, to bring forth a change of behavior of the target adopters. The communicated message could be rational, emotional, or moral. ${ }^{14}$ Rational messages show how the marketed object will be beneficial to the target adopters in terms of price, quality, or functionality of a marketed object. Emotional messages are meant to invoke sentiments and thereby instill some positive or negative feelings so that a behavior change would occur. The Bay Area Rapid Transit (BART) successfully used a well-known comedian for promotional purposes, showing that humor can also be an effective means of emotional communication..$^{15}$ Finally, moral messages can also be communicated for social marketing purposes. Conservation of fossil fuel for the future generations is an example of moral messages.

The intermediaries in the distribution of social marketing can be classified as the mass media, the interpersonal channels, and the advocacy and pressure groups. The various channels have different impacts on the behavior of the target adopters. Their use may be simultaneous, depending on the purpose of the marketing effort.

The mass media, comprising printed matter, radio, and television, is the most effective channel for rapid and extensive dissemination of the marketed concept. The media is effective primarily in generating awareness and interest among the target adopters, but not in changing their behavior.

Interpersonal channels are another method of information dissemination from the change agents to the target adopters, by means of a two-way conversation between the parties. This method of distribution is highly effective in changing behavior of the targets. 
Advocacy and pressure groups constitute another kind of intermediary in the marketing of concepts. In terms of effectiveness in changing behavior of the target populations and the expense of communication, advocacy and pressures groups are located between the mass media and the interpersonal channels. Advocacy groups adopt a top down approach in advising the population, while pressure groups adopt a bottom up approach to pressurize the government for social change. In the context of public transit marketing, for example, advocacy groups would advice the target adopters to use transit as the popular mode, while pressure groups would demand a better service from the transit agencies.

\section{The Marketing Challenge to Public Transit}

Public transit's share of passenger trips has been decreasing substantially over the years. Transit's share of person trips in the year 1977 was 2.4 percent, which declined to 2.0 percent by $1990 .^{16}$ Transit's share of commuting trips also shows a similar decline, as the proportion of the trips reduced from 12.6 percent in 1960 to 6.2 percent in $1980 .{ }^{17}$ This substantial decrease is evident in almost all the metropolitan areas of the country. The loss of transit passengers in the last few years is evident among all the traditional user groups, namely, the racial minorities, women, senior citizens, and the low-income populations. Loss is also evident for almost all trip purposes,$^{18}$ showing the seriousness of the problem.

Transit's market started deteriorating back in the 1920s. The decline was most visible a few years after the World War II. ${ }^{19}$ The 1950 s and the 1960 s experienced substantial construction of freeways and a tremendous growth in suburban home-building. The association of transit's decline during this period with the growth of suburbia and the extensive construction of freeways can be inferred from the fact that almost 200 transit agencies went out of business between 1954 and 1963, leaving many medium-sized cities without transit service. ${ }^{20}$

With the increasing suburbanization of high income households, transit services were extended to the suburbs in spite of a relatively high cost of service provision in these areas. Wachs attributes this expansion of transit services to the concerns of taxpayers about transit subsidization. ${ }^{21}$ However, in the absence of 
serious marketing efforts, and for various other reasons, the provision of transit services has not led to an increasing popularity of transit among the suburban populations.

The situation facing public transit cannot be called a happy state. Aside from the problem of losing ridership, there are threats from government to reduce subsidies. Reactions to public transit's failure have often been severe, and scholars have developed cases for privatization or deregulation of transit.2 ${ }^{22}$ There is also a concern about subsidies because of the feeling among some sections that taxpayers' money is being wasted on a futile bid.

The passenger trips lost by transit have invariably been added to the automobile, as the latter is the only mode that has significantly gained in the share of metropolitan travel. In other words, the marketing challenge to public transit comes from the popularity of the automobile. This challenge to transit from automobile is substantial, for the automobile is not only a status symbol, but it also provides "independence, mobility, comfort and privacy that people will not easily give up." ${ }^{23}$ The marketing of cars, car parts, accessories, gasoline, and even commercial banking has significantly contributed to the increasing popularity of the automobile. Due to the tremendous challenge from the automobile and related industries, transit marketing needs substantial augmentation.

\section{Limitations of Current Transit Service Marketing Practice}

Although transit can be viewed both as a service and a concept, available transit marketing literature essentially treats it as a service. The emphasis on service marketing of transit is clear from this assertion of the National Cooperative Transit Research \& Development Program: "The major marketing characteristics usually considered are the four "P"s: product, place, price, and promotion. In transit use, product and place are usually represented by service."${ }^{.24}$ Similar arguments are found in other transit marketing literature also, as apparent from this statement: "In the context of urban transportation, a services marketing approach is appropriate because many urban travel modes could be characterized more as a service than a product...." ${ }^{25}$ And yet again, "Public transportation is a consumer product where product and place are related to the service and 
price is related to the fare." ${ }^{.26}$ All these postulations do not seem to consider that service marketing emerged outside the public and nonprofit sectors, and hence its applicability to public transit is limited. Most of the available service marketing literature, including the American Management Association's Handbook of Marketing for the Service Industries, excludes public transit altogether. ${ }^{27}$ Since transit marketing is to be conducted in the public sector and it has to appeal to social sentiments, the concept marketing of transit is at least as relevant as its service marketing.

Dunbar and Lovelock maintain that transit management became professional and sophisticated in regards to marketing in the 1970s. ${ }^{28}$ Significant efforts were made during the 1960s and the 1970s to revive the transit market, and the industry received a major boost from federal funding. ${ }^{29}$ The marketing effort during that period was a part of the general efforts to revive the transit industry. Although transit marketing techniques may have substantially improved in the 1970s, the term "social marketing," as it is understood today, cannot be used to describe the marketing practices of that time. The social marketing approach received wide acceptance only in the $1980 \mathrm{~s},{ }^{30}$ and its application continues to spread to various disciplines even today.

One cannot deny, however, that the service marketing of transit has adopted some components of the social marketing approach. It is, for example, not too uncommon to come across transit promotional campaigns referring to pollution and congestion. Yet, the processes of marketing services and concepts are significantly different. Moreover, in areas like transit, where voluntarism is an important requirement, social marketing is a still more favorable approach than service marketing.

The service marketing of transit relies on the traditional assumption that the important considerations for a public transportation system are unit costs, input of resources, relative distribution of costs, provision of service, and collection of revenues. ${ }^{31}$ From the users' point of view, the considerations are said to be cost of travel, convenience and comfort, reliability, safety, and security. ${ }^{32}$ While these are certainly important considerations from the viewpoint of the transit providers 
and users, one cannot afford to ignore the significant welfare and environmental missions of transit.

A significant work has already been done that evaluates the current state of transit marketing. Research by Smith, Razzouk, and Richardson, ${ }^{33}$ which included information from 85 bus transit agencies in different parts of the country, showed that only about half of the agencies had separate marketing departments. According to another survey, conducted by the American Public Transit Association in 1988, about 60 percent of the transit agencies had separate marketing departments. ${ }^{34}$ The work of Smith et al. shows that current marketing research of the agencies focuses only on the current users. The mass media seems to be the only distribution channel used in the transit marketing efforts. Market segmentation was found to be poor. While transit marketing experts have gone to the extent of suggesting that potential car purchasers can be an exclusive market segment, ${ }^{35}$ current transit marketing practices have failed to capture even broad categories such as gender and social class.

From the review of current transit service marketing practices, a few ideas emerge about their limitations and the prospects for the future. First of all, transit marketing has so far concentrated mainly on the typical user classes. The second critical limitation of transit service marketing has been in detailed segmentation of the market based on demography, geography, class, culture, income, race, reference group, etc.

The third limitation of current transit service marketing is the absence of adequate service differentiation. Differentiation of public transit implies a diversified set of services that fulfills the travel needs of the various target segments. The differentiation perspective suggests a shift of emphasis towards a more demand-responsive service than that provided by the current fixed-route, fixedschedule systems. However, demand-responsive services, when attempted, have turned out to be highly expensive, and vehicle productivity has been found to be much lower than anticipated. ${ }^{36} \mathrm{~A}$ relatively low emphasis on demand-responsive services by transit providers is evident from the fact that such services accounted for less than one percent of the total transit trips in the country in 1993. ${ }^{37}$ Based on the experience with demand-responsive transit so far, one can question the 
extent to which service-differentiated marketing can possibly be adopted by transit agencies under the current circumstances of decreasing revenue.

The fourth limitation of transit service marketing has emerged from the overemphasis on monetary costs of travel as a component of price. As Rothschild mentions, the involvement of nonmonetary costs makes the marketing of nonbusiness goods and services more difficult than the marketing of business goods and services. ${ }^{38} \mathrm{~A}$ realistic evaluation of the price involved in a mode shift from automobile to transit has to include not only monetary considerations, but also the inconvenience, the slow speed, and the psychic costs of using transit. These considerations are not common for transit service marketing and, whenever these considerations have been made, transit agencies have adopted, knowingly or unknowingly, certain components of the social marketing approach.

Finally, a serious limitation of current transit service marketing is observed in terms of distribution or channeling. The distribution channel that appears to be the most dominant in current transit service marketing is the mass media, which is not as effective a mechanism for bringing about a behavior change as some of the other channels. According to a 1988 survey of public transit agencies by the American Public Transit Association, news releases and radio advertisements were the most frequently used distribution channels. ${ }^{39}$ In contrast, efforts to reach out the target adopters by distribution channels such as direct mail, customer service centers, and information kiosks were far less common. In the light of Andreasen's definition of social marketing, where behavior change of the target is the basic objective, the current distribution efforts by transit agencies seem ineffective.

\section{The Requirements for Social Marketing of Transit}

The fundamental objective of social marketing of transit will be to convey the important message to the targets that transit has significant benefits to the society. It has to be clearly emphasized that transit is a solution to many social problems, including reduction of air pollution and traffic congestion. It also needs to be conveyed that by serving the poor, the disabled, and the elderly, public transit has been significantly contributing to the welfare of the society. 
Another important objective of the social marketing approach to transit will be to improve transit's image. Since transit currently carries a substantial amount of minority and low-income passengers, in society's outlook the current transit riders may be the weaker sections. This may be one of the reasons for the reluctance of the general population to use transit.

The metropolitan societies in the United States have diverse populations, where certain sections are more privileged than the others in terms of opportunities and choices. Metropolitan societies are diverse not in regards to income and affordability alone, but also due to cultural, ethnic, and racial variations. In a diverse society, the sections with fewer opportunities and choices have a tendency to emulate the more privileged sections. The increase in automobile trips among minorities in the recent years is very likely the result of this tendency. Engel and Blackwell have provided an example of minority behavior by noting that certain immigrant minority populations are unwilling to use promotional coupons for purchases since such transactions seem to denigrate them. ${ }^{40}$ For the same population, the use of public transit most likely has an identical or similar meaning as promotional coupons; if they are still using transit, it is not because of the appeal but the sheer necessity. It can be inferred from such minority behavior that the onus to improve public transit's image is on the general population rather than the current riders of transit.

The goals of social marketing can be identical or similar to the goals of service marketing. In the case of public transit, although minor objectives may vary from agency to agency, because of almost a national concern about transit's deteriorating market, increasing ridership is a primary objective for most agencies. Both service marketing and social marketing can be useful for achieving this objective. For achieving the same objective, however, the two approaches will exhibit differences in the marketing process, namely, in the selection of target adopters, in market segmentation, in determination of the components of price, in the selection of messages for communication, and in the selection of distribution channels.

Marketing transit as a social concept will require emphasis in certain respects that are ignored by transit service marketing. The first such consideration 
is about the size of the target adopters. While current transit service marketing mainly focuses on a small segment of the society-namely, the users-transit's social marketing will have to address a larger population, possibly segments covering the entire society.

The larger audience also requires that the market segments be more precise. Market segmentation will need to consider the importance of reference groups in making decisions by the target. In the case of blood donation campaigns, for example, it has been clearly shown that the influence of friends and family is significant on the commitment of the target donors. ${ }^{41}$ The influence of social norms on individual behavior has also been shown to be very distinct in another blood donation study, ${ }^{42}$ indicating clearly the importance of reference groups in the social marketing approach.

The most important target segments for social marketing of transit would be the affluent or elite and the educated, for these groups can afford to be more concerned about the society and the environment than any other sections of the population. Similar to recycling and blood donation campaigns, social marketing of transit will require a significant amount of voluntarism, which can be expected more from the socially aware populations than the rest. Targeting the elite population will be especially important because it serves as the ideal for the other populations.

For social marketing of transit, the younger age groups appear to be another promising market segment. The success of anti-smoking campaigns among school children shows that targeting the young population in their formative ages has significant positive consequences. Learning at younger ages has important influence on a person's lifetime habit formation. ${ }^{43}$ Moreover, beneficial social changes depend to a large extent on the education and socialization of children. ${ }^{44}$ As evident from occasional programs to familiarize children with transit operations, ${ }^{45}$ the importance of targeting children as potential users is not unknown in transit marketing. Yet a full-scale effort in this direction has always been absent.

Due to a greater voluntarism among women for social causes, it may be appropriate for social marketing of transit to appeal to this section of the population with particular emphasis. Research has shown that a significantly higher 
proportion of women donates blood in the voluntary procurement drives than in the market-based procurement efforts. ${ }^{46}$ This special quality in women has been attributed to their nurturing role and altruistic nature. Since the social marketing of transit will have to depend to a great extent on the altruism of the population, the role of women in popularizing transit could be important.

Women's transit use in the last few years has been decreasing at a faster rate than men's, and scholars have attributed this rapid decline in women's transit use to changes in their employment status, access to an automobile, and so on. ${ }^{47}$ Other scholars maintain that the likelihood of forming chained trips is higher for women than for men, ${ }^{48}$ and the increasing need to make chained trips may have contributed to the decline in their transit trips. The effects of increasing women's participation in the work force, their increasing access to the automobile, and the need to make complex trips provide a challenge to the transit industry in retaining this broad market segment. The use of social marketing appears to be one of the ways that can help retaining this traditional market segment of transit.

The communication of the concept to the target adopters will have to be mainly emotional and moral. Although rational communications about price, quality, and functionality are significant from the perspective of transit service marketing, they are less significant in the social marketing of transit because of its appeal to voluntarism for a social cause. Emotional messages can be highly effective on young targets. Generating fear can be one of the most effective emotional communications, as has been explicitly exhibited in the case of the antismoking and safe sex campaigns. Such communications can be directed in transit marketing against the competing automobile mode, portraying messages of damage to the environment by the automobile, or of lives lost in automobile accidents.

Moral communication will have no less significance than emotional messages in the social marketing of transit. The appeal towards a better environment, which would be an avenue for social marketing of transit, has a serious moral connotation. Although predominantly used by religious and charitable organizations, moral messages have found their rightful place in the environmental campaigns, thereby indicating that such messages can be extremely useful for transit as well. 
Transit agencies so far have almost exclusively relied on the mass media for distribution or channeling of their services. For marketing the transit concept, however, transit agencies will have to look beyond the media, as its effectiveness does not go much beyond generating awareness and interest among the target adopters.

Nonprofit organizations, transit lobbies, local politicians, community leaders, environmental groups, and local businesses can significantly contribute to the social marketing of transit. Social marketing was popularized mainly in the areas of health and environment, where advocacy and pressure groups play a dominant role. Their role will also be important in marketing the transit concept. While the mass media will be able to generate awareness and interest about the concept among large sections of the citizenry, the role of advocacy and pressure groups will be important for effecting the actual behavior change at the level of communities.

Although it may currently appear almost impossible to form advocacy and pressure groups to popularize transit in the suburban areas, where transit is currently least popular, once the mass media effectively performs its tasks of generating awareness and interest, formation of such groups may be relatively simple. The role of politicians in advocacy and pressure groups is extremely important. In neighboring Canada, for example, the role of politicians in matters related to transit advocacy is substantial, where public transit provides a significant platform for the election of mayors. ${ }^{49}$ Similar efforts by politicians in the U.S. may be somewhat less probable, yet their increasing involvement is possible if the mass media can generate the required amount of awareness in the initial period of the marketing drives.

Interpersonal communication, or personal contact, is a familiar term in transit service marketing, ${ }^{50}$ although its merit seems to be substantially greater in the context of transit concept marketing. Interpersonal distribution of the transit concept will depend not only on initiation by the mass media but also on the success of the advocacy and pressure groups. Its importance, therefore, will increase in the later stages of the marketing campaigns. 


\section{Conclusion}

Discussions in this paper have shown that, currently, transit is considered essentially in the domain of service marketing, while there is ample scope to consider it as a concept for social marketing. The nature of transit, especially due to its environmental and welfare missions, qualifies it as a socially desirable concept.

The current transit marketing practices, by accepting the service marketing approach, have failed in terms of market identification, segmentation, price, communication, and distribution. The analysis of transit in the social marketing framework suggests the importance of appealing to the upper social classes comprised of the affluent or elite and the educated, as well as women and children. In terms of communication of the marketing messages, emotional and moral messages seem appropriate for this purpose. For the distribution of the concept, the mass media should take the initiative to generate awareness and interest among the targets, so that advocacy and pressure groups, and subsequently interpersonal channels, can take over. The study envisions a greater political involvement in transit due to the emphasis of social marketing on advocacy and pressure groups.

As the social marketing of transit would need to target sections of the population that are quite different from those traditionally targeted by transit service marketing, it will be appropriate to continue the two approaches simultaneously. The distinctions between the two approaches in terms of price, communication, and distribution also support simultaneity of the efforts.

It must not be expected, however, that a shift from automobile to transit will be achieved with little effort, for the change will be a high-involvement decision for the targets due to the high prices in terms of time, efforts, lifestyle, and psyche. The effectiveness of the social marketing approach will certainly be higher in attracting the general population if simultaneous efforts are made towards improving the quality of transit services.

\section{Notes}

1 Philip Kotler and Eduardo L. Roberto, Social Marketing: Strategies for Changing Public Behavior (New York: The Free Press, 1989), 6. 
2 Alan R. Andreasen, "A Social Marketing Research Agenda for Consumer Behavior Researchers," Advances in Consumer Research 20 (1993): 1.

3 Alan R. Andreasen, "Social Marketing: its Definition and Domain," Journal of.Public Policy \& Marketing 13 (1994): 110.

4 Seymour H. Fine, "Introduction to Social Marketing," in Social Marketing: Promoting the Causes of Public and Nonprofit Agencies, ed. Seymour H. Fine (Boston: Allyn and Bacon, 1990), 1.

5 D. Wayne Taylor and Thomas E. Muller, "Eco-Literacy and Environmental Citizenship: a Social Marketing Challenge for Public Sector Management," Optimum 23 (Winter 1992): 7.

6 Nyles V. Reinfeld, Community Recycling: System Design to Management (Englewood Cliffs, NJ: Prentice Hall, 1992), 14.

7 Ibid., 12.

$8 \quad$ Ibid., 36

9 Ernie S. Lightman, "Women and Voluntary Blood Donation," Journal of Sociology \& Social Welfare 9 (December 1992): 619.

10 George M. Smerk, The Federal Role in Urban Mass Transportation (Bloomington: Indiana University Press, 1991), 3.

"Philip Kotler, "From Mass Marketing to Mass Customization," Planning Review 17 (September/October 1989): 11.

12 Philip Kotler, Principles of Marketing (Englewood Cliffs, NJ: Prentice-Hall, 1983), 44.

13 Seymour H. Fine, The Marketing of Ideas and Social Issues (New York: Praeger Publishers, 1981), 84.

14 Philip Kotler and Alan R. Andreasen, Strategic Marketing for Nonprofit Organizations (Englewood Cliffs, NJ: Prentice-Hall, 1987), 512.

is Judy McCusker, "How BART Won Riders Back," Railway Age 190 (March 1989): 45.

16 Alan E. Pisarski, Travel Behaviors Issues in the 90's (Falls Church, Virginia: US Department of Transportation, Federal Highway Administration, 1992), 17.

17 Alan E. Pisarski, Commuting in America (Westport, CT: Eno Foundation for Transportation, 1987), 48.

18 Pisarski, 1992, 19.

19 David W. Jones, Jr., Urban Transit Policy: An Economic and Political History (Englewood Cliffs, NJ: Prentice-Hall Inc., 1985), 15. 
20 Martin Wachs, "U.S. Transit Subsidy Policy: In Need of Reform," Science 244 (June 1989): 1545.

21 Ibid., 1547.

22 Peter Gordon, Myths and Facts of Nation's Transit Policy (Los Angeles: Reason Foundation, 1991), 16.

23 Michelle Frumkin-Rosengaus, Increasing Transit Ridership through a Targeted Transit Marketing Approach (Berkeley: University of California, Dissertation Series, 1987), 2. National Cooperative Transit Research \& Development, Transit Marketing: Successes and Failures (Washington, D.C.: Transportation Research Board, 1987), 1.

P. B. Everett and L. K. Ozanne, "Marketing Theory and Urban Transportation Policy," Transportation Research Record No. 1402 (1993), 52.

Frumkin-Rosengaus, 13.

Carole A. Congram, ed., The AMA Handbook of Marketing for the Service Industries (New York: AMACOM, 1991). The only article on transportation in this Handbook essentially focuses on airline and freight, without any mention of urban transit services. See chapter by Craig E. Cina, "Transportation," 455-468.

Frederick C. Dunbar and Christopher H. Lovelock, "The State of the Art in Urban Travel Consumer Research," in Marketing Public Transportation: Policies, Strategies and Research Needs for the 1980's, ed. Richard K. Robinson and Christopher H. Lovelock (Washington, D.C.: American Marketing Association, 1981 ), 87.

Christopher H. Lovelock and others, Marketing Public Transit: A Strategic Approach (New York: Praeger Publishers, 1987), 5. Fine, 1990, 1.

See, for example, Anthony R. Tomazinis, Productivity, Efficiency and Quality in Urban Transportation Systems (Lexington: Lexington Books, 1975), 60. Ibid., 66. Mary F. Smith, Nabil Y. Razzouk and Scott A. Richardson, "The Role of Marketing in Mass Transit: An Empirical Investigation," Transportation Journal 30 (Fall 1990).

${ }^{34}$ Estimated from American Public Transit Association, 1988 Survey of Transit Marketing Methods and Marketing Expenditures (Washington, D.C.: American Public Transit Association, 1988), Table 4A. Lovelock and others, 12.

Roger F. Teal and others. Shared-Ride Taxi Services as Community Public Transit (Irvine: University of California, Irvine, 1980), 6. 
Estimated from American Public Transit Association, 1996 Transit Fact Book(Washington, D.C.: Statistics and Information Systems Division, American Public Transit Association, 1996), Table 5.

Michael L. Rothschild, "Marketing Communications in Nonbusiness Situations: or Why It's So Hard to Sell Brotherhood Like Soap," in Public and Nonprofit Marketing: Cases and Readings, ed. Christopher H. Lovelock and Charles B. Weinberg (New York: John Wiley \& Sons, 1984), 58.

39 American Public Transit Association, 1988, Table 2A.

40 James F. Engel and Roger D. Blackwell, Consumer Behavior, 4th ed. (Chicago: Dryden Press, 1982), 80.

41 Randy P. McCombie, "Blood Donation Patterns of Undergraduate Students: Family and Friendship Correlates," Journal of Community Psychology 19 (April 1991): 162.

42 Jane A. Piliavin and Donald Libby, "Personal Norms, Perceived Social Norms, and Blood Donation," Humboldt Journal of Social Relations 13 (Fall/Winter \& Spring/ Summer, 1985/1986): 192.

43 Lewis P. Lipsitt, "The Future of Training in Human Infant Development," in Child Behavior and Development: Training for Diversity, ed. Joan H. Cantor, Charles C. Spiker and Lewis P. Lipsitt (Norwood, NJ: Ablex Publishing Corporation, 1991), 278.

44 Sheldon H. White. "Graduate Training in the Fourth Establishment: Tradition and Change in the Study of Human Development," in Child Behavior and Development: Training for Diversity, ed. Joan H. Cantor, Charles C. Spiker and Lewis P. Lipsitt (Norwood, NJ: Ablex Publishing Corporation, 1991), 177.

45 Noel A. Smith, "The State of Marketing in Mass Transit," Metro Magazine 84 (MayJune 1988): 52.

46 Lightman, 616.

47 Pisarski, 1992, 25.

48 James G. Strathman, Kenneth J. Dueker, and Judy S. Davis, "Effects of Household Structure and Selected Travel Characteristics on Trip Chaining," Transportation 21 (1994): 34-35.

49 Lovelock and others, 7.

so See, for example, National Cooperative Transit Research \& Development, 2. 


\section{References}

American Public Transit Association. 1996. 1996 Transit Fact Book. Washington, DC:

Statistics and Information Systems Division, American Public Transit Association. American Public Transit Association. 1988. 1988 Survey of Transit Marketing Methods and Marketing Expenditures. Washington, DC: American Public Transit Association, 1988.

Andreasen, A. R. 1993. A Social Marketing Research Agenda for Consumer Behavior Researchers. Advances in Consumer Research 20: 1-5.

Andreasen, A. R. 1994. Social Marketing: its Definition and Domain. Journal of Public Policy \& Marketing 13: 108-114.

Congram, C. A., ed. 1991. The AMA Handbook of Marketing for the Service Industries.

New York: AMACOM.

Dunbar, F. C., and C. H. Lovelock. 1981. The State of the Art in Urban Travel Consumer

Research. In Marketing Public Transportation: Policies, Strategies and Research Needs for the 1980's, ed. Richard K. Robinson and Christopher H. Lovelock. Washington, DC: American Marketing Association.

Engel, J. F., and R. D. Blackwell. 1982. Consumer Behavior. 4th ed. Chicago: Dryden Press.

Everett, P. B., and L. K. Ozanne. 1993. Marketing Theory and Urban Transportation Policy. Transportation Research Record No. 1402: 51-56.

Fine, S. H. 1990. Introduction to Social Marketing. In Social Marketing: Promoting the

Causes of Public and Nonprofit Agencies, ed. Seymour H. Fine. Boston: Allyn and Bacon.

Fine, S. H. 1981. The Marketing of Ideas and Social Issues. New York: Praeger Publishers. Frumkin-Rosengaus, M. 1987. Increasing Transit Ridership through a Targeted Transit Marketing Approach. Berkeley: University of California, Dissertation Series.

Gordon, P. 1991. Myths and Facts of Nation's Transit Policy. Los Angeles: Reason Foundation.

Jones, D. W., Jr. 1985. Urban Transit Policy: An Economic and Political History. Englewood Cliffs, NJ: Prentice-Hall Inc.

Kotler, P., and A. R. Andreasen. 1987. Strategic Marketing for Nonprofit Organizations. Englewood Cliffs, NJ: Prentice-Hall.

Kotler, P., and E. L. Roberto. 1989. Social Marketing: Strategies for Changing Public Behavior. New York: The Free Press. 
Kotler, P. 1989. From Mass Marketing to Mass Customization. Planning Review 17 (September/October): 10-13+.

Kotler, P. 1983. Principles of Marketing. Englewood Cliffs, NJ: Prentice-Hall.

Lightman, E. S. 1992. Women and Voluntary Blood Donation. Journal of Sociology \& Social Welfare 9 (December): 613-625.

Lipsitt, L. P. 1991. The Future of Training in Human Infant Development. In Child Behavior and Development: Training for Diversity, ed. J. H. Cantor, C. C. Spiker, and L. P. Lipsitt. Norwood, NJ: Ablex Publishing Corporation.

Lovelock, C. H., and others. 1987. Marketing Public Transit: A Strategic Approach. New York: Praeger Publishers.

McCombie, R. P. 1991. Blood Donation Patterns of Undergraduate Students: Family and Friendship Correlates. Journal of Community Psychology 19 (April): 161-165.

McCusker, J. 1989. How BART Won Riders Back. Railway Age 190 (March): 45-47.

National Cooperative Transit Research \& Development. 1987. Transit Marketing: Successes and Failures. Washington, D.C.: Transportation Research Board.

Piliavin, J. A., and D. Libby. 1985/86. Personal Norms, Perceived Social Norms, and Blood Donation. Humboldt Journal of Social Relations 13 (Fall/Winter \& Spring/ Summer): 159-194.

Pisarski, A. E. 1987. Commuting in America. Westport,CT: Eno Foundation for Transportation.

Pisarski, A. E. 1992. Travel Behaviors Issues in the 90's. Falls Church, VA: U.S. Department of Transportation, Federal Highway Administration.

Reinfeld, N. V. 1992. Community Recycling: System Design to Management. Englewood Cliffs, NJ: Prentice Hall.

Rothschild, M. L. 1984. Marketing Communications in Nonbusiness Situations: or Why It's So Hard to Sell Brotherhood Like Soap. In Public and Nonprofit Marketing: Cases and Readings, ed. C. H. Lovelock and C. B. Weinberg. New York: John Wiley $\&$ Sons.

Smerk, G. S. 1991. The Federal Role in Urban Mass Transportation. Bloomington: Indiana University Press.

Smith, M. F., N. Y. Razzouk, and S. A. Richardon. 1990. The Role of Marketing in Mass Transit: An Empirical Investigation. Transportation Journal 30 (Fall): 30-35.

Smith, N. A. 1988. The State of Marketing in Mass Transit. Metro Magazine 84 (MayJune): 52-58. 
Strathman, J. G., K. J. Dueker, and J. S. Davis. 1994. Effects of Household Structure and Selected Travel Characteristics on Trip Chaining. Transportation 21: 23-45.

Taylor, D. W., and T. E. Muller. 1992. Eco-Literacy and Environmental Citizenship: A Social Marketing Challenge for Public Sector Management. Optimum 23 (Winter): 616.Teal, R. F., and others. 1980. Shared-Ride Toxi Services as Community Public Transit. Irvine: University of California, Irvine.

Tomazinis, A. R. 1975. Productivity, Efficiency and Quality in Urban Transportation Systems. Lexington: Lexington Books.

Wachs, Martin. 1989. U.S. Transit Subsidy Policy: In Need of Reform. Science 244 (June): 1545-1549.

White, S. H. 1991. Graduate.Training in the Fourth Establishment: Tradition and Change in the Study of Human Development. In Child Behavior and Development: Training for Diversity, ed. J. H. Cantor, C. C. Spiker, and L. P. Lipsitt. Norwood, NJ: Ablex Publishing Corporation.

\section{About the Author}

DevajYotı Deka is a doctoral student at the School of Urban Planning and Development, University of Southern California. 


\title{
The Puzzle of Income, Race, and Density: \\ Preliminary Evidence on Transit Use from the 1991 American Housing Survey
}

\author{
Sandra Rosenbloom \\ Kelly Clifton \\ The Drachman Institute, The University of Arizona
}

\begin{abstract}
The article presents the results of a preliminary analysis of transit ridership data from the 1991 American Housing Survey. The findings suggest that transit operators may find new markets in places they had not thought to look: among high income travelers, including high income minority travelers.
\end{abstract}

\section{Introduction}

The importance of public transit in the travel patterns of many Americans has decreased sharply in the last two decades; today, no more than 1 in 20 American workers commutes via transit. In response to declining or threatened ridership many public transit operators have attempted to either 1) find or create new markets, or 2) strengthen and expand ridership among their current markets. Unfortunately, transit operators may not fully understand the nature of transit use among current riders or the potential market niches among other groups in society. 
The Drachman Institute of the University of Arizona, under contract to the Transit Cooperative Research Program of the National Research Council, has been investigating the nature of existing and emerging transit markets in the United States. This paper reports on the initial phase of that research, focusing on the role of income, race and ethnicity, and density in transit usage patterns.

A preliminary assessment of the 1991 American Housing Survey (AHS) suggests that these factors do not always work in the ways we have traditionally assumed. Low income is not always related to greater transit use, nor high income to lower transit use. Moreover, blacks and Hispanics are more likely to use transit at all income levels than comparable white workers. Finally, the size of a metropolitan area is more predictive of higher transit use than is its density. All these findings suggest that transit operators will have to 1) more carefully target services to various groups and, 2) re-think the kind of services which they offer various markets.

The first section below compares 1991 AHS transit patterns to those seen in other national data and in earlier AHS. Subsequent sections focus on traditional ways to segment those who generally commute by transit and evaluations of the impact of community density (people/sq. mile) on transit use among specific market groups.

\section{The Data Source}

\section{Basic Details}

The AHS provides extensive information on housing at the national and metropolitan statistical area (MSA) level; it also allows researchers to disaggregate market niches for the home-to-work trip, seeing who the current riders of transit really are. Conducted by the Bureau of the Census in odd-numbered years, roughly 50,000 housing units are surveyed; however, transportation data are collected only as a supplement to housing data and only for the commute trip. Because the focus of analysis is the housing unit rather than the household or its members, the uses to which the transportation data should be put are limited. While the survey attempts to sample a wide variety of types of housing units; 
there is no effort to ensure a comprehensive sample of people by race, sex, income, etc.

The Census Bureau provides weighting coefficients for the data, which allows data users to create a national sample - by housing type-but not by the characteristics of the people living in those houses. Because the 1991 data are not weighted by demographic variables, AHS data cannot be normalized to represent a national survey of transit users. However, as long as there are sufficient responses in specific demographic categories, the AHS can describe transit use by different kinds of people-so we can question, for example, what percentage of women or blacks or people making over $\$ 60,000$ generally take some form of public transit to go to work.

The transportation data in the AHS do suffer from other problems in addition to not being collected specifically for transportation purposes: 1) respondents are asked to recall their most frequent modes (rather than writing down each trip and mode) and 2) they are asked to state their most common work trip mode even if they use more than one. As a result, a) people can forget some of the trips which they made and b) people who take transit one or two days per week are not counted as transit users.

\section{National Comparisons}

Table 1 compares 1991 AHS data both to previous AHS and to two major 1990 surveys - the Census and the Nationwide Personal Transportation Survey (NPTS). The 1991 AHS data appear to be reasonably close to those collected from other sources for time and distance on the work trip commute; there are more differences on transit usage. Overall, the AHS has traditionally shown a slightly lower rate of transit ridership for the home to work commute than other sources; the 1990 Nationwide Personal Transportation Survey reports 5.5 percent of workers using transit compared to 4.32 percent of 1991 AHS respondents.

The AHS, however, is consistent with the other data sets in depicting a continual decline in transit use. From 1985 to 1989, when the percentage of workers using transit dropped to roughly 4.5 percent, the number of work trips actually increased more than 12 percent; thus the real drop in market share was more than 
4 percent between 1985-89.' As Table 1 shows, from 1989 to 1991 transit use for the work trip dropped still further-to 4.32 percent.

Data from the 1990 Census show the same trends; both the number and percentage of workers using transit to commute to work has dropped substantially since 1980. In 1990, 5.12 percent of workers used a public transit modecompared to 6.22 percent in $1980 .{ }^{2}$ This was an almost 18 percent drop in the actual number of workers commuting via transit even as the total number of workers increased almost 20 percent between 1980 and $1990 .{ }^{3}$ Public transit use was slightly higher in metropolitan areas over one million-9 percent in 1990 - but the number and percentage of public transit commuters was also falling in these larger areas.

The NPTS data also show steadily declining transit usage: in 1990, 5.5 percent of home to work trips were made using public transit; the comparable percentage was 8.1 percent in $1969 .{ }^{4}$ Some analysts feel that the surveying tech-

\section{Table 1}

Comparing AHS Data to Other Recent Transportation Surveys

\begin{tabular}{ccccc} 
& AHS & & $\begin{array}{c}\text { U.S. } \\
\text { Census }\end{array}$ & NPTS \\
\hline $1985^{\prime}$ & $1989^{\prime}$ & 1991 & $1990^{2}$ & $1990^{3}$
\end{tabular}

Transit Use

for Work Trip

$\begin{array}{lllll}5.10 \% & 4.50 \% & 4.32 \% & 5.12 \% & 5.50 \%\end{array}$

Average Length

$10.80 \mathrm{mi} \quad--$

$11.99 \mathrm{mi}$

$10.60 \mathrm{mi}$

(All Modes)

Average Time of Work Trip

$20.90 \mathrm{~min} \quad--$

$20.81 \mathrm{~min}$

$22.40 \mathrm{~min}$

$19.70 \mathrm{~min}$

(All Modes)

'Alan E. Pisarski, Travel Behavior Issues in the 90's, U.S. Department of Transportation, Federal Highway Administration, July 1992: 19.

${ }^{2}$ U.S. Department of Transportation, Federal Highway Administration, Journey-to-Work Trends in the U.S. and Its Major Metropolitan Areas 1960-1990, FHWA-PL-(\$-012), November 1993: 2-2. ${ }^{3}$ Patricia S. Hu and Jennifer Young, Summary of Travel Trends: 1990 NPTS, U.S. Federal Highway Administration, March 1992: 22. 


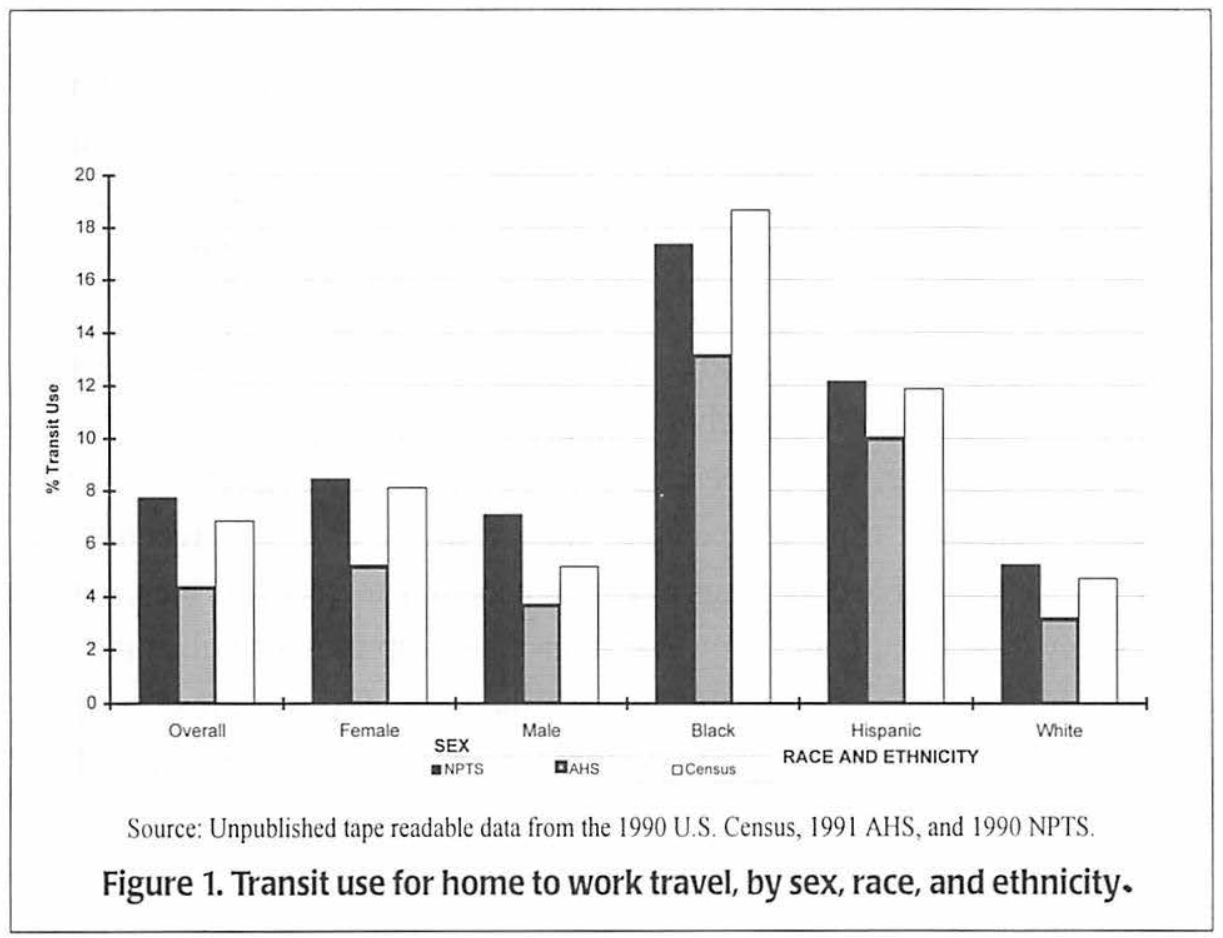

niques used by the NPTS have lead to a substantial undercounting of all transit trips ${ }^{5}$ - some contend as much as 20 percent..$^{6}$ If true, the fact that AHS data show even lower transit usage may suggest that the approach used to generate an appropriate sample of housing units in some way leads to an even greater undercounting of transit use.

The 1991 AHS also indicates that groups long dependent on public transit are still disproportionately more likely to commute by transit: for example, women and minorities. Figure 1 shows that more than 5 percent of all women but only 3.65 percent of men were transit commuters. At the same time Hispanics (of any race), blacks, and Asians were substantially more likely to use public transit for their work trips than whites. For example, over 13 percent of blacks and 10 percent of Hispanics (of any race) used transit to go to work - compared to just over 3 percent of whites. 


\section{The Role of Income in Transit Use}

Analysts generally believe that income is an important predictor of transit use; much of the reliance of women and minorities on public transit is assumed to be the result of the generally lower income of these large groups. However, the AHS data show that the relationship between traditional indicators-income, race, sex-and transit ridership is more complex than traditionally thought.

First, Figure 2 shows that-in contrast to general expectations-people with very low incomes were less likely to use public transit than those with higher incomes. For example, only 3.5 percent of those with incomes under $\$ 5,000$ used transit for their work trip-compared to 5.6 percent of those with incomes between $\$ 5-10,000$. Table 2 suggests a reason: people with very low incomes are more likely to work at home. However, transit still captures a smaller share of very low income people who actually leave their home to work than of those making more money-roughly 3.82 percent (compared to 4.76 percent of those making $\$ 10-15,000$, for example).

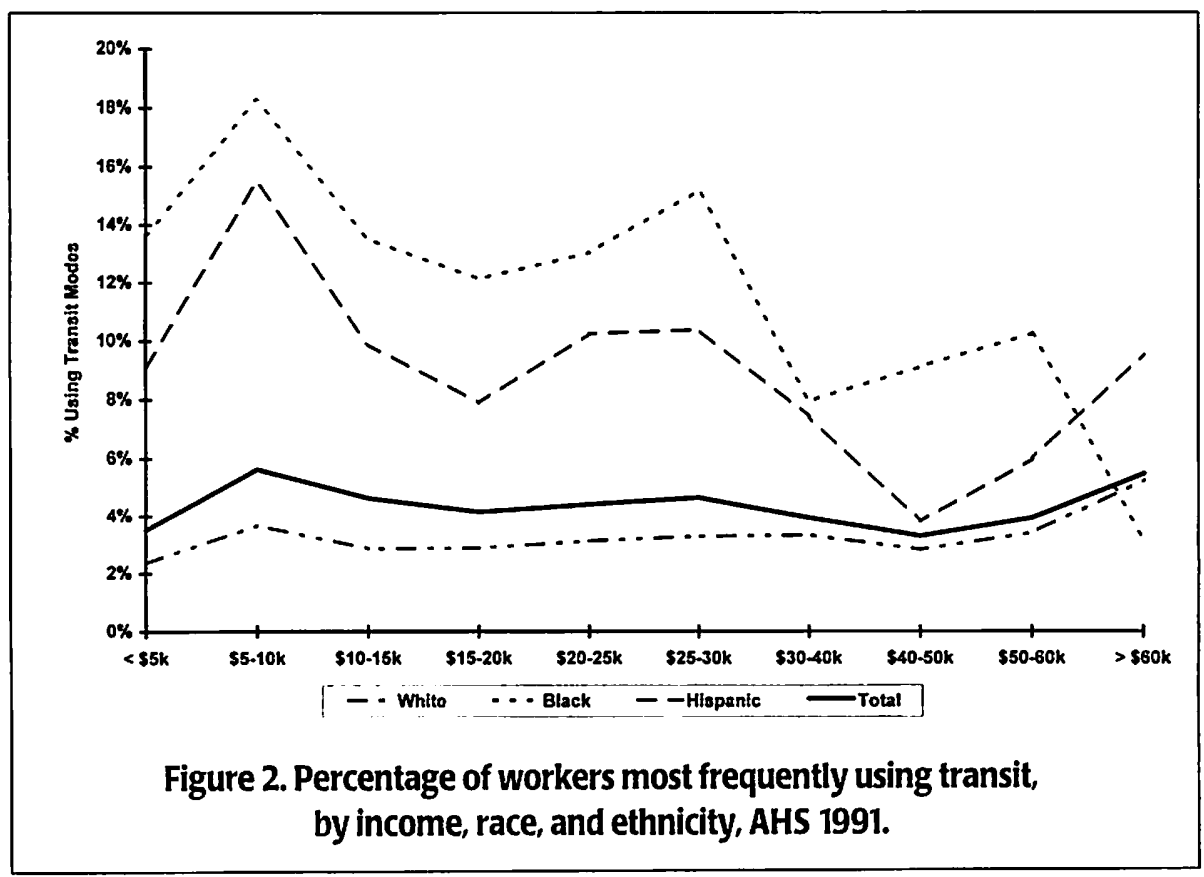


Second, as traditionally assumed, the propensity to use public transit does generally decline as income increases-but not nearly as directly as thought. To begin, overall transit use did not drop as rapidly as income increased; for example, the same percentage of workers with incomes between $\$ 10-15,000$ and between $\$ 25-30,000-4.6$ percent—used transit to commute to work. Just as importantly, transit usage went up as income went above $\$ 40,000$, so that people making between $\$ 10-15,000$ and those making more than $\$ 60,000$ had the same propensity to commute via transit.

Third, Figure 2 shows sometimes remarkable differences between those from different ethnic and racial backgrounds. At all income levels, blacks and Hispanics (of any race) were substantially more likely to use transit than whites or than the average. At the same time, transit usage was relatively stable among whites from incomes of $\$ 5-50,000$ so that the same percentage of whites making $\$ 20,000$ and making $\$ 50,000$ used transit to work.

There are some traditional explanations for these findings; transit use by high income travelers may be related to the use of heavy and commuter rail in the cities that account for so large a percentage of total transit ridership-New York, Chicago, Philadelphia, Boston, and Washington. As Figure 3 shows, the relationship between traveler income and transit use does vary among the transit modes. While bus use drops sharply with income, subway and commuter rail use increases fairly consistently with income-roughly 1 percent of workers

\begin{tabular}{|lcccc|}
\hline \multicolumn{5}{|c|}{$\begin{array}{l}\text { Table 2 } \\
\text { Principal Home-to-Work Mode of Selected } \\
\text { Income Groups, 1991 AHS }\end{array}$} \\
& \multicolumn{4}{c|}{ Household Income Levels (in 000) } \\
\cline { 2 - 5 } & $>\$ 5$ & $\$ 5-10$ & $\$ 10-15$ & $\$ 30-40$ \\
All Transit & $3.50 \%$ & $5.64 \%$ & $4.63 \%$ & $3.95 \%$ \\
$\quad$ Walked Only & 5.75 & 5.07 & 3.71 & 1.81 \\
$\quad$ Works at Home & 8.47 & 2.88 & 1.92 & 1.19 \\
$\quad$ Bike & 0.80 & 0.66 & 0.59 & 0.29 \\
$\quad$ Motorcycle & 0.13 & 0.18 & 0.17 & 0.24 \\
All Low Cost Efforts & 15.15 & 8.79 & 6.39 & 3.53 \\
Car/Truck/Van & 80.73 & 85.07 & 88.69 & 92.00 \\
\hline
\end{tabular}


with incomes between $\$ 10-15,000$ and almost 2 percent of workers with incomes between $\$ 40-50,000$ used the subways or elevated systems to go to work. In fact, rail as well as subway/elevated use was highest among workers with incomes above $\$ 60,000$; more than 2 percent of all workers with incomes between $\$ 60$ 70,000 used commuter rail (compared to 0.23 percent of all travelers).

However, while increasing rail and subway use among high income people explains the angle of the upward curve, it doesn't explain the magnitude. In fact, the 1991 AHS data show that bus use also increases at higher incomes. For example, 4.11 percent of those earning more than $\$ 60,00$ use bus-roughly the same percentage as those earning between $\$ 30-40,000$.

A traditional explanation for the bus use patterns is that, since most transit riders live in larger, denser communities where there are better transit options, they are more likely to use the bus even at higher incomes. Since blacks and Hispanics are also more likely to be concentrated in larger, denser cities, their higher dependence on transit in aggregate national figures may just be an artifact

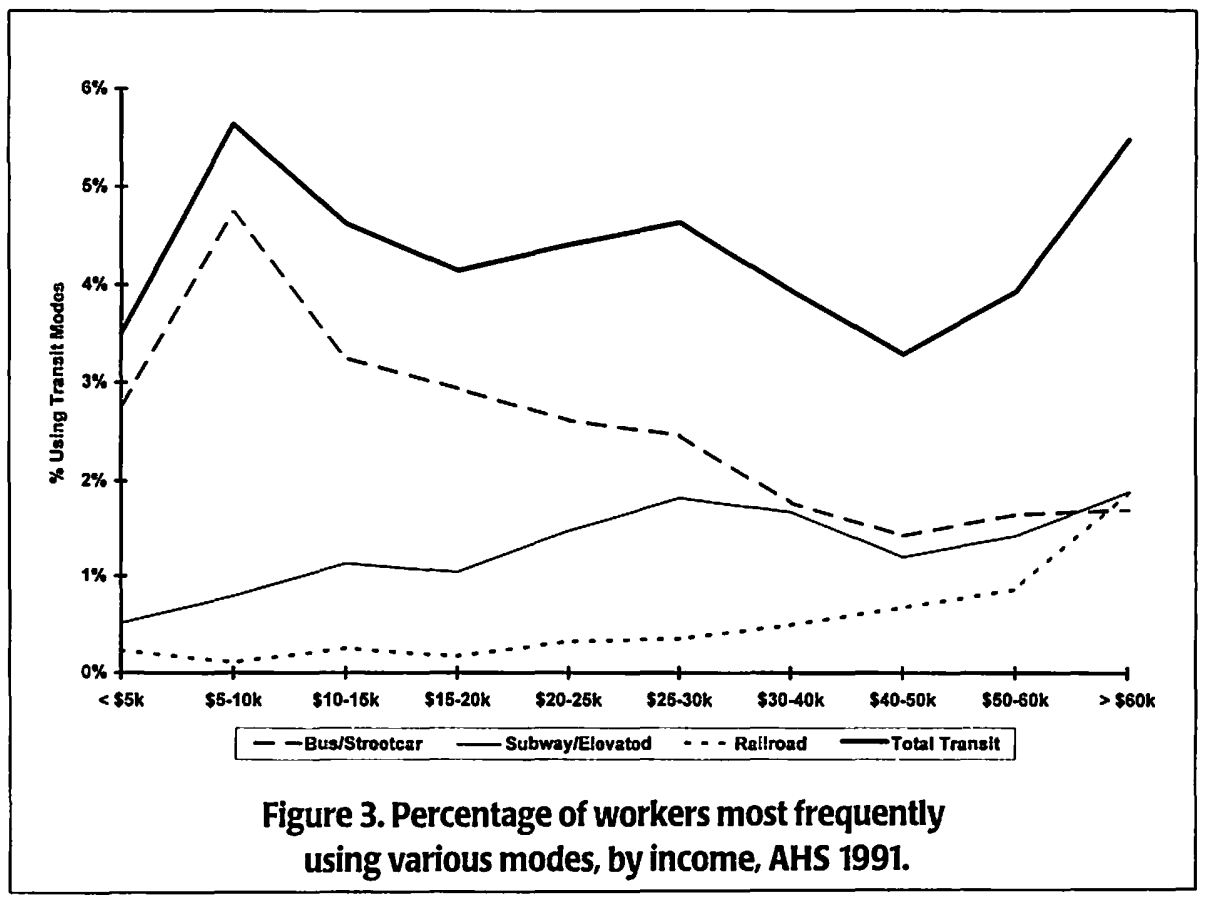


of where they live. In short, one possibility is that transit use does not generally increase with incomes over $\$ 40,000$, nor that blacks are more likely to use transit at all incomes, but rather that more blacks and Hispanics and people making those incomes live in New York or Chicago or Boston, etc, where transit use is inherently higher. If so, 1) most high income transit use would disappear in smaller metropolitan areas, and, 2) people of color would not be more likely than other workers with comparable incomes to use either bus or rail transit-within specific individual metropolitan areas, even high density ones.

To assess this explanation, the AHS data were divided into 14 metropolitan categories, characterized by both size and density. The density data were taken from the 1990 Census (Summary Tape File 3-STF3) as people/sq.km which were converted to people/sq. miles, and imported into the AHS data set. We used four sizes of metropolitan area:

- under 200,000

- 200-500,000

- 500,000 to one million

- over one million

We also used four categories of density: very low-under 50 people per square mile, low-50-1,000 people per sq. mile; medium $-1,000-2,000$ people per sq. mile; and high-over 2,000 people per mile. In addition, New York and Chicago were broken out separately; ultimately there were 14 categories since cities did not exist in each of the 16 potential size/density categories. In addition, the very low density categories fell out of the analysis because they lacked transit services. Obviously, using such large categories, and categorizing as high density those cities with only 2,000 people per sq. mile, may introduce some large biases, as does the use of average density data to represent an entire city.

In order to assess whether high income transit ridership in aggregate U.S. data was explained by rail use in large cities, Figure 4 evaluates bus ridership as well as rail use in high density metropolitan areas. It is clear, as predicted, that larger denser cities had much higher relative bus mode splits-which tended to decrease with increasing income. In all high density metropolitan areas over one million, bus use - while relatively higher than in smaller cities—plummeted as 
income increased. However, in an unexpected outcome, bus use suddenly began to increase at incomes above $\$ 60,000$. In short, while higher rail use in large cities explains some of the higher income transit use seen in aggregate national figures, it does not explain it all.

Figure 5 helps us analyze the second part of the question: does higher bus use in larger, denser cities explain higher income transit use in aggregate U.S. figures? If it did, we would not expect to see higher incomes groups taking the bus to work in smaller or less dense cities; Figure 5 focuses on bus use by income in three smaller service environments. While the trend is not entirely "clean," it appears that bus use first falls steadily with increasing income-but then begins to rise again at incomes above $\$ 40,000$. For example, in medium density metropolitan areas between one-half and one million, a higher percentage of those making more than $\$ 60,000$ used a bus than those making $\$ 20-25,000$. In low density areas of the same size, those making $\$ 50-60,000$ used the bus to work

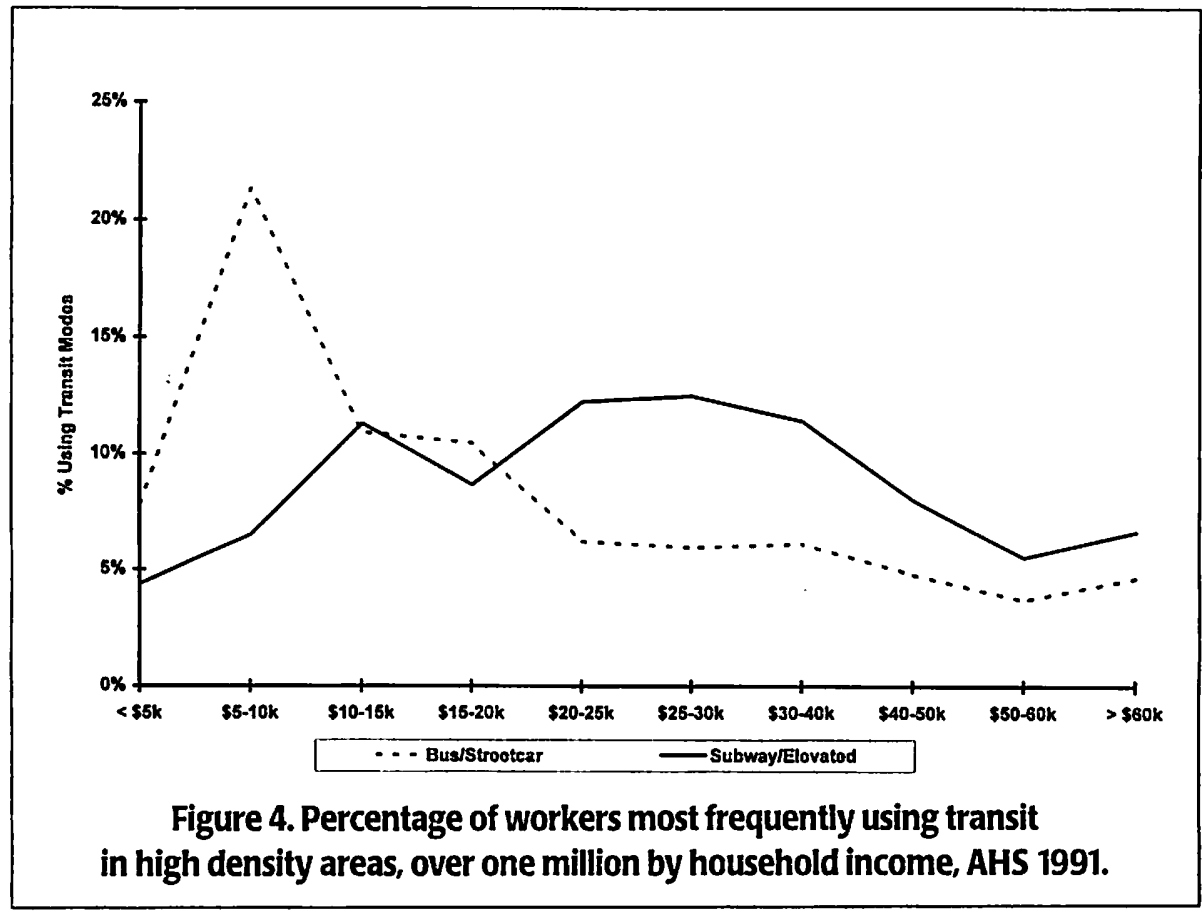


more than those making $\$ 25-30,000$. In fact, the tendency for bus use to rise with increasing income after $\$ 40,000$ is found in 10 of the 14 service environments. In short, neither rail or bus use in very large, dense cities fully explains why high income people are seen to use transit more in aggregate figures.

A comparable analysis of transit use patterns by race and ethnicity in the 14 service environments also does not support the hypothesis that higher transit use
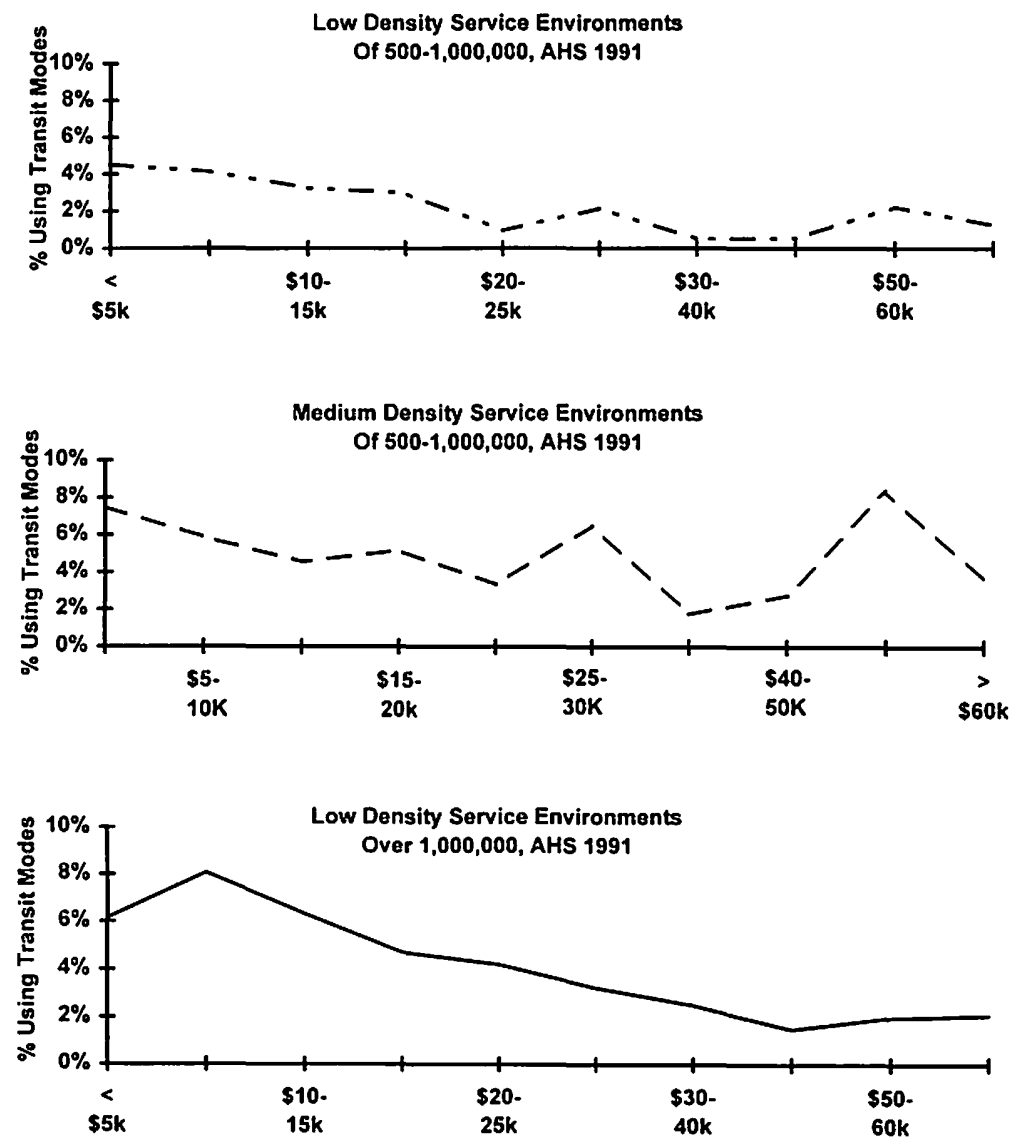

Figure 5. Percentage of bus use by income in three service environments. 
among blacks and Hispanics in the aggregate national figures results in a greater number of those groups live in large transit-oriented cities. Blacks were more likely to use transit than others of comparable income in 11 of the 14 service environments, including the smallest; Hispanics were more likely to use transit than other workers with comparable incomes in 9 of the 14 service environments. Of course, a metropolitan area is a very large unit; blacks and Hispanics may be concentrated in the (relatively) transit-rich areas of even the smallest and least dense community. However, as bad as housing segregation might be, it is unlikely that all people of color making relatively high incomes are living in older, denser, areas of town.

In short, while traditional explanations partially explain the income anomalies in the aggregate AHS data, they do not explain them all. Higher income workers and workers of color regardless of income are more likely to use transit, relatively independent of the characteristics of the metropolitan area.

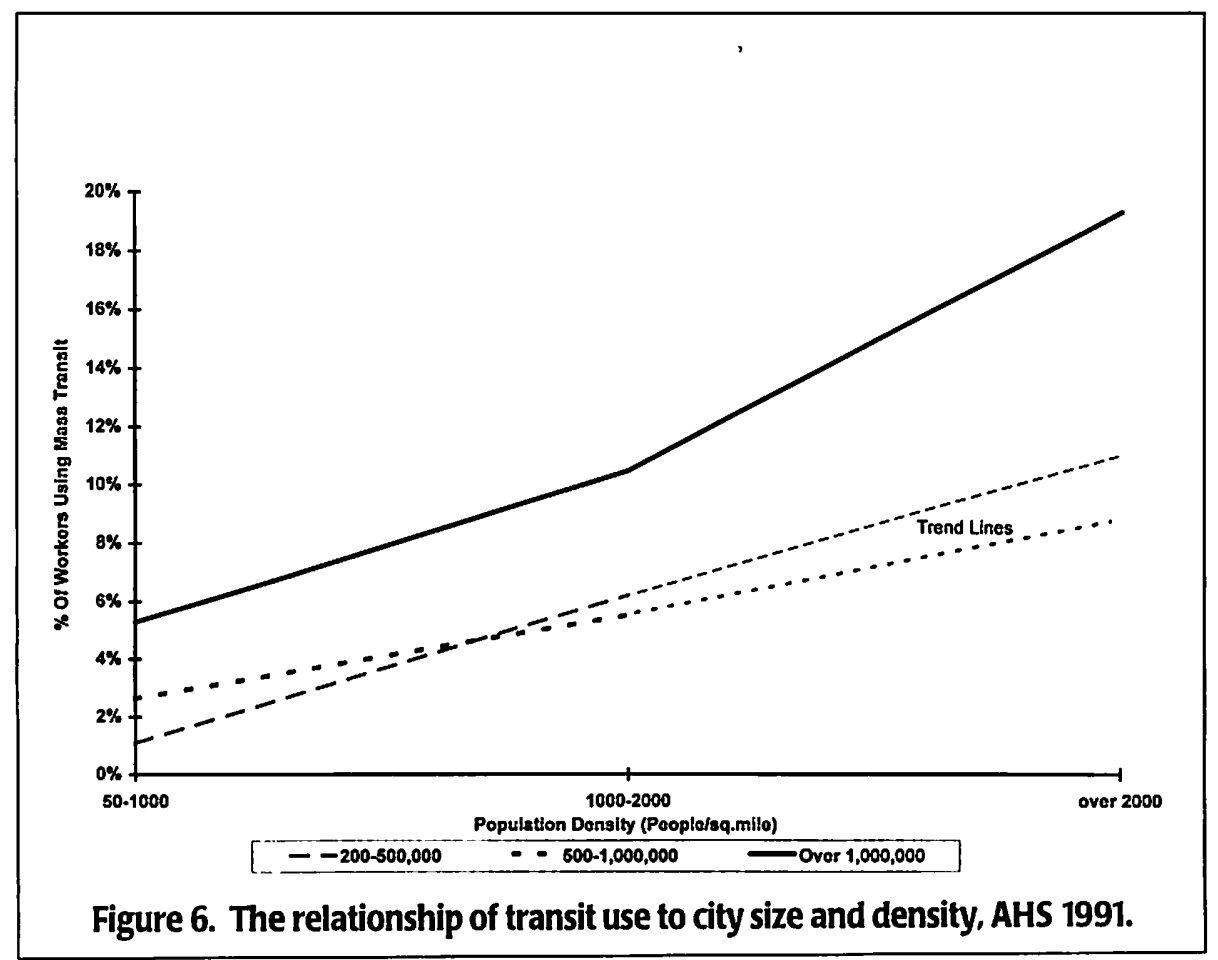




\section{The Role of Density}

A second surprising finding in the AHS data is the relationship between population density and transit ridership. While it is fairly well established that there is a positive relationship between the two, the role of density in enhancing transit ridership or affecting ridership among target groups is less clear. And, in fact, the AHS analyses suggests some perplexing interactions with community size.

Figure 6 shows that metropolitan area population itself explains more of the variation in transit use than does density. The figure first makes clear that, while both the size of the city and its density are directly proportional to transit use, the transit modal shift is generally substantial higher in larger cities-regardless of density. For example, at low densities (between 50-1,000 people/sq. mile) more than 5 percent of all workers in cities over one million used transit to commute to work, compared to only 1.4 percent of workers in cities below a half million.

While there are no cities under one million with high density (as defined here), a simple extrapolation of the trend line shows that even if smaller cities had higher density they would not have ridership equivalent to that found in larger cities. Note that no city with a population under one million-even with high density-would have even 10 percent of its workers using public transit, compared to almost 20 percent of workers in high density large cities.

It is, of course, possible that the relationship between density and ridership is not linear or that the way the density data have been categorized has "created" the trends seen in Figure 4. Moreover, the use of averages for a category that includes communities as disparate as New York and Chicago, on one hand, and Los Angeles and Houston, on the other, may obscure the "real" patterns. However, these findings should give us pause.

It may well be that people do not need to live at high average density to have access to the concentrated employment clusters that make transit more usable; perhaps bigger cities, like Los Angeles and Houston, offer sufficient suburban as well as CBD complexes to make transit more feasible for the work trip. Many large low density cities have both a) more people employed outside the traditional core than in it, and b) several suburban employment complexes, each with more workers than the traditional core. 
It may also be that larger cities simply offer more transit service, even in lower density areas. We know that people are more likely to use public transit if they live close to existing routes. For example, data from the 1990 NPTS show that, while transit use for all trips among the entire population is roughly 2 percent, it rises to 3.1 percent in areas where transit is generally available, and to 4.1 percent where transit is within one-quarter mile of the household. ${ }^{7}$ This suggests that there may be markets for transit in even some low density areas in larger cities.

\section{Summary}

The initial analyses of 1991 AHS transit data suggest that certain groupssuch as blacks and Hispanics-may be more likely to use transit than their incomes or residential locations alone would predict. The analyses also suggest that there may be an unexplained propensity to use transit among those with very high incomes. And, finally, the data hint at a complicated relationship between density and population size, with the size of a metropolitan area having more impact on transit use than density.

These findings could be, in part, a result of the way that the AHS sampled housing types, or the way the data were organized, although preliminary analyses of U.S. Census data suggest the same patterns. ${ }^{8}$ The findings are important enough, however, that these issues should be addressed in other national data sets ${ }^{9}$ and in local data sets which allow for more geographic disaggregation. In the initial analyses, the AHS patterns have messages for transit operators concerned with increasing or maintaining ridership.

Transit operators cannot assume captive ridership among many groups of traditional users; many low income workers do not use transit. At the same time, transit operators should not assume that there are no opportunities to attract high income users and moderate income minorities. Finally, the density analysis suggests that large but fairly low density communities might be able to create new or expand existing transit markets.

If these assumptions are true, and transit operators are seeking to both increase ridership from among current markets and increase ridership among those not generally using transit, they must focus more clearly on the needs of each 
group. Transit operators should begin to assess the kinds of services and options that would better meet the needs of people already more likely to use transit even if they do not fit traditional profiles (higher income riders, particularly those of color) and people who do fit traditional profiles but are not currently transit users (low income women, for example).

Transit operators cannot assume that ridership increases among either group can come from simply expanding current services or responding as they have historically. Rather, operators must focus on those options and services-from route restructuring to reverse commute routes-that match the real needs of the groups they are targeting Some of these groups may be served by the additional of traditional fixed route services while others would be better served by less traditional options-from vanpooling to general public dial-a-ride.

Above all, transit operators should be guided not by outdated understandings of why people use transit but by the experiences of communities that have specifically targeted these groups (and others) with a variety of transit servicesand succeeded in increasing transit ridership. Individual properties and the transit industry as a whole must both experiment with new approaches to marketing and service delivery to selected groups, and carefully monitor and disseminate the results.

\section{Acknowledgments}

Kelly Clifton was responsible for organizing the AHS data so transit use on the home to work trip for all workers could be evaluated and for organizing those data by community size and density; she was assisted by Paul Bechtel. Graphics were done by Jeff Walsh and Angela Mazzi.

\section{Notes}

1 Alan E. Pisarski, Travel Behavior Issues in the 90's, U. S. Department of Transportation, Federal Highway Administration, July 1922: 19.

2 U.S. Department of Transportation, Federal Highway Administration, Journey-ToWork Trends in the United States and Its Major Metropolitan Areas, 1960-90, Publication No. FHWA-PL-94-012, November 1993: 2-2.

3 U.S. Department of Transportation, Journey-to-Work Trends: 2-2. 
4 Patricia S. Hu and Jennifer Young, Summary of Travel Trends; 1990 Nationwide Personal Transportation Survey, U.S. Federal Highway Administration, Office of Highway Information Management, March 1992: 22.

$s$ Given the small number of transit trips-relative to the number of private vehicle trips-even a 20 percent undercount would not equal more than a very small percentage difference in the public modal split for the work trip.

6 Patricia S. Hu and Jennifer Young, 1990 NPTS Databook, Vol. I, U.S. Federal Highway Administration, Office of Highway Information Management, November 1993: 1-5.

7 U. S. Department of Transportation, Travel Behavior Issues in the 90 's: 22.

8 The Drachman Institute with G. J. Fielding, Transit Markets of the Future- The Challenge of Change, TCRP H-4B, Transit Cooperative Research Program, November 1995.

9 See The Drachman Institute with G. J. Fielding for a comparable assessment of these factors in the 1990 NPTS and the 19905 percent PUMS Census data.

\section{References}

Black, A. 1995. Urban Mass Transportation Planning. New York: McGraw Hill (esp. Chapters 5 and 12).

Fielding, G. J. 1995. Transit in American Cities. In S. Hanson, ed., Geography of Urban Transport, 2nd Edition. New York: Guileford Press.

Levinson, H. S. 1992. System and Service Planning. In G. E. Gray and L. Hoel, eds., Public Transportation, 2nd Edition. New York: Prentice Hall.

Rossetti, M., and B. Ebersole. 1993. Journey to Work Trends in the United States and Its Major Metropolitan Areas, 1960-1990. FHWA-PL-94-012, HPM-40/12-93, U.S. Department of Transportation, Federal Highway Administration.

\section{About the Authors}

SandRa Rosenbloom is the Director of the Roy P. Drachman Institute of the University of Arizona and a Professor of Planning in the University's Interdisciplinary Planning Program. Kelly Clifton is an Eisenhower Fellow working on her Ph.D. in Planning at the University of Texas at Austin. 


\title{
California's Transit Village Movement
}

\author{
Robert Cervero \\ University of California, Berkeley
}

\begin{abstract}
Transit villages-dense, mixed-use communities near rail stops-could increase rail ridership and reduce automobile dependency; however, few good examples exist in the U.S. today. Barriers to building transit villages include questionable market viability, conservative lending practices, and neighborhood opposition to multi-family housing. This paper shows, however, that there is a reasonably strong market demand for well-designed transit-oriented neighborhoods. After viewing visual images of simulated transit villages, more respondents from the San Francisco Bay Area expressed a willingness to live in a moderately dense community with nice amenities than in one with a third lower densities but little neighborhood open space or consumer services. Many current occupants of transit-based housing in California are young professionals living in one or two person households with just one car. What most distinguishes tenants of transitbased housing is their tendency to work in downtowns and other locations well-served by rail transit. The demand for good quality housing near rail has allowed some rail-served apartments in the Bay Area to command rent premiums. Strong market interest in railbased housing, coupled with recent state enabling legislation, bode favorably for the future of transit villages in California.
\end{abstract}




\section{Introduction}

In California, a movement is currently under way to create transit villages around urban rail stations. In October 1993, Governor Pete Wilson signed the Transit Village Act, Assembly Bill 3152, which encourages cities and counties to build higher density housing and more concentrated development around the state's rail stops. California has invested over $\$ 10$ billion in urban rail transit infrastructure over the past 20 years and is poised to spend upwards of $\$ 60$ billion more over the next 30 years (mainly in Southern California). Yet most development in recent years has turned its back on transit, focused on freeway-served suburban corridors instead. Since the 1972 opening of the Bay Area Rapid Transit (BART) system, 35 million square feet of private office space has been built in parts of Alameda and Contra Costa Counties unserved by BART, compared to only 9 million square feet within one-half mile of BART stations in the two East Bay counties (mostly limited to downtown Oakland, Walnut Creek, and Concord) (Cervero and Landis 1995).

One consequence of growth occurring away from transit stops has been mass transit's declining market share of metropolitan trips. While transit journeys rose in absolute numbers in California during the 1980s (one of the few states where this was the case), transit's share of commute trips fell in the state's four largest metropolitan areas, despite their new rail systems: greater Los Angeles-5.4 to 4.8 percent; San Francisco Bay Area-11.9 to 10 percent; San Diego-3.7 to 3.6 percent; and Sacramento-3.7 to 2.5 percent. Nor do these trends appear to be slowing. A "State of the Commute" report by the Commuter Transportation Services (1994) - the annual tracking study of commuter behavior in the greater Los Angeles region-showed Southern California's drive-alone rate increased from 77 percent in 1992 to 79 percent in 1993.

Given the tremendous sunk investment states like California have in urban rail transit, these ridership trends are worrisome. Transit villages, proponents argue, will help reverse, or at least stave off, the trend toward growing autodependency and shrinking transit market share. Besides capitalizing on expensive public investments in rail, proponents argue that focusing future development around rail stops will produce other social benefits: increased regional ac- 
cessibility and reduced traffic congestion along rail-served corridors; a more compact, sustainable urban form that conserves energy and reduces pollution; increases in affordable housing; more choices on where to live and how to travel; increased mobility for the transportation disadvantaged; and the creation of village environments where people from all walks of life come into daily contact with each other, similar to America's streetcar communities of yesteryear.

This article examines recent progress toward creating transit villages around California's urban rail stations. Examples of housing development clustered around California rail stations are described, followed by a discussion of the opportunities and barriers to transit villages. The market potential for large-scale transit village development is then assessed using visual simulation techniques. Characteristics of California's existing rail-based housing projects are later profiled in terms of tenant composition, ridership levels, and rent premiums. The article concludes with a discussion of California's transit village legislation and other public policy initiatives that might be pursued in promoting future railoriented development.

\section{Defining Transit Villages}

The somewhat nostalgic-sounding name of "transit villages" has gained currency in recent years to describe places conducive to transit riding-compact, mixed-use communities that, by design, invite residents, workers, and shoppers to drive their cars less and use transit more. Under California's Transit Village Act, transit villages extend roughly a quarter mile from a transit station, a distance that can be covered by foot in about five minutes; beyond this distance, suburbanites are far more likely to drive to their destinations rather than walk to a station to access a train. The centerpiece of the transit village is the station itself and the civic and public spaces that surround it. The transit station is what connects village residents and workers to the rest of the region, providing convenient and ready access to downtown, major activity centers (e.g., sports stadium, college campuses), and other popular destinations. The surrounding public square or open area serves the very important function of being a communal gathering place and a site of special events and celebrations-a modern-day agora. In the 
mornings, the public square might be converted to an outdoor farmer's market, populated by flower stalls, fruit stands, and food vendors. On weekends, concerts might be held there. What is important is that the transit station functions as a window, or gateway, to the rest of the region and is physically tied to and associated with the village's major gathering place. Such settings are common at rail stations throughout Europe. Residents are drawn to transit nodes by the attractiveness and vibrancy of the surrounding civic areas. And concessionaires, street artists, and neighborhood merchants are drawn to these settings because of the heavy walk-on traffic. It's a win-win proposition.

Transit villages are hardly new ideas. They borrow from the visions of early city planners like Ebenezer Howard in England and Frederic Law Olmstead and Edward Bellany in America, who advanced the idea of building pedestrian-oriented garden cities. Howard's vision was to build self-sufficient satellite communities of around 30,000 inhabitants that would orbit London, separated by protected greenbelts and connected by inter-municipal railways. Some vestiges of transit villages survive in the former streetcar suburbs of turn-of-the-century America, such as Shaker Heights in Cleveland, Chestnut Hill in Boston, Riverside near Chicago, and Roland Park in Baltimore. Streetcar suburbs depended on pedestrian access to transit to reach downtown jobs and neighborhood centers, since many were built prior to the invention of the automobile. America's early rail-served neighborhoods featured a range of housing from large estates to small cottage houses, had distinctive gridiron street patterns, and focused on a prominent civic space near the rail stop to instill a sense of community. In order to attract early residents to distant suburbs, these early transit villages were designed as safe, secure, and attractive places-notably with the placement of the train depot and public square in the heart of the community and the use of restrictive covenants and other development standards to control the physical environment.

In recent years, the terms "neo-traditional" development and "new urbanism" have gained currency to describe places that are compact, "quaint"-feeling, and rich in land-use mixture, and as a result, are more conducive to walking and transit riding. New urbanists, like Miami-based Andres Duany and Californian 
Peter Calthorpe, borrow many of the successful elements from traditional American towns like Princeton, New Jersey and Annapolis, Maryland. Among the hallmarks of neo-traditional designs are a commercial core within walking distance of several thousand residents, a well-connected grid-like street network, narrow roads with curbside parking (to buffer pedestrians), back-lot alleys, diverse land uses, and varying styles and densities of housing.

Outside of a few turn-of-the-century neighborhoods, few good examples of transit village development can be found in the U.S. today. Of course, there are high-rise apartment towers near subways in big cities like New York and Chicago and some recent mixed-use concentrations near suburban rail stations in metropolitan Washington, D.C. (e.g., Ballston, Bethesda) and San Francisco's East Bay (e.g., Walnut Creek, Pleasant Hill); however, few such places could be characterized as "villages." Europe perhaps offers the best modern-day examples of transit village development, where dozens of compact, mixed-use satellite communities are interconnected by regional rail systems in metropolises like Stockholm and Copenhagen. Europe's transit villages are built on a scale that encourages pedestrian circulation. Most rail stops focus on town centers with a public square and an outdoor marketplace. The accent on livability is showcased by pedestrian amenities - park benches, newspaper kiosks, bus shelters, sidewalk cafes, open-air markets, and arcades designed to protect pedestrians from the elements. In Vällingby, one of Stockholm's rail-served satellites, the rail station shares space with a super market, where returning customers can do their daily shopping on the way home. The station is adjacent to a car-free village square lined with more shops and service establishments, including several daycare centers (Figure 1). More than 50 percent of Vällingby's employed residents commute by transit—despite the fact that Sweden has one of the highest per capita car ownership rates in Europe (Cervero 1995).

It is important to recognize that transit villages are not just physical entities. There are important social and economic objectives behind the transit village concept as well. One objective is to create an urban milieu that brings people from many walks of life into daily, face-to-face contact. Early streetcar villages had these qualities. Today's auto-oriented suburbs, in contrast, have segregated 


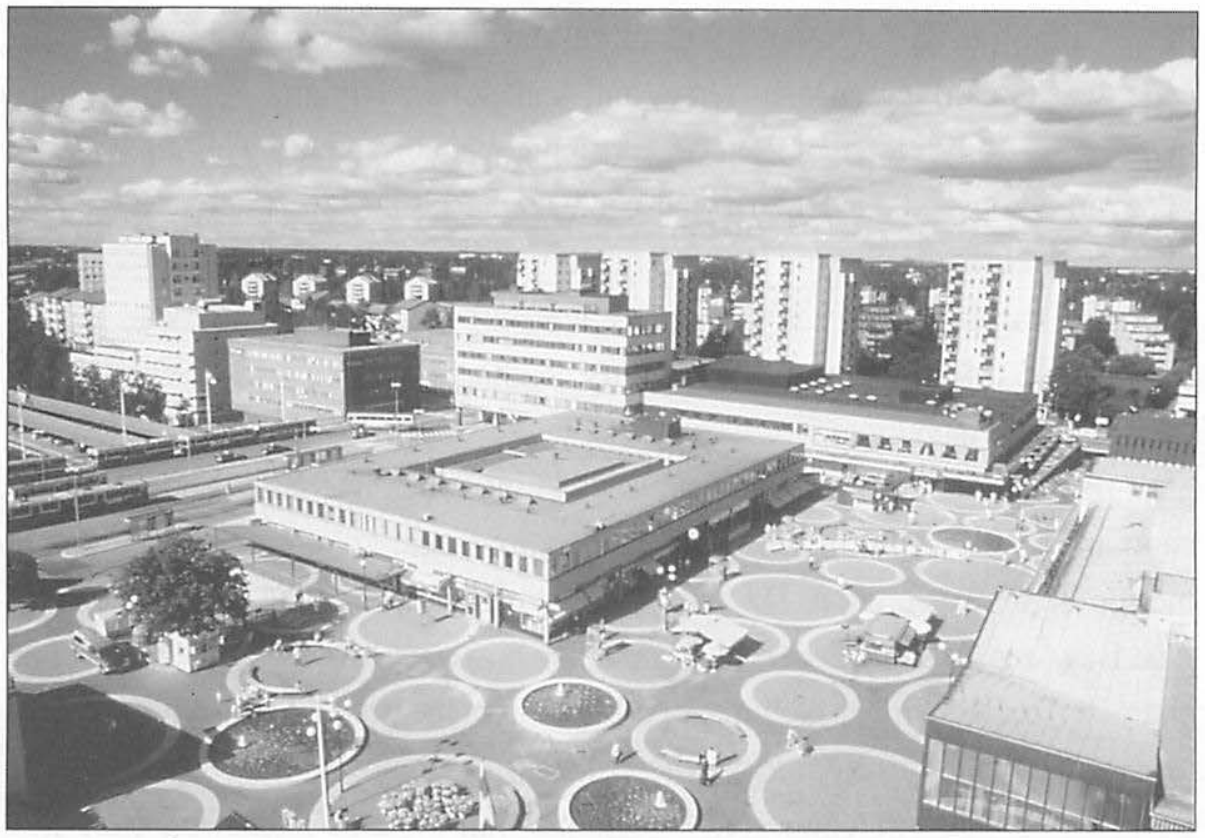

Figure 1. Vällingby station area, a pedestrian-friendly, car-free town center. Entry to rail station via shopping center and surrounding civic space. High-density mixed land uses near station taper off to lower densities farther away. Photo by Jeff Kenworthy.

cultures and isolated people by age, class, and race-old from young, rich from poor, whites from blacks. Social commentators like Anthony Downs (1994) blame low-density and class-segregated growth for creating deep divisions in American society and for isolating, both physically and socioeconomically, many blacks, Hispanics, and recent immigrants. Social integration is extremely difficult to achieve in a laissez-faire society with high levels of automobility and personal freedom. Transit villages are just one of many ways of building new kinds of communities that offer wider lifestyle choices. By creating an attractive, lively, but safe neighborhood environment, it is likely that a subpopulation of people from different social backgrounds and income levels will be drawn to these settings. While these ideals are admittedly steeped in beliefs of physical determinism, experience shows, both historically and internationally, that transit-oriented 
settings can impart a sense of belonging and an attachment to place, besides inducing people to ride transit.

Transit villages must also be economically viable and financially self-sustaining. Creating attractive urban environments that have good transit access to the rest of the region should, by definition, produce economic benefits. Foremost, the advantages of being near rail in an attractive urban environment should translate into higher property values and commercial rents. To the degree that governments can recapture some of these economic benefits, such as through property tax proceeds or special benefit assessments, then transit villages, in theory, can become economically self-supporting. Transit villages might also spin-off secondary economic benefits-such as providing opportunities for joint development (e.g., building a retail store adjacent to a rail station and generating lease revenues for a transit authority), station-area concessions (e.g., food kiosks), and community-based services (e.g., operating jitney connections between a neighborhood and the transit stop).

Transit villages could also serve as catalysts to economic development and community rebuilding. Recently, the Federal Transit Administration and Department of Housing and Urban Development joined forces to create a "Livable Communities" initiative that aims to empower distressed inner-city neighborhoods across the U.S. by making them eligible for special grants and tax credits. Some livable communities, like the Fruitvale district in Oakland, California, receive urban rail services. The hope is that by creating better quality neighborhoods in areas with superior transit services, private capital will return to these areas, putting them on a road to financial recovery. In the case of the Oakland's Fruitvale neighborhood, community leaders hope to one day create a transit village focused on the BART station (Knack 1995). Plans call for building attractive apartments, creating a public square, and siting a child care center near the station, as well as transforming the BART station itself into a true intermodal transfer center. The neighborhood also hopes to create a mobility enterprise that would provide neighborhood jitney services and reverse-commute runs to suburban job centers, with local residents in charge of operating, dispatching, maintaining, and servicing the shuttle vans. 


\section{Rail-Focused Development in California}

California is a natural breeding grounds for a transit village movement in that it is the nation's most urbanized and transit-oriented state. California has the most urban rail transit systems-at current count, two heavy rail, five light rail, and three commute rail services-and the highest metropolitan population densities in the nation (Larson 1993).

While modern-day transit villages remain merely a concept today, inroads have been made in recent years in focusing housing development near rail stations in California that could form the building blocks of future transit villages. Table 1 lists 26 large housing projects built within one-quarter mile of California urban rail stations between 1985 and 1994; collectively, these projects have added over 6,500 housing units within easy walking distance of rail stops. Most are rental apartment complexes with densities of 20 to 60 dwelling units (du) per acre, well above the $12-15$ du per acre benchmark used by planners as minimum thresholds necessary to support rail in the suburbs (Puskarev and Zupan 1977). Presently, both Santa Clara County Light Rail and BART are in the process of converting surface parking lots at several stations into residential/retail projects. Developers have been attracted to these sites since, by building on existing parking lots, they do not bear the risk of negotiating land purchases among multiple property owners, any one of whom can hold out, thereby stalling a project. Bay Area planners hope that building housing atop former park-and-ride lots will eventually lead to mini-communities mushrooming around dozens of rail stations, as was envisaged when BART was conceived over 40 years ago.

Local governments are doing a lot to promote transit-oriented development in California. In the Bay Area, the cities of Hayward, Union City, El Cerrito, and Pleasant Hill have recently formed redevelopment districts around BART stations for the very purpose of jump-starting new development (see Figure 2 for a map of the BART system and its stations). El Cerrito's redevelopment authority has used tax-exempt financing to help underwrite the cost of assembling land and financing nearly $\$ 10$ million of the $\$ 14$ million in infrastructure improvements necessary to support several housing projects near the Del Norte BART station. The city worked closely with a developer to create the Del Norte Place 


\begin{tabular}{|c|c|c|c|c|c|c|c|}
\hline \multicolumn{8}{|c|}{ Table 1. Major Housing Projects Near California Rail Stations, Built Between 1985 and 1994} \\
\hline Rail System & Station Name & Property Name & City & Units & Year Built & Density* & Unit Type \\
\hline BART & El Cerrito Del Norte & Del Norte Place & El Cerrito & 135 & 1992 & 30 & rental \\
\hline BART & Pleasant Hill & Park Regency & Pleasant Hill & 892 & 1992 & 43 & rental \\
\hline BART & Pleasant Hill & Bay Landing & Pleasant Hill & 360 & $1986-1988$ & 37 & rental \\
\hline BART & Pleasant Hill & Wayside Plaza: Phase 1 & Pleasant Hill & 36 & $1985-1986$ & 24 & ownership \\
\hline BART & Pleasant Hill & Wayside Plaza: Phase 2 & Pleasant Hill & 60 & $1986-1987$ & 60 & ownership \\
\hline BART & South Hayward & The Foothills & Hayward & 188 & $1986-1987$ & 33 & rental \\
\hline BART & Fremont & Mission Wells & Fremont & 392 & 1989-1991 & 35 & rental \\
\hline SCCLRT & Almaden & The Homes at Almaden Lake & San Jose & 84 & 1993 & 12 & ownership \\
\hline SCCLRT & Almaden & The Apts. at Almaden Lake & San Jose & 144 & 1994 & 37 & rental \\
\hline SCCLRT & Almaden & Park Almaden & San Jose & 370 & $1989-1994$ & 40 & ownership \\
\hline SCCLRT & Civic Center & Ryland Mews & San Jose & 132 & 1993 & 33 & rental \\
\hline SCCLRT & River Oaks & Villagio & Santa Clara & 273 & 1989 & 25 & ownership \\
\hline CalTrain & California Ave. & Palo Alto Central & Palo Alto & 74 & 1985 & 18 & ownership \\
\hline CalTrain & California Ave. & California Park Apartments & Palo Alto & 45 & 1989 & NA & rental \\
\hline SD Trolley & Amaya & Villages of La Mesa & La Mesa & 384 & 1989 & 20 & rental \\
\hline SD Trolley & La Mesa & La Mesa Village Plaza & La Mesa & 95 & 1991 & NA & ownership \\
\hline SD Trolley & Barrio Logan & Mercado del Barrio & San Diego & 144 & 1994 & NA & rental \\
\hline SD Trolley & 47th Street & Creekside Villas & San Diego & 144 & 1989 & NA & rental \\
\hline SRT & Butterfield & Windsor Ridge & Sacramento & 112 & 1988 & NA & rental \\
\hline LA-Blue Line & Pacific@5th & Bellamar & Long Beach & 160 & 1990 & NA & rental \\
\hline LA-Blue Line & Transit Mall & Pacific Court & Long Beach & 142 & 1992 & NA & rental \\
\hline \multicolumn{8}{|c|}{$\begin{array}{l}\text { Note: BART = Bay Area Rapid Transit; SCCLRT = Santa Clara County Light Rail Transit; CalTrain = CalTrain Commuter Rail Service; SD Trolley = San } \\
\text { Diego Trolley; SRT = Sacramento Regional Transit; LA-Blue Line = Los Angeles Metrorail Blue Line Light Rail Transit; NA = not available or not known } \\
\text { "Number of dwelling units per acre. } \\
\text { Source: NTRACProject Database, } 1994 .\end{array}$} \\
\hline
\end{tabular}




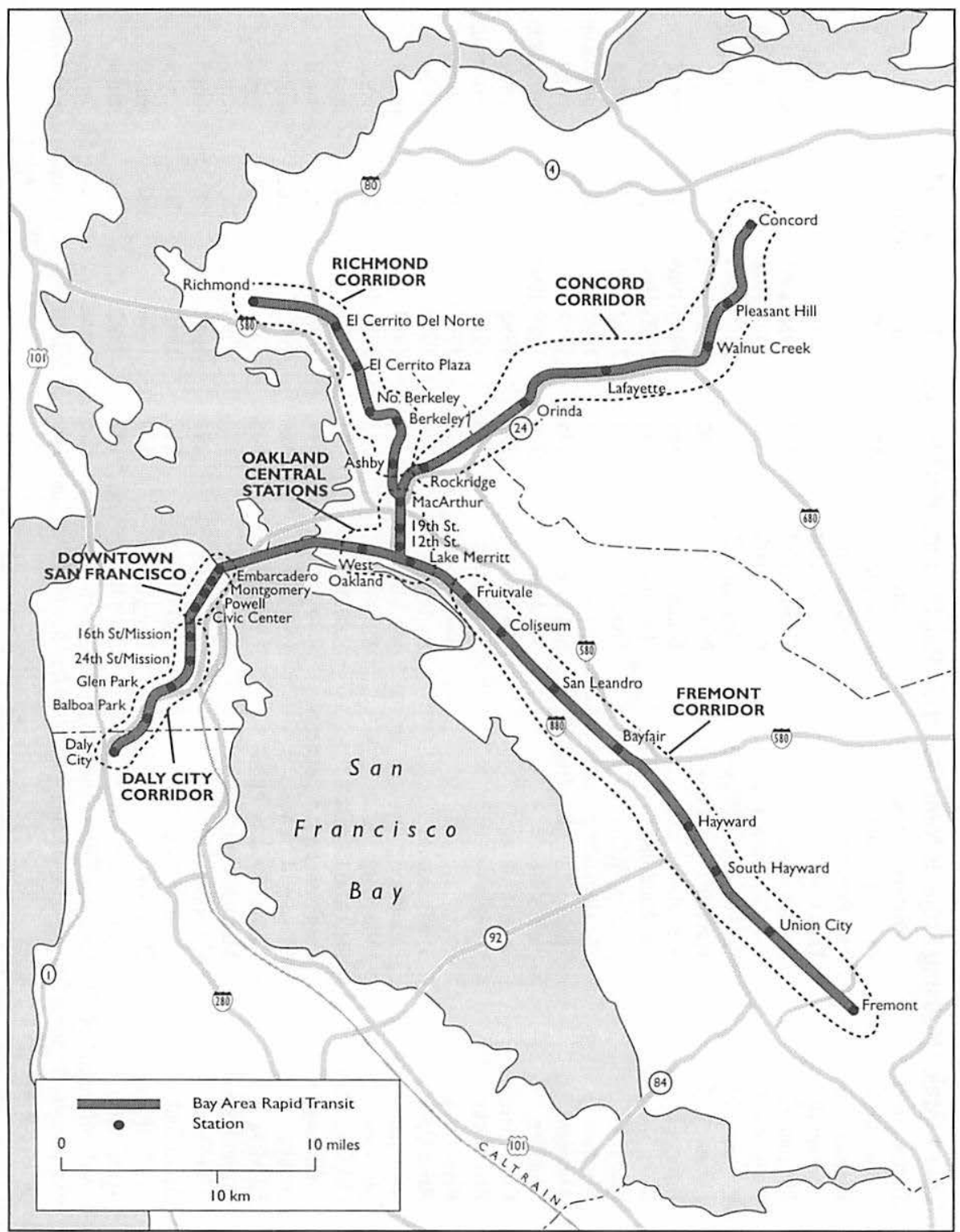

Figure 2. BART system map. 
project, a 135-unit apartment complex with 19,000 square feet of ground-floor retail; 27 of the units are priced below market as set asides for low-and moderateincome families (Figure 3). To make the project work, the redevelopment authority became an equity partner, leasing land to the developer for $\$ 1$ per year and 1520 percent of cash flow. Del Norte Place has leased rapidly. It opened in mid1992 and by mid-1993, 97 percent of its apartments were occupied.

The Bay Area's best example of suburban transit-oriented development encircles the Pleasant Hill BART station. Between 1988 and 1993, over 1,800 housing units and 1.5 million square feet of class $\mathrm{A}$ office space was built within a quarter mile of the Pleasant Hill station (Figure 4). Pleasant Hill's success is attributable to three key factors: one, the creation of specific plan in the early 1980s that served as a blueprint for targeting growth near the rail station over the ensuing 15 years; second, the existence of a proactive redevelopment authority

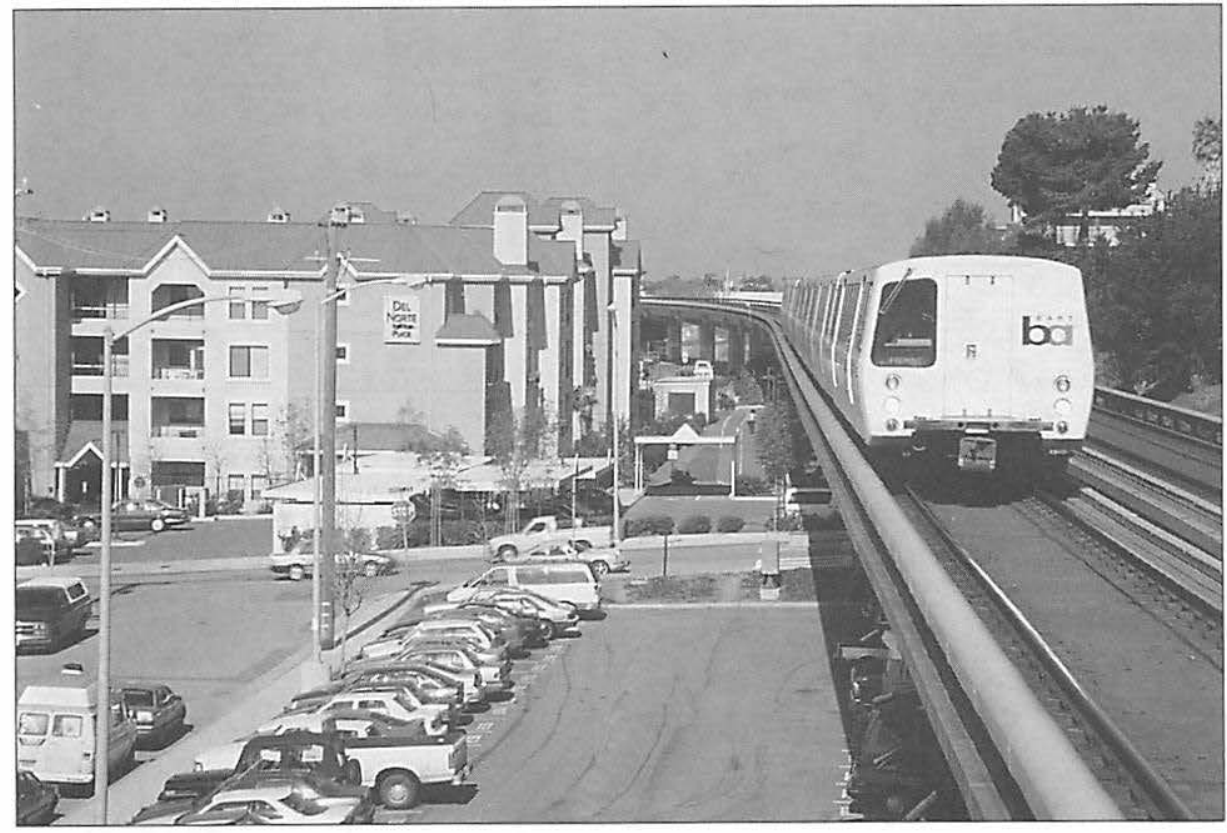

Figure 3. Del Norte Place mixed-use project at El Cerrito del Norte Station. The project abuts the BART station and is separated from the aerial BART track by a linear park. Photo by Robert Cervero. 
whose staff aggressively sought to implement the plan by assembling irregular parcels into developable parcels and issuing tax-exempt bond financing for public and private improvements; and third, having a local elected official who became the project's "political champion," working tirelessly and participating in innumerable public hearings to shepherd the project through to implementation (Cervero, Bernick, and Gilbert 1994). Current plans call for converting two BART parking lots at the Pleasant Hill station into structured replacement parking to open up land for restaurants, retail shops, and a regional cultural-entertainment complex, activities that are currently missing but are widely viewed as vital toward creating a more village-like atmosphere.

Plenty of building activity can also be found around other rail stations in California. In Santa Clara County, over 2,500 apartment and condominium units

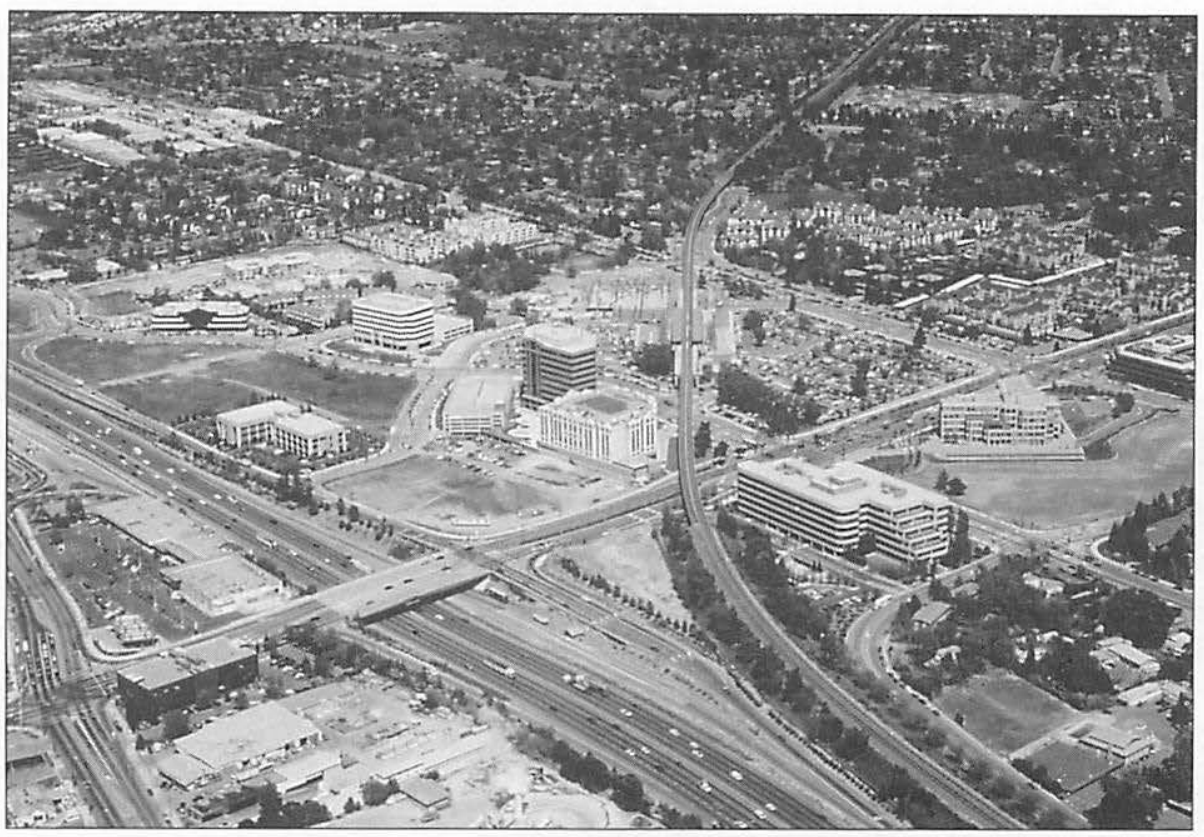

Figure 4. Pleasant Hill BART station area. Some 1,800 housing units and 1.5 million square feet of office and retail building space surround the Pleasant Hill station. Photo from BART files. 
have been built near light rail stops in the past five years. A recently completed 250-unit project, Almaden Lake Village, was built on the transit district's parkand-ride lot adjacent to the Almaden station. As part of the County's Housing Initiative Program, plans are under way to build an additional 1,700 units of moderate-density housing (at 12 to 40 du per acre) near light rail stations over the next five years. Sacramento's updated General Plan calls for using an array of development incentives at 13 light rail stations, including higher allowable densities, lower minimum parking requirements, tax increment financing, and industrial development bonds. The City of San Diego has perhaps done the most in recent years to embrace transit-oriented design concepts, adopting a formal policy "to direct growth into compact neighborhood patterns of development, where living and working environments are within walkable distances of transit sys-

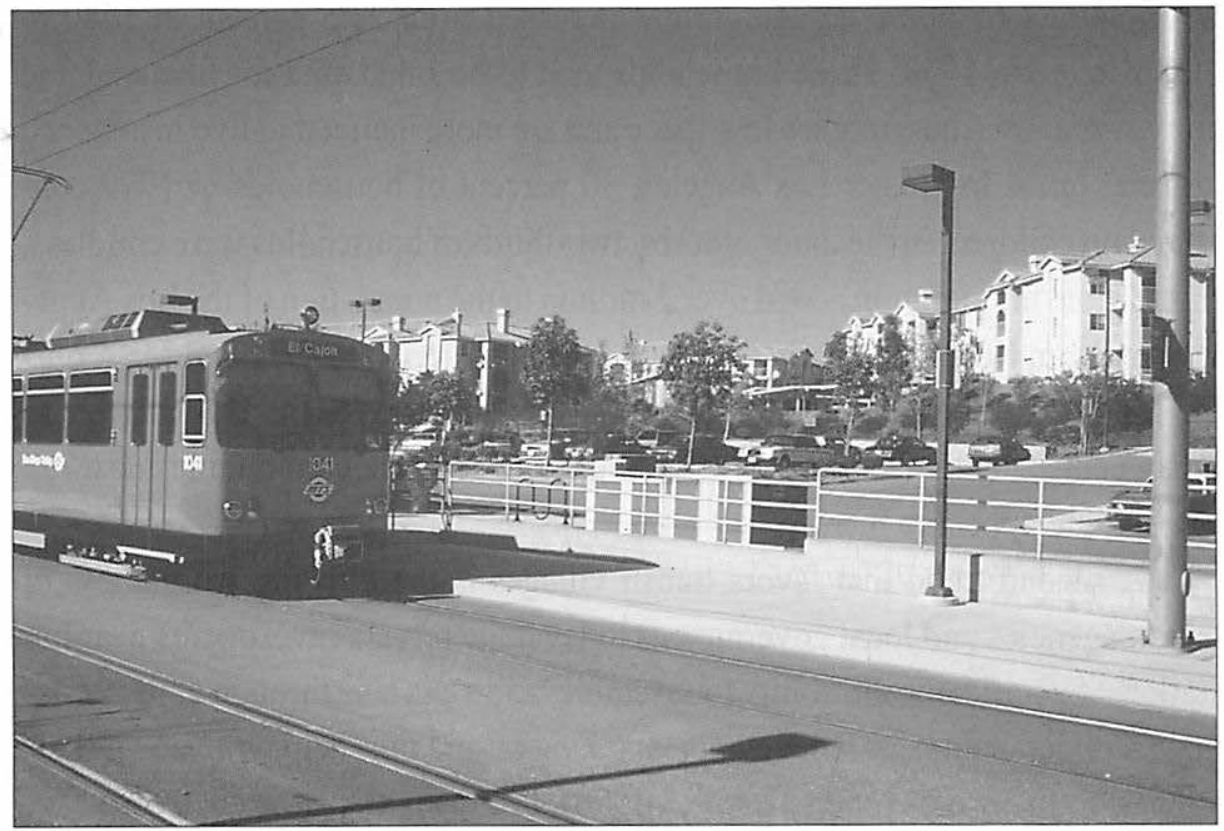

Figure 5. Amaya Station area on the El Cajon line. More than 300 apartment units of the Villages of La Mesa abut San Diego Trolley's Amaya Station. Photo by Robert Cervero. 
tems" (City Council Policy 600-39). Since 1990, more than 380 modern apartment units have been built adjacent to the La Mesa-Amaya light rail station (Figure 5). Currently under construction is Otay Ranch, a master-planned community adjacent to the cities of San Diego and Chula Vista, that will feature five village clusters, at blended densities of $18 \mathrm{du}$ per acre, and, developers hope, will be served directly by an extension of the trolley line.

\section{Opportunities and Barriers to Transit Villages}

\section{Market Opportunities}

Three types of opportunities are working in favor of transit village development in states like California. One opportunity has been demographic growth in population groups that are prime candidates for transit-oriented living: young households, retirees, childless households, and in-migrants from foreign countries. In the San Francisco Bay Area, for instance, the share of population in the 25-to-34 and 65-and-over age groups increased from 23.5 percent in 1980 to 30.8 percent in 1990. These households tend to be small, and for financial and convenience reasons, require less space and are more inclined to live in attached housing units. In greater Los Angeles, 30 percent of households in 1990 contained no children; in the inner suburbs, two-thirds of households were childless. In addition, immigration added over 2 million to the population of the Los Angeles-Anaheim MSA and nearly 600,000 to the San Francisco-Oakland MSA during the 1980s (Speare 1993). Because many new arrivals to the U.S. migrate to urban centers and seek affordable housing, more compact communities near rail stops might appeal to many.

A second trend that favors transit villages is the growing willingness of transit agencies and local governments to leverage private investments near rail stations. Specifically, the ability to assemble land-such as through eminent domain, condemnation, or redevelopment takings - and thus help write down costs appeals to many developers (Bernick 1993). For many transit agencies, surface parking lots surrounding stations are their biggest development asset. Parking lots represent large tracts of pre-assembled, cleared land that are relatively cheap to build upon. Converting park-and-ride lots to housing constitutes de facto land 
banking. One of the reasons why so much urban growth has clustered around rail stations in cities like Toronto and Stockholm is that local governments were able to acquire land over and beyond what was necessary to build rail stations, allowing them to lease or sell extra land to real estate developers. In the U.S., eminent domain laws prohibit excess land acquisitions. Reusing park-and-ride lots achieves similar results to land banking, however. Such was the case at the Ballston station in Arlington, Virginia, when its status changed from a terminal to an intermediate station following the extension of Metrorail's Orange Line to Vienna, Virginia. The relocation of park-and-ride spaces and a bus transfer facility to the new terminal freed up land, helping to trigger a massive redevelopment of the Ballston station area, including the construction of a 28 -story office-residentialretail complex above the station.

A third opportunity for transit village development is today's receptive policy and legislative environment for coordinating transit and land use decisions. Recent federal initiatives such as the 1991 national surface transportation act (ISTEA), clean air act amendments (CAAA), and Empowerment Zone/Enterprise Communities (EZ/EC) programs provide funding sources and a legislative context for promoting transit-oriented development. ISTEA explicity calls for a close coordination of transportation projects and urban development. Clean air laws encourage transit initiatives, such as transit-supportive development, as a possible transportation control measure (TCM) in non-attainment areas. The EZ/ EC program promotes such neighborhood transportation strategies as mobility enterprises and neighborhood intermodal travel centers. Transit villages are clearly consonant with these legislative initiatives.

\section{Barriers to Transit Villages}

Working against transit village development in California and elsewhere loom two significant barriers: (1) fiscal: factors that detract from the financial feasibility of transit-oriented projects, such as questionable market viability and lack of conventional financing; and (2) political: land-use policies and NIMBY forces that impede multi-family housing development. 
Americans' preference for low-density living is firmly rooted. A 1993 survey by the Building Industry Association of Northern California found that 82 percent of surveyed households preferred a single-family home over all housing types. It is a fundamental rule, according to one northern California developer, that "as density goes up, the general interest from the consumer goes down" (Bookout 1992, 15). In part because of the questionable marketability of denser housing, coupled with the softness of today's real estate markets and the fallout from the savings and loans crisis of the late-1980s, banks are understandably hestitant to provide permanent financing for largely untested products like transit-based housing. The higher construction costs, development fees, and risks associated with higher density housing are also major financial obstacles. As multi-unit buildings become taller, costs for design, construction, and liability insurance increase commensurately. Beyond $40 \mathrm{du}$ per acre, podium or other expensive parking structures become necessary. Once construction goes above four stories, the more expensive steel-frame construction, elevators, and lobby areas drive up unit costs. While, in theory, denser housing near rail stops should produce less traffic than if the same number of units were built as single-family homes, in practice denser projects pay relatively higher impact fees. A series of recent lawsuits holding condominium builders liable for faulty construction as late as 10 years after project completion has also frightened some California developers away from the high-density housing market.

A pair of "isms"-localism and NIMBYism - stand as the biggest political hurdles to transit village development. In California, Proposition 13, the 1978 initiative that reduced local governments' capacities to generate revenues through property taxes, is often blamed for prompting communities to be more competitive than cooperative. Some jurisdictions keep high-density housing out through fiscal zoning-"zoning in" high tax-yielding land uses, like office parks, and "zoning out" service-demanding activities, notably apartments (that burden already overburdened schools and city services). To many, transit-based housing carries with it the specter of more crowded schools and congestion, the stigma of low-income projects, and the prospect of tarnishing the character of an estab- 
lished neighborhood, thus lowering property values. NIMBY opposition to apartment proposals resulted in restrictive land-use policies and the passage of building moratoria in several neighborhoods surrounding BART stations that were prime for more intensive redevelopment, including Rockridge, North Berkeley, Walnut Creek, and the Mission District in San Francisco. In Hunt Valley, Maryland, a major employment hub north of Baltimore that recently received light rail services, NIMBY pressures resulted in the rezoning of prime land that was proposed for some 1,500 apartment units to a rural-conservation designation, despite the presence of light rail and an imbalance of more than three jobs for every available housing unit in the area.

\section{The Market for Transit Villages}

Relatively little is known about the market potential of transit village development, in large part because little has been built to date, mainly due to the barriers cited above. Transit-oriented communities such as the celebrated Laguna West development south of Sacramento, designed by architect Peter Calthorpe (1993), have struggled financially and for the most part incorporate modest transit provisions. Presently, the entire transit village movement seems caught in a "Catch-22": there are few examples, in part, because of questionable market feasibility, and the market potential of transit villages is questionable because there are few examples.

In the absence of good U.S. examples of transit villages, researchers with the National Transit Access Center (NTRAC) at the University of California recently attempted to dynamically simulate them using computer-generated images (Cervero and Bosselmann 1994). The main objective was to gauge the degree to which people might be willing to accept higher densities needed to sustain rail transit services in exchange for more public amenities, like neighborhood parks and close-by retail shops and eateries. Nine photoslide images that simulated a "walk" through four neighborhoods with different density/amenity mixes were presented to residents of the San Francisco Bay Area in the spring of 1994. Each simulated "walk" began by showing a view out the rear and front windows of a hypothetical house located three blocks from a BART station, pro- 
ceeded along two residential streets toward a neighborhood retail plaza, and ended at a nearby public square fronting a BART station.

As the densities of the four photosimulated neighborhoods increased from 12 to 24 to 36 to 48 du per acre, so did the acreage of public parks, number of shops, and amount of landscaping in the neighborhoods increase. These densities span the minimum necessary to support rail transit (12 du per acre), as established by Pushkarev and Zupan (1977), as well as the upper boundary (48 du per acre) of what can be built without going to more expensive steel-framed structures with elevators, lobby space, and structured parking. Four photoslide im-
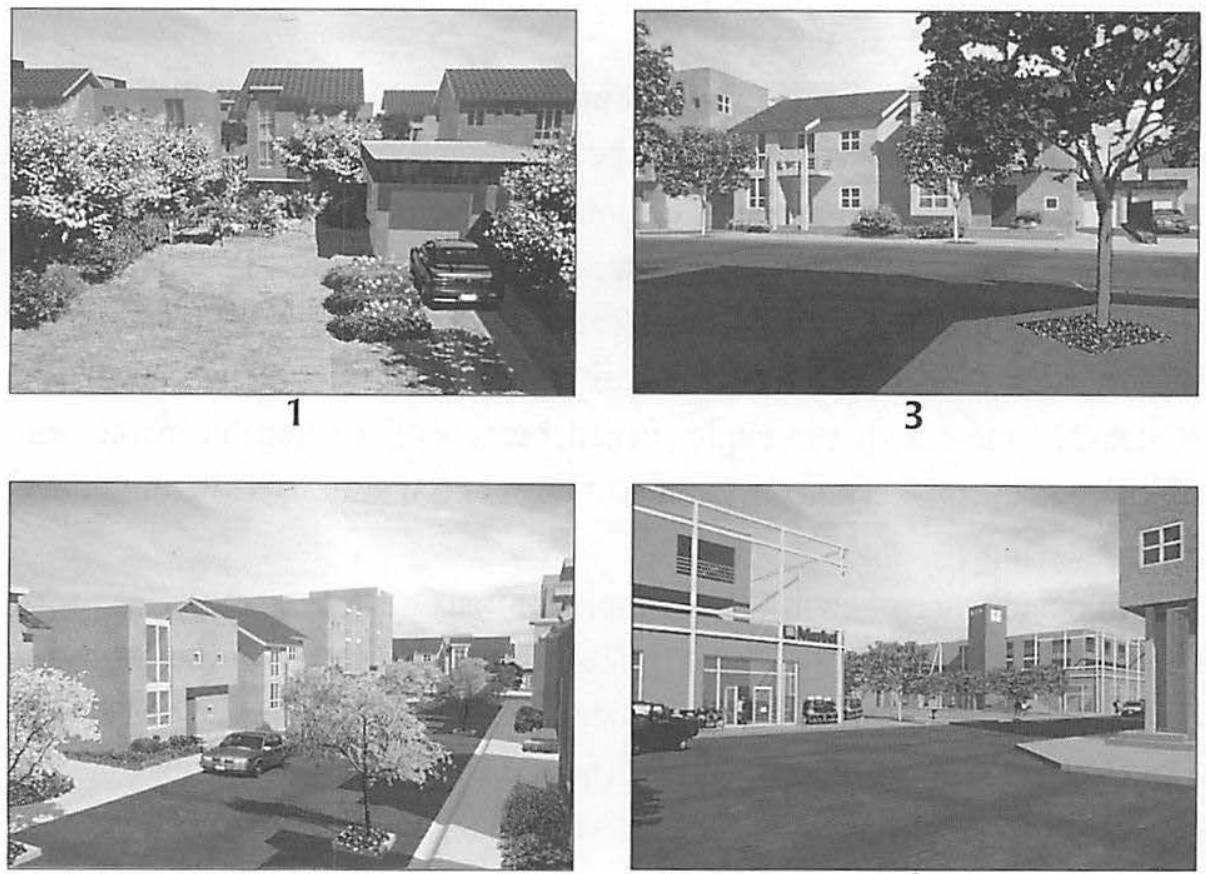

2

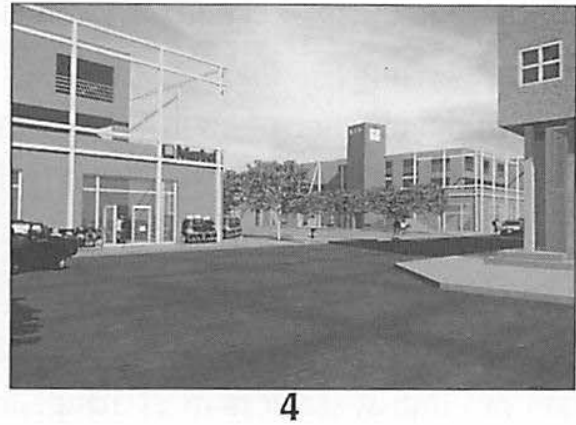

Figure 6. Four slide images of a computer-simulated transit village designed at 12 dwelling units per acre. The first image shows a view out of a second-story window into the rear yard of a house in the village. The second shows a view out the front door looking down the street. The third shows houses at the end of the street. The fourth depicts a modest retail plaza that leads to the nearby rail station. 
ages created for two of the simulated transit villages - the 12 du per acre one with the fewest neighborhood amenities and the 48 du per acre one with the most amenities - are shown in Figures 6 and 7. All images were generated using threedimensional computer modeling and animation techniques. Factors such as building style and newness, the amount of sunlight, and street widths were controlled so that only densities and amenities varied across the neighborhoods.

Based on the survey responses of 170 Bay Area residents who viewed the slides, the lowest density neighborhood was the most preferred-58 percent of the respondents ranked it as the most desirable. However, far more respondents
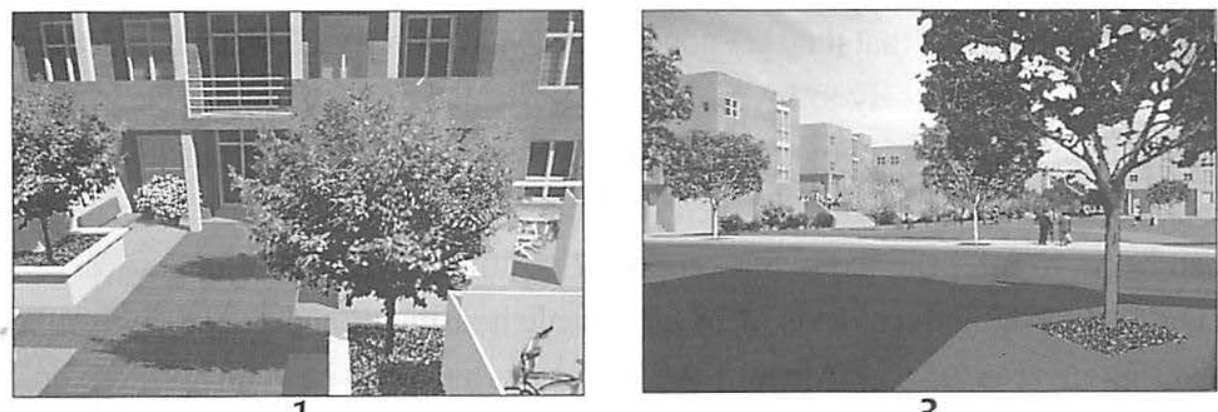

3

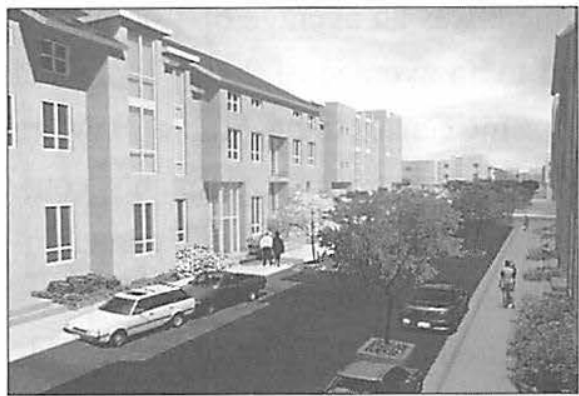

2

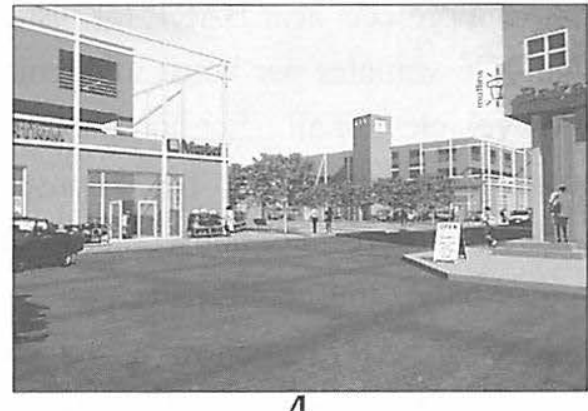

4

Figure 7. Four slide images of a computer-simulated transit village designed at 48 dwelling units per acre. The first image shows a view out of a second-story window into a courtyard. The second shows a view out the front door looking down the street. The third shows houses at the end of the street (that did not exist in the lower-density neighborhoods). The fourth depicts a retail plaza with more activities. 
liked the transit village built at 36 du per acre with nicer public amenities than the transit village designed at 24 du per acre but with fewer community services or amenities. Notably, people preferred tightly spaced two-and-a-half story row houses with modest backyards located near a public park and retail shops, to one-to two-story row houses with larger rear yards and more street frontage, but with no nearby park and fewer local services. Those most receptive toward higherdensity transit villages were young adults with moderate incomes who currently reside in apartments.

\section{Profiling Residents of Transit-Based Housing}

Of course, the limitation of visual simulations, however attractive or fanciful they might be, is that they are nonetheless "make-believe." Many developers and lenders are unlikely to invest in transit-oriented projects until a clear consumer demand can be demonstrated. While no true modern-day transit villages exist in the U.S. today, there is plenty of transit-based housing from which one can begin to infer the likely market profiles of transit village residents. We recently surveyed the residents of 28 large-scale housing projects near California rail stations (Cervero and Menotti 1994). Tenants tended to be young professionals, singles, and empty-nesters, with typically just one car per household. In 12 housing projects near BART, for instance, there was an average of 1.66 people and 1.26 vehicles per household, compared to an average of 2.40 people and 1.64 vehicles for all other households in the same census tracts (Table 2). More than 90 percent of transit-based households had just one or two occupants, compared to 58 percent of households in surrounding tracts. Fewer than 8 percent of transit-based households had children. More than 70 percent of surveyed households near BART had one or no vehicles, compared to 48 percent of households in the same census tracts. While tenant characteristics of transit-based housing were not statistically different from characteristics of surrounding census tracts, based on mean statistics from Table 2, it is clear that those choosing to live in apartments and condominiums near rail stops live in comparatively small households with relatively low automobile ownership rates. 


\section{Table 2}

Matched-Pair Comparisons of Household and Occupant Characteristics of Transit-Based Housing and Surrounding Census Tracts

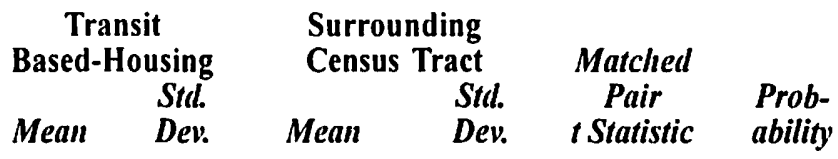

\section{Household Characteristics}

No. of vehicles

available

$1.26 \quad 0.68$

1.61

$1.11 \quad 1.56$

.091

Occupant Characteristic

$\begin{array}{llllll}\text { Age }(17+\text { years }) & 36.3 & 14.7 & 42.1 & 17.7 & 1.38\end{array}$

Note: The "Surrounding Census Tract" consists of the census tract that encompasses the housing project, with the estimated population for the transit-based housing projects netted from census tract data.

What most distinguishes residents of housing near California rail stations is their tendency to work downtown and in other locations well served by transit. In the case of five apartment and condo complexes near the Hayward and San Leandro BART stations, 43 percent of employed residents worked in downtown San Francisco or Oakland, compared to just 13 percent of employed residents in the surrounding census tracts. And an estimated one-half of the residents of 1,800 apartment units near the Pleasant Hill BART station worked in downtown San Francisco or Oakland, compared to a citywide average of just 10 percent. In a study of residential location choice in greater Philadelphia, Voith (1991) found similar examples of residential sorting, wherein people gravitated toward locations with comparative accessibility advantages to job sites. Census tracts with commuter rail service nearby had 12 percent more of their residents working in downtown Philadelphia than did surrounding census tracts. Like BART, Philadelphia's rail system radially connects suburban communities to the CBD.

Builders are starting to realize that a number of downtown workers, many of whom are young professionals earning good wages, are attracted to rail-based 
housing. Projects with nice amenities and which cater to the tastes of young professionals seem to appeal to many childless households seeking condominiums and apartments near rail. One example is the Park Regency apartment complex near the Pleasant Hill BART station, an upmarket complex complete with a pool, $\mathrm{spa} /$ sauna, and recreational building that has a waiting list to move in. Threequarters of the Park Regency's occupants are in the 18-34 year age group, and more than 50 percent earn more than $\$ 40,000$ annually. Another high-amenity project is Del Norte Place near the El Cerrito del Norte BART station; its marketing brochures emphasizes the project's fireplaces, bay views, ground-floor retail, and proximity to BART. In an interview with The New York Times, the project developer stated that he aggressively put in a bid to the El Cerrito redevelopment authority to build on the site because he believes living near rail stations will become increasingly attractive as regional traffic congestion worsens (McCloud 1992).

With so many residents of transit-based housing working downtown and other rail-served destinations, these projects should generate high rates of rail commuting. Recent surveys show that Californians living within a quarter mile of an urban rail system are around three times as likely to commute by rail transit as the average worker living in the same city (Cervero 1994). One-third of employed residents living in apartments and condominiums near BART stations commute by rail, compared to 8 percent of all commuters living in the three BART-served counties (San Francisco, Alameda, and Contra Costa). The two most important determinants of rail usage are trip destination and availability of free parking. Among those living in multi-family projects near BART stations and heading to San Francisco job sites with no free parking, nearly 9 out of 10 work trips are by BART. If they can park free in downtown San Francisco, around 60 percent commute by rail. For commutes to secondary urban centers like Oakland and Berkeley, around half are by BART. For all other destinations (where often workers park free), on average only 6 percent of commute trips by stationarea residents are by rail. Clearly, clustering housing around rail stops will do little good if, as during much of the 1980s, job growth occurs mainly along suburban freeway corridors. Both ends of work trips-housing and job sites-must 
be within reasonable proximity of stations if clustered growth is to pay significant transportation and environmental dividends-in short, more mixed-use transit village development is necessary.

Because rail-based households own relatively few cars and frequently patronize transit, zoning standards should be relaxed to allow just one parking space per unit at complexes near rail stations. This would lower construction costs by an estimated $\$ 12,000$ per unit in the Bay Area (the typical cost of a tuck-under, podium parking space), and also create a more pedestrian-oriented environment. Tenants with more than one car might be given the option of leasing a second space. Another novel idea suggested by Holtzclaw (1994) would have banks grant those living in rail-based condominiums an "efficient-location" loan for home purchases. If rail-based housing lowers transportation costs (mainly in the form of only having to own one car), then these savings might be subtracted from principal, interest, taxes, and insurance expenses when calculating mortgage qualifications. This acknowledges that lower transportation costs frees more money for housing consumption. Such loan adjustments could further attract prospective homebuyers to transit village locations.

\section{Rail-Based Housing and Rents}

If rail-based housing projects are becoming increasingly desirable addresses, this should be reflected in rent levels. Comparisons were recently made between 1994 rents at multi-unit projects within a quarter mile of the Pleasant Hill BART station versus otherwise similar projects in Pleasant Hill and the nearby cities of Walnut Creek and Concord that were beyond walking distance of a rail stop (Bernick, Cervero, and Menotti 1994). Rents per square foot for one bedroom/ one bathroom units near the Pleasant Hill station were $\$ 1.20$, compared to an average of $\$ 1.09$ for similar projects (in terms of size, age, and amenities) in the same geographic submarket but away from BART. Two bedroom/two bathroom units near the Pleasant Hill stations leased for around $\$ 1.09$ per square foot compared to around $\$ 0.94$ per square foot for comparable units away from BART. These findings translate into a 10 to 15 percent rent premium associated with being near BART. 
A hedonic price model was also estimated for measuring the rent premium commanded by rail-based housing. Using multiple regression analysis, a hedonic price model does what matched-pair comparisons are unable to: statistically control for a large number of attributes of the "housing bundle," allowing the unique effects of each attribute (including proximity to BART) to be parcelled out.

Table 3 presents the findings of the estimated model. Units within a quartermile of the Pleasant Hill BART station rented for around \$34 more per month than otherwise comparable units farther away from BART, controlling for the influence of unit size, amenities, and other factors. More bathrooms, bedrooms, and amenities like playgrounds and weight rooms likewise increase monthly rents. Table 3 also reveals that units in more compact projects rent for more than comparable units in lower-density ones. Project density, it should be noted, reflects units per acre within a complex as opposed to the density of the surrounding neighborhood. The rental premium associated with compact projects could reflect the benefits of tenants being closer to pools, playgrounds, and other amenities, as well as living in a communal setting. The rail-based projects used in this analysis, moreover, were comparatively dense, suggesting some interaction between these two factors-closeness to stations and project density. The finding that both proximity to transit and project compactness get capitalized into higher rents bodes well for the future of transit village development in the Bay Area.

\section{Stimulating the Market for Transit Villages}

Perhaps the most promising recent development in California's transit village movement was the passage of the Transit Village Act, AB 3152. The Act stipulates that no public works projects, tentative subdivision maps, or parcel maps may be approved, nor zoning ordinances adopted or amended, within an area covered by a transit village plan unless the map, project, or ordinance is consistent with the adopted transit village plan. This was a small but important step toward bringing the transit village idea to fruition. The bill, as originally drafted, would have allowed municipalities to designate a "transit village district," similar to a redevelopment district, with special land assemblage and tax increment financing privileges. The original bill also stipulated that developers 


\section{Table 3}

\section{Hedonic Price Model for Multi-Family Rental Units in the} Pleasant Hill Station Area and Surrounding Submarket, 1994

Dependent variable $=$ rent per month, in dollars

\section{Variable}

BART station within one-quarter mile

$(\mathrm{l}=\mathrm{yes}, 0=\mathrm{no})$

Size of unit (sq.ft.)

No. of bedrooms

No. of bathrooms

Playground on site $(1=y e s, 0=$ no)

Weight room on site $(1=y e s, 0=$ no)

Project density (units/acre)

Project age (in years, from 1991)

Project in Concord $(1=y=s, 0=$ no)

Proportion of total units in project

of unit type

Laundry room on site ( $1=y e s, 0=n o)$

\section{Summary Statistics:}

Number of observations

R-Squared

F statistic

Significance F
Coefficient

34.101

.427

29.488

42.039

30.461

66.544

.397

$-10.971$

$-129.842$

$-44.545$

$-21.221$

60

49.331

.000

building within the district be granted density bonuses of at least 50 percent. Because of stiff opposition from fiscal conservatives, most of these provisions were later stripped from the bill. Regardless, the Act gave newfound legitimacy to California's transit village movement.

As passed, $\mathrm{AB} 3152$ is a voluntary statute encouraging cities and counties to plan more intensive development around rail stations, though it provides few fiscal powers or special authority to do so. Sponsors hope the bill will be expanded in coming years to provide more financial incentives, perhaps granting transit village districts priority access to discretionary state funds, such as from the national transportation act (ISTEA) and fuel price rebate programs. California's transit village movement suffered a recent setback, however, when Governor Wilson vetoed an Assembly Bill (AB 1338) in the spring of 1995 that would have established local revolving funds (from state and federal transportation plan- 
ning monies) and provided loans to cities and counties to enable them to prepare specific transit village plans. The veto, most observers agree, had more to do with the generally conservative fiscal mood of the times than an opposition to the principle of transit-oriented development. Still, the veto underscores the reality that transit-oriented development is not high on the priority lists of many politicians, and that transit villages face an uphill struggle in becoming a reality in states like California.

Notwithstanding such political setbacks, it is encouraging that some housing projects near rail stations are leasing quickly, commanding rent premiums, and attracting residents who patronize transit. Local governments can leverage transit-oriented development by emulating what was done in Pleasant Hill and El Cerrito-namely, by creating specific plans to guide development and using tax increment financing and other tools to assist with land assemblage and absorb some of the risks of project development. Given some of the doubts over the marketability of higher density housing and today's conservative lending practices, some degree of risk-sharing between the public and private sectors will be necessary if transit villages are ever to take form. Relaxing zoning standards to allow fewer parking spaces at rail-based projects and rewarding those buying condominiums near rail stops with "efficient-location" loans would further promote transit-oriented growth. Together, strong market interest, public-private cooperation, and a conducive public policy environment would prove a powerful combination in taking the transit village movement from idea to implementation.

\section{Acknowledgements}

This research was supported by a grant from the California Department of Transportation and the University of California Transportation Center. Many people contributed to the work reported in this paper, including Michael Bernick, Peter Bosselmann, Val Menotti, and Jill Gilbert. The views expressed are those of the author and not necessarily those of the sponsors. 


\section{References}

Bernick, M. 1993. The Bay Area's Emerging Transit-Based Housing. Urban Land Vol. 52, No. 7: 38-41.

Bernick, M., R. Cervero, and V. Menotti. 1994. Comparison of Rents at Transit-Based Housing Projects in Northern California. Berkeley: Institute of Urban and Regional Development, Working Paper 624.

Bookout, L. 1992. The Future of Higher-Density Housing. Urban Land Vol. 51, No. 9: 14-18.

Building Industry Association of Northern California. 1993. Survey of Housing Preferences in Northern California. San Francisco: Building Industry Association of Northern California, unpublished report.

Calthrope, P. 1993. The Next American Metropolis. Princeton: Princeton Architectural Press.

Cervero, R. 1994. Transit-Based Housing in California: Evidence on Ridership Impacts. Transport Policy, Vol. 1, No. 3: 174-183.

Cervero, R. 1995. Sustainable New Towns: Stockholm's Rail-Served Satellites. Cities 12 1: 41-52.

Cervero, R., M. Bernick, and G. Gilbert. 1994. Market Opportunities and Barriers to Transit-Based Development in California. Berkeley: Institute of Urban and Regional Development, Working Paper 621.

Cervero, R., and P. Bosselmann. 1994. An Evaluation of the Market Potential for TransitOriented Development Using Visual Simulation Techniques. Berkeley: Institute of Urban and Regional Development, Monograph 47.

Cervero, R., and V. Menotti. 1994. Market Profiles of Rail-Based Housing Projects in California. Berkeley: Institute of Urban and Regional Development, Working Paper 622.

Cervero, R., and J. Landis. 1995. Development Impacts of Urban Transport: A U.S. Perspective. In Transport and Urban Development, D. Banister, ed. London: Chapmand and Hall.

Commuter Transportation Services. 1993. The State of the Commute. Los Angeles: Commuter Transportation Services, Inc., unpublished report.

Downs, A. 1994. New Visions for Metropolitan America. Washington, D.C.: The Brookings Institution. 
Holtzclaw, J. 1994. Residential Patterns and Transit, Auto Dependence, and Costs. San Francisco: Resources Defense Council.

Larson, J. 1993. Density is Destiny. American Demographics Vol. 15, No. 2: 38-42.

McCloud, J. 1992. High-Density Housing Near San Francisco: Builder Betting Proximity to Commuter Line. New York Times Vol. 141, Section 1, July 5: 23.

Pushkarev, B., and J. Zupan. 1977. Public Transportation and Land Use. Bloomington: Indiana University Press.

Speare, A. 1993. Changes in Urban Growth Patterns 1980-90. Cambridge, Massachusetts: Lincoln Institute of Land Policy, Working Paper.

Voith, R. 1991. Transportation, Sorting and House Values. American Real Estate and Urban Economics Association Journal Vol. 19, No. 2: 117-137.

\section{About the Author}

Robert Cervero is Professor in the Department of City and Regional Planning at the University of California, Berkeley. 